University of Louisville

ThinkIR: The University of Louisville's Institutional Repository

Electronic Theses and Dissertations

$5-2007$

\title{
Development and validation of a scale to measure health-related socioeconomic well-being in persons with a cancer diagnosis.
}

\author{
Barbara Anderson Head \\ University of Louisville
}

Follow this and additional works at: https://ir.library.louisville.edu/etd

\section{Recommended Citation}

Head, Barbara Anderson, "Development and validation of a scale to measure health-related socioeconomic well-being in persons with a cancer diagnosis." (2007). Electronic Theses and Dissertations. Paper 594.

https://doi.org/10.18297/etd/594

This Doctoral Dissertation is brought to you for free and open access by ThinkIR: The University of Louisville's Institutional Repository. It has been accepted for inclusion in Electronic Theses and Dissertations by an authorized administrator of ThinkIR: The University of Louisville's Institutional Repository. This title appears here courtesy of the author, who has retained all other copyrights. For more information, please contact thinkir@louisville.edu. 
DEVELOPMENT AND VALIDATION OF A SCALE TO MEASURE

HEALTH-RELATED SOCIOECONOMIC WELL-BEING IN

PERSONS WITH A CANCER DIAGNOSIS

\author{
By \\ Barbara Anderson Head \\ B.S.W., Union College, 1972 \\ M.S.S.W., University of Louisville, 1974

\begin{abstract}
A Dissertation
Submitted to the Faculty of the

In Partial Fulfillment of the Requirements

for the Degree of
\end{abstract} \\ Graduate School of the University of Louisville
}

Doctor of Philosophy

Kent School of Social Work

University of Louisville

Louisville, Kentucky

and

College of Social Work

University of Kentucky

Lexington, Kentucky

May 2007 
Copyright 2007 by Barbara A. Head

All rights reserved 


\title{
DEVELOPMENT AND VALIDATION OF A SCALE TO MEASURE \\ HEALTH-RELATED SOCIOECONOMIC WELL-BEING IN \\ PERSONS WITH A CANCER DIAGNOSIS
}

\author{
By \\ Barbara Anderson Head \\ B.S.W., Union College, 1972 \\ M.S.S.W., University of Louisville, 1974
}

A Dissertation Approved on

March 26, 2007

By the following Dissertation Committee:

Anna C. Faul, Ph.D., Committee Chair

Dorothy Brockopp, Ph.D.

Mark Pfeifer, M.D.

Jamie Studts, Ph.D.

Pam Yankeelov, Ph.D.

Dan Wulff, Ph.D. 


\section{DEDICATION}

This dissertation is dedicated to all cancer survivors

and the researchers and healthcare professionals

who work everyday to make survival

a reality. 


\section{ACKNOWLEDGMENTS}

I would like to acknowledge the following people for their encouragement, assistance, and support:

Annatje Faul, PhD, my committee chair, who has provided countless hours of direction and encouragement and who remained enthusiastic, energetic, and encouraging throughout the process. She has been a brilliant mentor and a special friend to me over the past five years.

Ruth Huber, $\mathrm{PhD}$, director of the doctoral program, who believed in me and was the inspiration for my ever considering or entering a doctoral program. Her belief in the potential of each individual and her undying support and encouragement of others to become all that they can be is a model for every social worker.

Mark Pfeifer, MD, my "boss," colleague, and friend who made getting my $\mathrm{PhD}$ a priority and believed in me and my work.

Jamie Studts, $\mathrm{PhD}$, for sharing his expertise in behavioral oncology and psychometrics and for always being patience with my ignorance.

Pam Yankeeluv, PhD, who cheerfully reviewed and offered valuable direction even though it meant a loss of sleep.

Dan Wulff, $\mathrm{PhD}$, who always asked the challenging questions and was a great encourager.

Dorothy Brockopp, PhD, my "wildcat" member who willingly shared her knowledge in research, oncology, and quality of life issues. 
My husband, Carl Head, my sons, my stepdaughters and their families, who hopefully know that they are more important to me than any other endeavor or accomplishment in my life.

My parents who taught me the importance of hard work and made many sacrifices so that I could have the education they were not privileged to enjoy.

My first husband, Tom Anderson, who was wise beyond his years and taught me to accept and believe in the abilities of every person.

My fellow doctoral students who I was privileged to learn from and be with as we journeyed together over the past five years.

All my supportive friends who cheered me on over the past five years and who I hope to become reacquainted with as I reclaim "my life" after doctoral studies.

And most of all I acknowledge my Lord and maker who is the source of all knowledge and wisdom and who has blessed me with great abundance in this life. To God be the glory for all that I am and will be and for the saving grace and love that accepts and forgives my human failures and shortcomings. 


\section{ABSTRACT \\ DEVELOPMENT AND VALIDATION OF A SCALE TO MEASURE HEALTH-RELATED SOCIOECONOMIC WELL-BEING IN PERSONS WITH A CANCER DIAGNOSIS}

\section{Barbara Anderson Head}

May 12, 2007

The impact of socioeconomic status on the diagnosis, treatment, survival, and overall quality of life in persons with cancer has been well documented. Yet, many studies overlook the relevance of socioeconomic factors when measuring the impact of cancer care. A multitude of tools exist for the measuring of health-related quality of life (QOL) in oncology, but the majority do not recognize socioeconomic well-being as a relevant domain. The FACT-G, perhaps the most often used measure of QOL in oncology, measures the domains of physical, functional, social/family, and emotional well-being as core measures with optional instruments available to address spiritual wellbeing and concerns related to specific cancer sites. The purpose of this dissertation was to develop and validate a theory-based subscale measuring the construct of socioeconomic well-being to be included as a core domain of the FACT-G.

Theories of socioeconomic status and related well-being were explored. The Ecological Theory of Germain and Gitterman (1996) and James Coleman's theory of social class (1990) were used as the basis for construct definition and item development. Following expert review, the proposed measure, a demographic questionnaire, and other 
instruments necessary for the validation study were mailed to a random sample of 1200 persons diagnosed with cancer between 1/1/2004 and 12/30/2007 and listed on the Tumor Registry of the James Graham Brown Cancer Center (JGBCC) and the University of Louisville Hospital. The study was approved by the University of Louisville, JGBCC, and University Hospital oversight committees for protection of human subjects.

Classical measurement theory directed the analysis of the proposed instrument. This iterative process included analysis of reliability via the Cronbach alpha, evaluation of corrected item total correlations and factor loadings, and analysis of content and construct validity at the item level via principal component analysis. This process resulted in one scale measuring overall socioeconomic well-being with two subscales (Material Capital and Social Capital) and a total of 17 items. Convergent and discriminant construct validity at the scale level was then established by comparing the new subscales and total scale to three sets of variables hypothesized to have differing degrees of correlation with the scales (Class I, II, and III criterion variables). Incremental validity was evaluated using a hierarchical regression model.

The resulting instrument for the measurement of health-related socioeconomic well-being could be used as a core component of the FACT-G or a stand alone measure, and is appropriate for application in both clinical and research settings. 


\section{TABLE OF CONTENTS}

\section{PAGE}

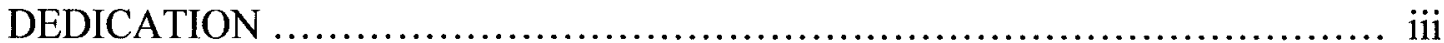

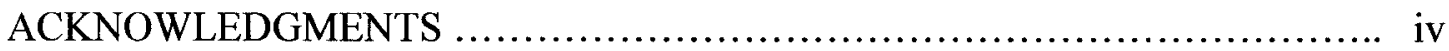

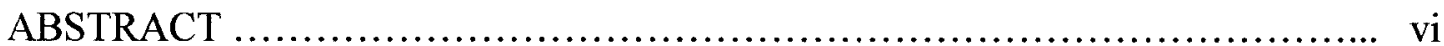

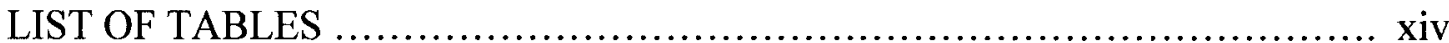

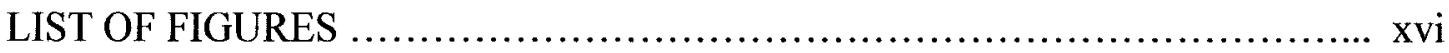

CHAPTER

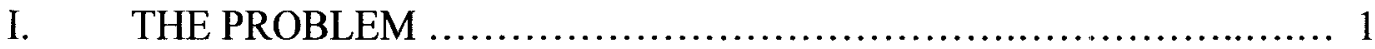

The Impact of a Cancer Diagnosis .................................. 3

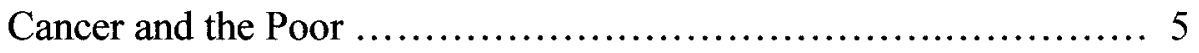

Socioeconomic Status and Cancer ......................... 5

Efforts to Address Cancer Disparities ...................... 7

The Relationship between Poverty, Health, and Cancer .... 10

The Impact of Insurance Status on Cancer Diagnosis,

Care and Outcomes ....................................... 15

Current Social Policies Impacting Healthcare Disparities ............ 17

Political Philosophy and the Evolution of Social Welfare .... 17

Medicaid: Healthcare Answer for the Poor? ................ 19

Efforts at Healthcare Reform ............................. 21

"Losers" and "Gainers" .................................... 23

Defining and Measuring QOL in Cancer .......................... .24 
Defining Quality of Life ................................ 26

Measuring Quality of Life .............................. 28

Using Measurement Results ............................... 33

Why a Socioeconomic Dimension? ................................ 36

Relevance to Social Work ........................................ 40

II. THE LITERATURE .............................................. 42

The FACT-G ............................................. 42

Background ......................................... 42

Development of the FACIT Scales and Subscales ............ 44

Psychometric Analysis of the FACT-G .................... 48

Theoretical Support for Including Socioeconomic

Well-Being when Measuring Cancer Related QOL ............... 50

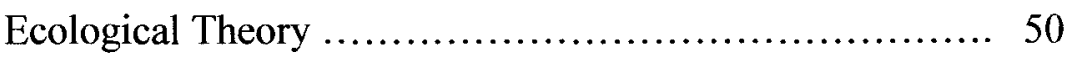

Person:Environment Fit ........................ 50

Life Stressors ..................................... 51

Coercive and Exploitative Power .................... 53

Habitat and Niche ................................ 54

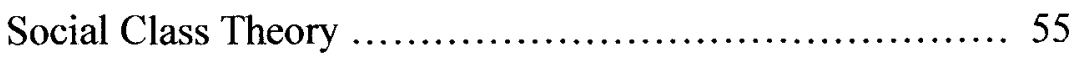

Marxism and Social Class .......................... 56

Weberian Thought $\ldots \ldots \ldots \ldots \ldots \ldots \ldots \ldots \ldots \ldots \ldots \ldots \ldots \ldots \ldots$

The Functionalist Tradition ....................... 58 
Connecting Social Class Theory to Measurement

of Socioeconomic Status

Defining Socioeconomic Well-Being 63

From Socioeconomic Status to Socioeconomic Well-being .... 67

Definition of the Construct 69

Existing Measures of Socioeconomic Well-Being in

Health Related Quality of Life Instruments 74

Conclusion 76

III. METHODOLOGY 77

Purpose of the Study .......................................... 78

Research Questions ............................................ 79

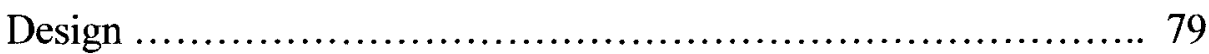

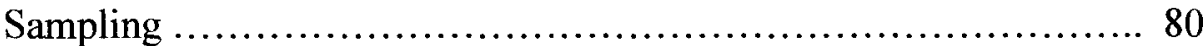

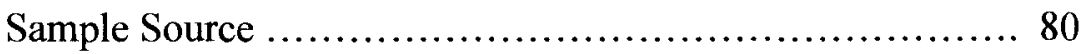

Sampling Procedures ................................ 80

Measures …....................................................... 81

Demographic Questionnaire ....................... 81

The FACT-G ............................... 82

Socioeconomic Well-Being Scale (SEWBS) ........ 82

Subjective Social Status Ladder Rating (SSSLR) ..... 85

Quality of Life Index - Cancer Version (QLI-CV)..... 86 
Analysis Plan .............................................. 87

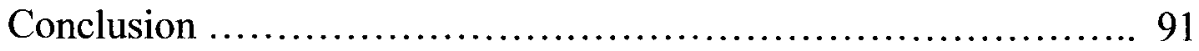

IV. RESULTS ............................................................... 92

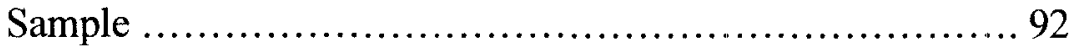

Demographics ....................................... 93

Comparison of Sample to Total Population ..................97

Demographic Summary ................................ 98

Comparison of Sample Performance on the FACT-G

Relative to Normative Data .............................. 99

Research Question 1: Is the proposed scale for evaluating health-related socioeconomic well-being supported by literature, theory, and expert review?

Research Question 2: Is the proposed scale for evaluating health-related socioeconomic well-being valid and reliable? 107

Reliability and Content Validity at the Scale Level 107

Construct Validity at the Item Level ........................ 114

Discriminant and Convergent Validity .................... 115

Summary of Reliability and Validity Analysis ................118 
Research Question 3: Is the inclusion of a socio-economic well-being domain to the FACT-G a valuable addition with explanatory power when evaluating QOL in persons with a cancer diagnosis?

V. DISCUSSION, CONCLUSIONS, AND SOCIAL WORK

IMPLICATIONS

Strengths 126

Limitations

Summary of Findings

Implications for Measurement of Socioeconomic Status and Quality of Life in Health Research 135

Potential Applications for this Scale 139

Implications for Social Work Practice

Future Research 143

Concluding Comments 144

REFERENCES 145

APPENDIX A: Validation Packet

APPENDIX B: Expert Review Packet 170

APPENDIX C: Final Disposition of Items. 188 


\section{LIST OF TABLES}

TABLE

PAGE

1. Behavioral Traits of "Culture of Poverty" Related to Cancer Incidence and Mortality

2. Summary of Initial Development/validation Study for FACT-G

3. Relevant FACT-G Validity and Reliability Studies

4. Demographic Measures of Socioeconomic Position

5. Theories and Definitions Contributing to Conceptual

Framework for Construct of Health-Related Socioeconomic

Well-being

6. Demographics of Sample: Age, Income, Education, and Subjective

Rating of Social Status

7. General Demographics: Gender, Race, Income, Marital Status,

Education

8. Disease Related Demographics

96

9. Comparison of Sample to Total Population

10. Sample Data Compared to Normative FACT-G Data 100

11. Results of Expert Review and Related Decisions 102

12. Items Deleted from SEWBS 108

13. SEMs of the Proposed Subscales and SEWB Scale 110

14. Subscale Analysis of the SEWBS

15. The Reliability, Content Validity, and Factor Loadings of the SEWBS 
16. Correlation Matrix Showing Construct Validity of the SEWB Subscales

17. Correlation Matrix with Class I Criterion Variables

18. Correlation Matrix with Class I Criterion Variables

19. Correlation Matrix with Class III Criterion Variables

20. Correlation Matrix-Potential Socioeconomic Predictors of QOL

21. Results of Hierarchical Regression Analysis-Socioeconomic Predictors of QOL with FACT-G Score as Dependent Variable

22. Changes Resulting from Hierarchical Regression Analysis-Socioeconomic Predictors of QOL with FACT-G Score as Dependent Variable

23. Results of Hierarchical Regression Analysis-Socioeconomic Predictors of QOL with QLI Score as Dependent Variable

24. Changes Resulting from Hierarchical Regression Analysis-Socioeconomic Predictors of QOL with QLI Score as Dependent Variable

25. Correlation Matrix - Subscales of FACT-G, SEWBS, and QLI

26. Results of Hierarchical Regression Analysis - Subscales of the FACT-G and the SEWBS with QLI Score as Dependent Variable

27. Changes in Hierarchical Regression Analysis-Subscales of the FACT-G and the SEWBS with QLI Score as Dependent Variable 


\section{LIST OF FIGURES}

1. Conceptual framework for defining socioeconomic well-being as a QOL dimension 73

2. Revised conceptual framework for defining socioeconomic well-being as a QOL dimension

3. FACT-G Quality of Life dimensions as conceived by Cella and Nowinski (2002) 138

4. Quality of Life dimensions inclusive of socioeconomic well-being 139 


\section{CHAPTER I}

\section{THE PROBLEM}

Few life events have the impact that is generated by a diagnosis of cancer, regardless of the stage or type of the disease. Such a diagnosis is universally feared due to the associated risk of mortality and the impact of the disease on multiple aspects of an individual's being — physical, emotional, spiritual, relational, and economic (Lauria, Clark, Hermann, \& Stearns, 2001). It is a disease fraught with loss (Ferrell, 1998) and the grief that accompanies human perdition.

When it comes to cancer, the poor suffer more (Freeman, 2004; Institute of Medicine, 1999, 2002, 2003; Ward et al., 2004). The reality of disparities in cancer care was clearly documented in 1989 when the American Cancer Society reported on a series of fact-finding hearings held throughout the United States (American Cancer Society, 1989). Freeman (2004, p.72) summarized the findings as follows:

1. Poor people lack access to quality healthcare and are more likely than others to die of cancer.

2. Poor people endure greater pain and suffering from cancer than most Americans.

3. Poor people face significant obstacles to obtaining and using health insurance and often do not seek needed care if they cannot pay for it. 
4. Poor people and their families must make extraordinary personal sacrifices to obtain and pay for health care.

5. Cancer education and outreach efforts are insensitive and irrelevant to many poor people.

6. Fatalism about cancer prevails among the poor and prevents them from gaining quality health care.

More recent studies have validated that such inequality continues into the $21^{\text {st }}$ century. The existence and outcomes of such disparity have been identified for over 15 years, yet progress toward ameliorating this social problem has been only minimal.

Efforts to measure the impact of cancer on the whole person have resulted in the development of specialized quality of life (QOL) measurement instruments and an area of research focused solely on the development, analysis, and utilization of such tools. It is generally agreed that QOL is a subjective, multi-dimensional construct (Cella, 1998; Higginson \& Carr, 2001; Osoba, 1991), but the included dimensions vary from tool to tool, and many claim a "gold standard" tool does not exist (Donnelly, 2000; Osoba, 1991). Commonly included dimensions or domains include: (a) physical, (b) functional, (c) emotional, (d) social, (e) family, and (f) spiritual. Some instruments contain a socioeconomic or financial domain, but such inclusion is not the norm.

If the reality of healthcare disparities has been proven and the negative consequences of such disparities in the lives of poor persons with cancer has been revealed as it has in so many studies, one might conclude that socioeconomic issues influence QOL —at least for those persons surviving at below or near poverty levels. The absence of socioeconomic well-being as a domain in the evaluation of one's QOL would 
be a deficit when evaluating the whole person response to cancer. Yet, such a domain is most frequently omitted in standardized instruments.

The problem under study in this dissertation is the relative absence of a socioeconomic well-being domain in a specific standardized QOL assessment instrument, the FACT-G. While there may not be agreement on a "gold standard" tool, the FACIT family of tools is one of, if not the most frequently used, family of tools for evaluating QOL in cancer.

This first chapter will now explore in depth the various components of the problem: the impact of a cancer diagnosis on the whole person, the relationship between cancer and socioeconomic well-being, and the current status of QOL measurement as relevant to socioeconomic variables.

\section{The Impact of a Cancer Diagnosis}

More than 1.3 million Americans were diagnosed with cancer in 2005, and approximately 9.8 million were living with a history of the disease (American Cancer Society, 2005). One out of three Americans will face a cancer diagnosis during their lifetime (Institute of Medicine, 1999a). One out of four deaths in America results from the ravages of cancer, making it second only to cardiovascular disease as the leading killer in the United States (Jemal et al., 2005). When deaths are aggregated by age, cancer has actually surpassed heart disease as the leading killer of persons under age 85 since 1999 (Jemal et al., 2005).

A diagnosis of cancer is universally feared due to its association with mortality and its potential impact on all spheres of life (Wells \& Turney, 2001). The majority of persons view cancer as an "exogenous adversary" - an enemy or deadly intruder to be 
hunted down and destroyed (Linder, 2004). Although the majority of cancers are now treatable, many people associate cancer with fears of pain, suffering and death (Gorman, 1998).

Being diagnosed with cancer disrupts one's life and can threaten one's security and sense of control. There is fear of physical devastation as one faces the rigors of surgery, chemotherapy, and/or radiation as well as the insult to the spirit (Ferrell, 1998). Some patients may feel ashamed or embarrassed by a diagnosis of cancer, especially if they feel some responsibility for getting the disease due to their risk behaviors (i.e., smoking, consuming alcohol, having multiple sexual partners) (Linder, 2004).

As Ferrell (1998) so aptly states, one of the hallmarks of the cancer experience is that of loss. Loss begins with physical changes such as loss of hair or bodily parts. Continued illness may lead to loss of relationships anc roles, autonomy and independence, and the threat of loss of life itself. Loss of a sense of health and the potential loss of a future affects persons even if their prognosis is seemingly good (Ferrell, 1998).

In an effort to recognize and address the psychosocial impact of a cancer diagnosis, the National Comprehensive Cancer Network developed standards of care for the management of distress (Wells \& Turney, 2001). This group defined this distress as it applics to cancer patients and their families as follows:

Distress is an unpleasant experience of an emotional, psychological, social, or spiritual nature that interferes with the ability to cope with cancer treatment. It extends along a continuum, from common normal feelings of vulnerability, sadness, and fears, to problems that are disabling such as true depression, anxiety, panic, and feeling isolated or in a spiritual crisis (National Comprehensive Cancer Network, 1999). 
Issues experienced by the person with cancer vary according to the different stages of the disease experience: the initial diagnosis, 1reatment, post-treatment, recurrence, and terminal illness (Christ, 1993). Wells and Turney (2001) list the following factors that influence the individual's or fanily member's adaptation to the cancer experience:

1. Type of cancer, cancer stage, and prognosis.

2. Degree of disability caused by the disease and its treatment.

3. Intensity of the treatment.

4. Person's age and stage in the life cycle.

5. Person's past experience with cancer.

6. Person's current situation (including socioeconomic (SES), healthcare access, QOL).

7. Person's unique emotional makeup.

8. Degree of social and caregiver support.

9. Typical coping mechanisms.

Knowing that a cancer diagnosis can have a monumental impact on any diagnosed person, we will now explore the relationship between socioeconomic status and cancer.

\section{Cancer and the Poor}

\section{Socioeconomic Status and Cancer}

Over 37 million Americans live below the poverty line $(\$ 14,680$ for a family of three)-a number that increased by more than a million in 2004 (Alter, 2005). This poverty rate of $12.7 \%$ is the highest in the developed world and is more than twice as 
high as in most other industrialized countries (Alter, 2005). Percentage living in poverty between 2002-2004 by race was as follows: White $-8 \%$; Black--24\%; American Indian/Alaskan native - 24\%; Pacific Islander-13\%; and Hispanic-22\% (Children's Defense Fund, 2005).

The U.S. Public Health Service published its first investigation of economic deprivation and ill health in 1916; the subject of this irivestigation was the experience of garment workers in New York City. The authors noted that economic conditions had a marked impact on the health of wage earners and their families, yet there was little data evaluating such effects (Warren \& Sydenstricker, 1916).

When it comes to cancer, the poor do suffer more (Freeman, 2004; Institute of Medicine, 1999, 2002, 2003; Ward et al., 2004). An inverse relationship between socioeconomic status and poor health has been documented since the twelfth century for numerous diseases, populations and places, and there is evidence that SES profoundly impacts people and populations with cancer at all stages (Balfour \& Kaplan, 1998). The poorer one is, the greater the risk of death from cancer and the shorter the survival time (Berg, Ross, \& Latourette, 1977; Jenkins, 1983; Lipworth, Abelin, \& Conelly, 1970). Persons of lower SES with a history of cancer are more likely to have a recurrence and to have it at a younger age (Berg et al., 1977).

Disparity in cancer survival between the poor and the more wealthy has been a recognized fact since 1963 when the State of California Department of Public Health released its cancer survival statistics revealing that patients receiving treatment in public hospitals had lower survival rates that those treated in private facilities (Wilkes, Freeman, \& Prout, 1994). National Cancer Institute studies published in 1944, 1959, 1969, and 
1971 documented higher mortality rates among Black Americans versus White Americans (Wilkes et al., 1994). In a study of patients with 39 different cancer types treated in the University of Iowa Hospital from 1940 until 1969, it was found that indigent patients had poorer survival for each cancer type; in this study, the majority of the patients were White and all received the same level of care (Berg et al., 1977).

Subsequent studies evaluated whether the difference in cancer incidence between Black and White Americans was the result of socioeconomic versus racial factors and found that socioeconomic status was the main determining factor for most types of cancer (Baquet, Horn, Gibbs, \& Greenwald, 1991; McWhorter, Schatzkin, Horn, \& Brown, 1989). The fact that Black Americans were disproportionately distributed at the lower socioeconomic levels accounted for the increased incidence.

\section{Efforts to Address Cancer Disparities}

Awareness related to the disparity in cancer incidence and mortality among disadvantaged populations led to major endeavors directed toward defining and reversing such trends (Wilkes et al., 1994). In 1979, the American Cancer society organized the first National Conference on Cancer in Black Americans which led to the establishment of a National Advisory Committee on Cancer in Minorities. Harold Freeman, Chief of Surgery at Harlem Hospital, took a leadership role in addressing the issue and was the first to suggest publicly that socioeconomic status rather than race was the more likely explanation for the disparity in cancer survival among poor black Americans (Wilkes et al., 1994).

In 1984, the Board of Directors of the American Cancer Society appointed a study group to investigate the relationship between socioeconomic status (SES) and differences 
in cancer survival between Black and White Americans; Freeman chaired this study group whose consensus report concluded that SES was indeed a major determinant. The Subcommittee on Cancer and the Economically Disadvantaged was then formed to study the influences of SES on cancer incidence, promptness of diagnosis and treatment, and overall access to care (Wilkes et al., 1994). The subcommittee reported the following major findings (Subcommittee on the Economically Disadvantaged, 1985):

1. Cancer incidence and survival are related to SES. When studies control for SES, mortality and incidence disparities arnong ethnic groups are usually reduced or disappear.

2. Overall 5-year survival rates are $10-15 \%$ less for the socioeconomically disadvantaged.

3. At least $50 \%$ of the survival difference is due to late diagnosis related to lack of early screening and poor access to the health care system.

4. Cancer mortality in Black males increased dramatically over the past 30 years probably because of the disproportionate number of black Americans who were poor.

5. Risk factors contributing to increased cancer incidence and mortality among the poor include smoking, diet, and occupational exposure.

6. Certain public myths about cancer contribute to late detection and need to be addressed with culturally sensitive, linguistically appropriate programs.

7. Prevention-type services are lacking. Compliance with prevention-focused procedures, adherence to treatment protocol, and follow-up visits are difficult for the individual of lower SES. 
These findings were documented in the American Cancer Society's Special report on cancer in the economically disadvantaged (American Cancer Society, 1986) and the 1989 report, Cancer in the poor: A report to the nation (American Cancer Society, 1989). In 1989 , a series of hearings were held to document the problems of the poor when seeking cancer care; these hearings revealed that the poor were often forced to accept substandard healthcare services, endured assaults on their personal dignity when seeking treatment, experienced increased obstacles when attempting to access care, and were unable to secure the necessary information to make decisions about their care (Underwood \& Hoskins, 1994). Poor persons participating in these hearings described themselves as lacking hope, power, trust and control and as being victimized by the medical and social system (Underwood \& Hoskins, 1994). Physician's attitudes and stereotypes of the poor as having more negative personality attributes have been documented and clearly have implications for the care received by those of lower SES (Cooper \& Roter, 2004).

Ten years later, the Institute of Medicine released its landmark report, The unequal burden of cancer. This report addressed racial and ethnic disparities in cancer prevention, diagnosis, treatment, and mortality while calling attention to the fact that medically underserved individuals compose a separate group which cuts across all ethnic groups. Included in this group are those who are underinsured or uninsured, those with low levels of education, rural and inner-city populations, unemployed persons, and/or those of low socioeconomic status (Institute of Medicine, 1999).

This Institute of Medicine report chided researchers for the error of attributing the health disparities between groups to race or ethnicity without attending to socioeconomic 
variability (Institute of Medicine, 1999). Lillie-Blanton and Laveist (1996) reviewed studies that examined the influence of race and social class on health, finding considerable evidence that socioeconomic conditions are a powerful explanatory variable for racial disparities in health; they encouraged consideration of the social context of health in which an individual's socioeconomic status is viewed as an "expression of the educational and economic opportunities available in one's social environment" (LillieBlanton \& Laveist, 1996). They further suggested that SES may be more relevant than race or ethnicity in assessing one's socioeconomic context or social environment and recommended an approach that incorporates the social forces that affect individuals and their health (Institute of Medicine, 1999).

\section{The Relationship between Poverty, Health, and Cancer}

Poverty in itself contributes to an overall deterioration in health due to the physical and emotional damage inflicted over time and the cumulative impact of such factors as malnourishment, substandard housing, undereducation, joblessness, excessive exposure to environmental pollutants, and chronic stress (Underwood \& Hoskins, 1994). Poor people are considerably more likely to report material hardships than the nonpoor (Iceland, 2003). Specifically, Iceland (2003) reported that for persons with income under $200 \%$ of the poverty threshold: 1 in 8 reported not having enough food to eat sometimes or often; $18 \%$ missed meals sometimes or often; 1 in 8 reported that a member of their family had postponed or did not get medical care in the past year; $1 \%$ had been evicted, and another $1 \%$ had had their utilities disconnected. Food and preventive medical care and screenings are flexible parts of a tight budget. Rent and utilities are non negotiable and can consume 50 to $75 \%$ of a poor family's earnings, but the food budget can be 
squeezed resulting in malnourishment among the poor, especially children (Shipler, 2004). All such hardships associated with socioeconomic status obviously contribute to poorer health status with the problems beginning in childhood. Approximately 1 in 4 American children live in poverty placing them at risk for developmental delay and other physical damage (Pearson, 2003).

Balfour and Kaplan (1998) hypothesize that there are both exogenous and endogenous pathways by which SES might influence patterns of cancer initiation and progression. Exogenous pathways include the influence of SES on life-style, health behavior, and medical care. Resulting life-style and health behavior differences determine a person's exposure to agents that cause or promote cancer. The endogenous pathways theory hypothesizes that the stress, resiliency, and other systemic changes incurred as a result of one's SES have direct physical effects on the host perhaps linking the person's social and physical health.

Mandelblatt, Yabroff, and Kerner (1999) developed a conceptual framework to describe patient, provider and system barriers to cancer services. In their model, patient level barriers identified were low social class, minority status, and age. Social class and race-related or class-related attitudes were factors seen as mediating cancer outcomes (Mandelblatt, Yabroff, \& Kerner, 1999).

Factors which have been implicated as contributing to poor cancer outcomes for those of lower SES include: differential levels of exposure to environmental carcinogens; differences in personal health habits (increased smoking rates, poor diet, lack of education regarding health risks); increased prevalence of negative health behaviors; barriers to awareness and behavioral change; poorer access to health-related information, 
nutritious foods, and role models such as survivors who can assist with help-seeking; concentration on day-to-day survival; a sense of hopelessness and/or powerlessness; and social isolation (Institute of Medicine, 1999).

Oscar Lewis created the concept of a "culture of poverty" in an effort to explain the coping processes developed and preserved by poor families (Lewis, 1966). Lewis explains this phenomenon as follows:

... the culture of poverty is both an adaptation and a reaction of the poor to their marginal position in a class-stratified, highly individuated, capitalistic society. It represents an effort to cope with feelings of hopelessness and despair that develop from the realization of the improbability of achieving success in terms of the values and goals of the larger society. (p. 188)

He grouped characteristic behavioral traits into three categories: economic, social, and psychological. Table 1 lists traits in each category and how such traits might affect increased cancer incidence and mortality.

Gornick (1999) found disparities in Medicare utilization by race and socioeconomic status and agreed that the lower use of self-initiated services such as physician office visits, influenza immunizations, and mammograms could be explained in part by the "culture of poverty;" however, she hypothesized that the disparities in the use of services which must be recommended by physicians (colonoscopy, coronary artery bypass surgery as examples) are better attributed to the "culture of advantage," a concept developed by Rainwater (Rainwater, 1969). Members of this culture are more likely to expect first rate medical care and obtain information about the best practices and practitioners; additionally, physicians may make decisions based on their stereotypes of 


\section{Table 1}

\section{Behavioral Traits of "Culture of Poverty" Related to Cancer Incidence and}

Mortality

\begin{tabular}{|c|c|c|}
\hline Category & $\begin{array}{c}\text { Behavioral Traits according to } \\
\text { Lewis }\end{array}$ & $\begin{array}{c}\text { Affect on Cancer Incidence } \\
\text { and Mortality }\end{array}$ \\
\hline Economic & $\begin{array}{l}\text { Unemployment, low wages and } \\
\text { unskilled occupations, no savings, } \\
\text { borrowing at inflated rates, frequent } \\
\text { daily food purchases in small } \\
\text { amounts }\end{array}$ & $\begin{array}{l}\text { Chronic malnutrition } \\
\text { Industrial exposure in low- } \\
\text { paying, unskilled jobs } \\
\text { Inadequate or no health } \\
\text { insurance preventing access } \\
\text { to care } \\
\text { Delayed diagnosis and } \\
\text { treatment }\end{array}$ \\
\hline Social & $\begin{array}{l}\text { Crowded living quarters with lack } \\
\text { of privacy, abandonment of women } \\
\text { and children, single parent families } \\
\text { headed by women, free unions with } \\
\text { early initiation into sex, political } \\
\text { apathy and cynicism, low education } \\
\text { and literacy levels, marginal } \\
\text { relationships to social } \\
\text { organizations, critical attitudes } \\
\text { towards beliefs of the dominant } \\
\text { class }\end{array}$ & $\begin{array}{l}\text { Increased risk for certain } \\
\text { cancers related to early } \\
\text { sexual activity and multiple } \\
\text { partners } \\
\text { Lack of health related } \\
\text { education } \\
\text { Isolation from social } \\
\text { supports } \\
\text { Class, cultural and language } \\
\text { barriers to relationships with } \\
\text { healthcare providers }\end{array}$ \\
\hline Psychological & $\begin{array}{l}\text { High incidence of alcoholism, } \\
\text { increased incidence of violence } \\
\text { against women and children, } \\
\text { feelings of helplessness, inferiority, } \\
\text { fatalism, and dependency, present- } \\
\text { time orientation, inability to defer } \\
\text { gratification as in future orientation }\end{array}$ & $\begin{array}{l}\text { Increased risk of cancers } \\
\text { related to smoking and } \\
\text { alcohol abuse } \\
\text { Absence of secondary } \\
\text { prevention as result of } \\
\text { present-orientation } \\
\text { Survival takes precedence } \\
\text { over screening and detection } \\
\text { for asymptomatic problems } \\
\text { Sense of fatalism deters } \\
\text { participation in screening } \\
\text { activities and delayed } \\
\text { treatment }\end{array}$ \\
\hline
\end{tabular}

the poor and minority populations and refrain from ordering certain procedures requiring compliance and a certain life-style for effective follow-up (Gornick, 1999). 
Class, culture, and language can create barriers between poor patients and the healthcare providers that provide their care. "Looking up from the lack of wealth and education, many working poor people see an impersonal establishment of white coats and glistening instruments, of incomprehensible vocabulary and condescension" (Shipler, 2004, p.209). Distrust of the medical establishment by Black Americans is often linked to memories of the federal government's Tuskegee experiment when treatment was withheld for 399 poor Black men with syphilis from 1932 to 1972 in order to study the effect of the disease (Shipler, 2004). In a more recent 2001 incident, 1,700 postal workers, mostly Black, known to be exposed to two anthrax-laden letters at a postal facility were bypassed while public health officials worked quickly to evacuate congressional office buildings, test staffers, and administer antibodies; the postal workers were left untested and untreated until two died, one of whom had been denied antibiotics by his HMO (Shipler, 2004).

Certain cancer sites have increased rates among those of lower SES. Termed "cancers of poverty" by Balfour and Kaplan (1998), these sites include lung, oral and esophageal, stomach, uterine, cervix, and pancreas. Adversely, Rimpela and Pukkala (1987) called sites which are more prevalent among those of higher SES "cancers of affluence." These include colon, rectum, testis, skin, prostate, breast and uterine corpus (Rimpela \& Pukkala, 1987). The most logical explanation for the association between specific cancer sites and SES is that risk factors for cancer at that site are patterned either directly or indirectly with SES (Balfour \& Kaplan, 1998).

Two examples of the association between risk factors, SES, and cancer site occur with lung cancer and breast cancer. In the case of lung cancer, the risk factors of 
smoking, occupational exposure, and air pollution are more predominant among those of lower SES and persons in this group have a higher incidence of that cancer (Balfour \& Kaplan, 1998). With breast cancer the risk factors include null parity, being older at first childbirth, early menarche, and later menopause. Reproductive behavior is influenced by social factors; those of lower SES have children younger, have more children, and suffer from poorer nutritional status which may contribute to later menarche and earlier menopause (Balfour \& Kaplan, 1998). Therefore, in the case of breast cancer, the incidence is increased in those of higher SES who have fewer children later in life and may have earlier menarche and later menopause as a result of superior nutritional status.

Lastly, lower socioeconomic status is a risk factor for poor QOL, including psychosocial distress (Ashing-Giwa \& Kagawa-Singer, 2006). Healthcare systemic factors (including access to cancer treatment and follow-up care and quality of medical care) often adversely affect the poor and contribute to a lower quality of life (Freeman, 1991). Socioeconomic factors have been found to be associated with the number of symptoms and the presence of pain and depression at the end of life (Silveira, Kabeto, \& Langa, 2005). Decedents with greater educational obtainment (one indicator of higher SES) were found to have had a better QOL even in the last months or years of life than less-educated decedents (Liao, McGee, Kaufman, Cao, \& Cooper, 1999).

\section{The Impact of Insurance Status on}

\section{Cancer Diagnosis, Care and Outcomes}

Approximately 45 million Americans (15.6 percent of the U.S. population) are without healthcare insurance during a typical month (Thorpe, 2004). Lack of insurance can be correlated with both income and ethnicity. Sixty percent of those with annual 
incomes of $\$ 20,000$ or less had been uninsured during the past two years compared to eight percent of those with incomes above $\$ 60,000$; African American and Hispanics are two to three times more likely to be uninsured than White Americans (Institute of Medicine, 2002a).

The Institute of Medicine, Committee on the Consequences of Uninsurance (2002) concluded that uninsured cancer patients generally have poorer outcomes and are more likely to die earlier from their disease than those with insurance; this is largely contributed to late diagnosis resulting from the fact that uninsured adults are less likely to receive preventive and screening services in a timely manner than adults with any type of insurance (public or private). Additionally, this committee found that care given to persons without insurance does not meet standards for chronic disease management and that these persons lack access to and maintenance of proper medication regimens.

Roetzheim and colleagues conducted a series of studies and found that both uninsured patients and patients on Medicaid had higher mortality rates for colon and breast cancer (Roetzheim, Gonzalez et al., 1999; Roetzheim, Pal et al., 2000), that uninsured and Medicaid patients are more likely to be diagnosed with late stage cancer at diverse sites (Roetzheim et al., 1999), and that treatments received by patients varied considerably according to their insurance payer (Roetzheim, Pal et al., 2000).

Medicaid, medical assistance to the poor, has not been an effective solution to the problem of uninsurance and the poor. Limitations with this social program include: low provider payment rates which reduce access to services and limit choice; delays in appointments and referrals to specialists; little continuity of care; intermittent coverage based upon changes in employment and health status of the recipients; the process of 
eligibility determination which may require redetermination as frequently as monthly; administrative requirements that result in lost coverage; and distinctive eligibility requirements allowing eligibility to only those of the lowest income levels, those with severe disability, and those with significant health expenses (Institute of Medicine, 2002a). The resulting recommendation of the IOM report (2002) was for broad based insurance strategies across the uninsured population, providing insurance well before the development of advanced disease and allowing for ongoing relationships with health providers. A look into the evolution of social welfare policy in the United States may illuminate reasons why this recommendation has not come to fruition.

\section{Current Social Policies Impacting Healthcare Disparities}

Why does such disparity in healthcare exist in the richest nation on earth? Freeman (2004) identified three causes contributing to the current situation-poverty, culture and social injustice. In the previous section, the problems of poverty and the related culture of poverty were discussed in relationship to healthcare disparities in cancer. An overview of political philosophy and policies in the United States will provide further understanding of social injustice related to healthcare.

\section{Political Philosophy and the Evolution of Social Welfare}

Karger and Stoesz (1998) provide an excellent synopsis of our country's political philosophy and the related evolution of our social welfare (including healthcare) programs and policies resulting in a pluralistic mix of private and public solutions. From the 1930s into the '70s, the prevailing political attitude toward the poor was liberal. People rallied together in support for the needy during the Great Depression, the Civil Rights Movement and the War on Poverty (Mongan \& Lee, 2005). Social programs such 
as those created by the Social Security Act, the Federal Housing authority home mortgages, student loans, and veteran's pensions benefited Americans of middle as well as lower economic status. There existed political support for the Keynesian hypothesis (Keynes, 1933) which postulated that money pumped into social welfare programs resulted in good for the economy and benefited everyone. However, Americans were never sold on centralized government as evidenced in some European countries. Even Keynes believed that pumping money into welfare programs should be a last resort for economic stabilization.

Until the seventies, the Democratic party in the United States was viewed as liberal in thought and practice, but after the defeat of Jimmy Carter in 1981, a new neoliberal attitude evolved as part of the party's effort to survive. The Reagan administration exploited American's leeriness towards large social programs. As America became more affluent, the common good took second place to a focus on individual rights and achievements (Karger \& Stoesz, 1998).

The new neoliberal Democrats shared many values in common with the neoconservative Republicans. Both were against centralized government programs and increased spending for social programs that would, in their minds, erode the work ethic. Both believed in frugality in government spending, workplace solutions, personal responsibility, thrift, and family focused solutions to the problem of poverty and related healthcare disparities. Welfare programs emphasized labor market participation (workfare not welfare) and benefits were viewed as time-limited assistance focused on returning to personal responsibility for one's wellbeing. 
"Supply side" theory (Karger \& Stoesz, 1998) overruled the Keynesian

hypothesis; this theory held that the economy (including the poor) would benefit more from decreased taxation for social programs in that the money would be invested in ways to expand the economy, create jobs, and raise everyone's standard of living. Large scale social and healthcare programs were viewed as detrimental in that they eroded the work ethic by supporting nonworkers and diverted money via taxes from the private sector which could be invested in capital formation.

In the midst of efforts to decrease public welfare expenditures, Americans continue to view healthcare as a general right. According to Beachamp and Childress (2001), this right is based upon two arguments. The first is the argument for collective social protection; just as we are protected against crime and terrorism, we should be protected against the threat of illness and disease. The second argument is the argument for fair opportunity based upon the belief that social institutions should counteract the lack of opportunity brought on by the misfortune of illness or other bad luck over which the person had no control. In America, efforts to provide the best possible healthcare for all, are tempered by a public concern for cost containment and the belief that healthcare provision is best accomplished in a free market, competitive environment (Beauchamp \& Childress, 2001),

\section{Medicaid: Healthcare Answer for the Poor?}

Medicaid was created under Title IX of the Social Security Act as the nation's healthcare answer for the poor (Centers for Medicare and Medicaid Services, 2006). This program is reflective of the current political philosophy supported by neoliberals and neoconservatives alike. Elements of the program reflective of this philosophy include: 
1. Medicaid is a joint program between the Federal and state governments. Outside of some specific federal guidelines, states make their own decisions about coverage leading to vast differences between benefits among the states (Centers for Medicare and Medicaid Services, 2005). This avoids centralization of a government program — an approach more palatable to most Americans.

2. Being poor is not enough to qualify for Medicaid in most states. While coverage for pregnant women and children (the most vulnerable members of our population) tends to be more liberal, the majority of the poor are not eligible for coverage unless they are totally unable to work, are ill, and have no income. Such policies do not allow able-bodied persons to become dependent on government-subsidized health benefits.

3. Insurance is viewed as a workplace benefit. This supports the idea that social problems are best resolved by workplace solutions.

4. Income limitations are very rigid. Persons making only a few dollars over the limit receive no benefits until they "spend down" their earnings by accumulating healthcare expenses. This measure also discourages dependence while requiring diligent record keeping and debt accumulation. Regardless of such restrictions, the Medicaid budget continues to escalate. In 2003, the state and federal governments spent approximately 285 million on the program (Burdetti, 2004). Why do costs continue to spiral? There are multiple reasons: 
1. The numbers of elderly and disabled persons is increasing. People are living longer with disease and illness.

2. Employers, especially small business employers, cannot afford to provide health insurance as a benefit due to escalating costs. When insurance options are available, they are regressive in nature. For instance, family health insurance premiums for the coach of a major university's basketball team and the maintenance person assigned to maintain the sports facility would cost the same, but the maintenance worker would contribute a much larger proportion of his/her paycheck to gain such coverage.

3. Technological advances and new medications are extremely costly and prolong life indefinitely.

4. The Medicaid program is paying more benefits to facilities serving increased numbers of indigent and uninsured patients because so many more persons have no health insurance (Burdetti, 2004).

Medicaid has not been successful if its goal is to provide a safety net and insure quality healthcare for all. Over 35 million Americans now live below the poverty level. There are over 45 million uninsured Americans and $80 \%$ of those are workers and their families (Burdetti, 2004). These uninsured will be on the brink of poverty should they be diagnosed with a serious disease such as cancer.

\section{Efforts at Healthcare Reform}

In 1993, the Clinton administration led a healthcare reform initiative that offered great promise for resolving the problem. The bill itself was massive - over 1,000 pages in length (Burdetti, 2004), and much of what it included would have appeared to have 
been palatable to both neoconservatives and neoliberals. Referred to as "managed competition" (Clinton, 2003), the program included workplace solutions for providing insurance coverage to all Americans. The government would have provided incentives and subsidies to both employers and employees so that everyone, including low-income individuals, low-wage workers, and small business employees would receive coverage at a level equal to that of most good employee health plans (Burdetti, 2004). Medicaid would have been privatized by incorporating beneficiaries into insurance alliances with everyone, therefore removing stigmatization by providers. Insurance pools would have been created allowing all employees, even those of small businesses, the option of choice (Burdetti, 2004). Risks would have been shifted to providers via capitation plans.

This pluralist mix of private and public sector involvement would seem to conform to the predominant political philosophy of the time, but the Health Security Act failed for two major reasons. First, the approach did not conform to the usual political maneuvering. Americans like to "tinker" (Mongan \& Lee, 2005) with legislation allowing special interests to have their say. Introducing such a massive plan all in one bill was political suicide. Secondly, the economic timing was not right. The country was in the middle of a recession and there was great fear that such a massive program would be disastrous. This Clinton initiative joined the failed efforts of the Carter and Nixon administrations to solve health insurance discrepancies via employer mandates (Burdetti, 2004).

In her book, Living history, Hillary Clinton (2003) admits to political naivety but also describes how special interest groups - the Health Insurance Association of America, small businesses and physicians already disgusted with managed care - helped 
to kill the legislation. Yet there were several good initiatives begun because of the effort including the Children's Health Insurance Program, nationwide screening programs for prostate and breast cancer, extended hospital coverage for women delivering babies, and restraint in healthcare price increases in the '90s (Clinton, 2003).

Twelve years after this major effort to reform healthcare, the problems persist. While Americans like to think of themselves as compassionate and devoted to the common good, most are not willing to make the sacrifices necessary to provide quality healthcare to all (Mongan \& Lee, 2004). There is no constituency currently in support of socialized medicine; rationing and increased taxes appear to be the only answer, and no one wants to support such an unpopular approach (Mongan \& Lee, 2004).

\section{"Losers" and "Gainers"}

In understanding social policy and social programs, assessing the "losers" and "gainers" resulting from the problem under study can help in understanding why the problem exists (Chambers \& Wedel, 2004). It appears that the special interest groups including health insurance companies, pharmaceutical companies, producers of medical technology, and physicians are gaining as a result of free, competitive healthcare markets. While it may appear that taxpayers gain when taxes are cut to stimulate the economy, the losses experienced by society as a result of our failure to appropriate monies to eliminate healthcare disparities costs more in the long run.

With this understanding of the problems relating to cancer and the poor, the next section considers the definition and measurement of cancer related QOL as an approach to evaluate the impact of a cancer diagnoses on the whole person. 


\section{Defining and Measuring QOL in Cancer}

\section{The Evolution of Quality of Life Measurement}

In the past thirty years, phenomenal advances in the diagnosis and treatment of diseases have enabled patients to survive once deadly conditions such as cancer. A desire to understand the individual's experience, the total burden of the disease and the impact of related treatments has led researchers to attempt to evaluate the whole person response to a diagnosis and the related treatment. This effort has culminated in the development of the concept of QOL and related efforts to measure it. In medicine, QOL measurement has served to legitimize the idea that the patient's perspective has equal validity to that of the practitioner when it comes to monitoring the effects and outcomes of disease and treatment (Leplege \& Hunt, 1997). QOL measurement also helps explain the commonly observed phenomena that two patients with the same clinical criteria experience dramatically different responses (Guyatt, Feeny, \& Patrick, 1993).

The initiation of clinical trials with cancer drugs also fed the interest in QOL as an outcome measure. Twenty years ago, the literature seldom reported quality of life benefits, but currently at least $10 \%$ of all randomized cancer clinical trials include healthrelated quality of life as the main end point (Bottomley, 2002). Ten years ago, Spilker (1996) and colleagues identified 215 measures, and instrument development and validation has since continued at a steady pace. "Since the 1970 's, the measurement of quality of life has grown from a small cottage industry to a large academic enterprise" (Gill \& Feinstein, 1994).

Cella and Nowinski (2002) suggest that there exist three important outcomes in healthcare: survival (how long people live); cost; and quality of life (how well people 
live). While survival and cost are objective measures, QOL is a subjective concept with diverse assessment criteria encompassing the physical and functional consequences of disease as well as subjective life satisfaction, happiness, and the individual's assessment of the value of various dimensions of his/her life (Cella \& Nowinski, 2002).

While the assessment of quality of life is valued, the difficult task is to measure a subjective concept with components that cannot be directly observed such as social functioning and spirituality (Bottomley, 2002). Osoba (1991) wrote a book on the impact of cancer on QOL, and he delineated numerous reasons for developing quantitative measures, some of which follow:

(a) development of the patient's health profile

(b) knowledge of the patient's values as an adjunct to treatment decision making

(c) evaluation of the cost-utility issues related to a treatment

(d) enabling standardized language to facilitate comparisons and discussions related to patients

(e) providing a quick, simple method for assessing patient's values and concerns

(f) overcoming qualitative descriptions which have different meanings to different persons

(g) consideration of all available information in clinical decision making. Osoba acknowledged that many feel that QOL is far too subjective to evaluate via a standardized measure, but he believed that rigorous psychometrics could result in valuable tools.

Several experts in the field have noted that while there exists no "gold standard" for the measurement of QOL, a researcher can select the instrument most suitable to the 
population under study and supplement the tool with additional questions specific to the research (Cella, 1994; Donnelly, 2000). Most of the early research and tool development related to QOL was generated by the medical community and was built around the medical model of care focusing on the patient and disease (inter and intra personal factors) rather than simultaneous concern for the person and environment as theorized by Germain and Gitterman (1996).

Perhaps the definition of quality of life underlying the theoretical approach and purpose of the research should guide the process of selecting an appropriate measurement tool. The next section explores the various definitions that have been used to guide tool development.

\section{Defining Quality of Life}

In 1984, K.C. Calman (a MD and medical ethicist) offered one of the first definitions of this QOL concept. Referred to as "Calman's Gap," he claimed that QOL was the gap between the individual's expectations and experience (Calman, 1984). A good quality of life exists when the individual's hopes are fulfilled by experience while poor quality of life occurs when hopes do not meet with the experience. Similarly, David Cella, a renowned expert in the development of instruments to measure QOL and the originator of the FACIT family of instruments, linked the reality of experience with the desired ideal or expected in defining QOL as the patient's appraisal of and satisfaction with his or her current level of functioning compared to what he or she views as ideal (Cella, 1994).

Calman must have had the soul of a social worker in that he stated that it was not enough to measure or identify this gap - once known, efforts to narrow or eliminate that 
gap and therefore improve that person's QOL are essential. He called for QOL assessment based upon the patient's own list of problems and priorities and the estimation of the "gap" followed by the development of a plan for modifying QOL in which the patient is fully involved (Calman, 1984).

If one accepts Cella and Calman's definitions, the fact that people have different expectations or ideals complicates measurement of QOL. Expectations are learned from experience, are highly specific, vary subject to differences in social, psychological, socioeconomic, demographic and cultural factors, and are closely related to people's relationships with their environment (Carr, Gibson, \& Robinson, 2001).

The World Health Organization (WHO) defines QOL as the individual's perception of his/her position in life in the context of the culture and value systems and in relation to goals, expectation, standards, and concerns (WHOQOL Group, 1993). In 1990, WHO stated that QOL was a multidimensional construct composed of at least the dimensions of physical and role functioning, social functioning and an overall measure of global QOL. According to Cella and associates (Cella \& Nowinski, 2002) the most comprehensive instruments measure at least three of four domains: physical, functional, social, and emotional well-being. Similarly, Aaronson (1990) stated that QOL should minimally be composed of four domains: functional status, disease, and treatment related symptoms, psychological functioning, and social functioning. However, there is not total agreement on the dimensions of importance. Many other dimensions have been identified and included in one or more tools. Cella and Tulsky (1990) identified thirty different dimensions. In some instruments, socioeconomic concerns are included in a 
separate dimension while in others economic issues are coupled with social well-being, but socioeconomic well-being is most frequently not viewed as a key domain.

Even when instruments contain similarly named domains or subscales, comparability may not result in practice. A study comparing four similar domains (physical, emotional, social and functional) of the European Organization for Research and Treatment of Cancer Core (EORTC QLQ-C30) and the FACT-G showed only low to moderate intercorrelations across four groups (Holzner et al., 2001).

Muldoon, Barger, Flory, and Manuck (1998) identified two operational definitions of quality of life: objective functioning and subjective well-being. Similarly, Cella and Nowinski (2002) state that the purpose of quality of life measurement is assessment of both the functional and subjective impact of illness and its treatment on the person. These are two obviously different dimensions, one being physical and the other mental. Yet, measurement of both aspects is often included in the same instrument, including the FACT-G.

\section{Measuring Quality of Life}

Knowing that most agree that QOL is a subjective, multidimensional, and dynamic concept (Aaronson, 1990; Cella, Chang, Lai, \& Webster, 2002; Osoba, 1991), it is no wonder that consensus on an ideal instrument does not exist. QOL has been described as a "latent" construct which is hypothetically assumed to exist while not being directly measurable or observable (Fayers, Hand, Bjordal, \& Goenvold, 1997). Yet, a multitude of instruments have evolved from efforts to measure this nebulous construct.

Instruments may be generic, targeted, or hybrid. Generic instruments measure a wide range of domains applicable to a variety of diseases and conditions in general 
populations (Cella et al., 2002). Such instruments lack specificity and sensitivity and may not be sensitive to clinically important and meaningful changes in individuals.

Targeted instruments may be disease-specific or condition-specific and are more sensitive to changes in QOL in groups of patients (Cella et al., 2002). Instruments designed for specific diseases or groupings within a disease (i.e., type or site of cancer) belong to this group.

Hybrid instruments combine the two aforementioned approaches beginning with a core questionnaire applicable to diverse disease states and patient populations and adding supplementary questions or modules specific to a disease, therapy or symptoms/side effects (Cella et al., 2002). The Functional Assessment of Chronic Illness Therapy (FACIT) Measurement System uses hybrid instruments. The Functional Assessment of Cancer Therapy-General (FACT-G) serves as a generic core set of questions related to cancer in general to which scales measuring symptoms and side effects specific to a type of cancer (i.e., breast, lung, colon) can be added.

In a series of articles in the British Journal of Medicine (2001), numerous questions were raised related to the validity of current QOL measures. Carr (an epidemiologist) and Higginson (2001) expanded the concept to include the social and cultural context of the respondent—factors not usually addressed but in agreement with the WHO definition. They criticized current instruments for imposing a particular set of values upon the respondent—values that may not be critical to the individual's selfevaluation. Carr writing with Gibson (a sociologist) suggested that expectations rather than actual experience was the determining factor in an individual's evaluation of QOL (Carr , Gibson, \& Robinson, 2001). A person whose quality of life is already suboptimal 
might evaluate his/her situation differently than one whose life has made a major turn for the worse as a result of illness. Also, the reference point related to expectations is always changing as a person adjusts to disease (Carr et al., 2001). Psychological adaptation, referred to as "response shift," occurs in cancer patients and others living with chronic disease (Muldoon, Barger, Flory, \& Manuck, 1998). Response shift is the change in scores over time as respondents change expectations as they adjust to illness; often this can contribute to difficulties in interpreting data (Varricchio, 2006). Therefore, questions related to wellbeing can elicit different answers over time regardless of disease progression or functional decline. Other studies have validated the "disability paradox"- a condition in which the patient's health is deteriorating yet it is not reflected in their QOL evaluation (Beadle et al., 2004; Clavarino, Najman, \& Beadle, 2003; Kutner et al., 2003).

A major criticism of quantitative standardized instruments for measuring QOL is their insensitivity to the individual's specific perceptions as to domains of relevance and the relative importance of each domain. Two instruments designed to overcome the problem of imposing an external value system on individuals rather than allowing them to describe their QOL in terms of factors they consider important are the Subjective Evaluation of Individual QOL (SEIQOL) and the Patient-Centered Index (King, 2006). The SEIQOL allows the patient to select cues related to factors they considered important to their QOL, rate their satisfaction in those areas and then design a pie chart indicating the weight of each of their cues (Waldron, O'Boyle, Kearney, Moriarty, \& Carney, 1999). While this does address the need for an individualized measure, it is a complicated and time-consuming process. 
Similar to the SEIQOL, the Patient-Generated Index allows individuals to select the five most important areas for their QOL, rate how badly each area has been affected and prioritize the areas as to which they would most like to improve (King, 2006).

Others have attempted to make measures more reflective of the individual's perspective by having the subject rate not only their satisfaction with a dimension but also the importance of that dimension to their QOL (Ferrans \& Powers, 1985).

In attempting to understand QOL measurement, one might ask about theoretical foundations for this area of inquiry. A clear conceptual basis for quality-of-life measures is lacking, and the few attempts to develop models or operational definitions of QOL have been inadequate (Leplege \& Hunt, 1997). Vallarand and Payne (2003) have written on the conceptual and theoretical basis for developing the QOL concept and related tools. They found that several tools were built upon nursing process, but the majority of tools have evolved inductively from qualitative studies in which patients described important components of their QOL, themes were identified, items were developed, and the researcher performed factor analysis resulting in identification of domains or dimensions, usually not related to each other. Vallarand and Payne concluded that the research to date was largely theory-generating rather than theory-testing. They called for studies that would test the validity of tools in diverse populations and evaluate the relationships between defined dimensions (Vallerand \& Payne, 2003). Leplege and Hunt (1997) found that research teams that tried to develop clear conceptual models failed to gather empirical data to test hypotheses drawn from the model; instead, measures are quickly developed and applied without evidence as to the closeness of fit of the model to the data. 
When selecting an appropriate QOL measure, a first step is to identify what will be measured including the dimensions of importance. Conceptual fit, the degree to which the measure evaluates the concepts or variables of interest to the researcher or clinician, should be of primary importance (Varricchio, 2006). The content of the instrument should be appropriate to the population of interest (Donnelly, 2000). Knowing that SES impacts health and the disease experience in multiple ways among most, if not all, populations, it would follow that socioeconomic well-being would be a variable of concern in many studies and patient assessments.

Cella and Tulsky (1990) make the following recommendations for selecting the most appropriate QOL measure:

(1) The term "quality of life" should be avoided if measuring only one dimension of the construct. At least three of the generally accepted components of QOL (physical, social and emotional) should be included.

(2) The selected QOL measure should derive from the study questions, not viceversa.

(3) Measures should be selected based upon the characteristics of the population to be studied.

(4) Existing scales should be supplemented with a few relevant and specific items tapping areas not included in the selected scale.

(5) Because QOL includes a sense of well-being and life satisfaction, the scale of choice should include such areas and not just address absence of dysfunction or distress. 


\section{Using Measurement Results}

Uses of measurement results include differentiating between people according to their quality of life (a discriminant instrument) and measuring the change in an individual's quality of life (an evaluative instrument) (Kirshner \& Guyatt, 1985). For discriminant instruments, reliability is the most important characteristic in that reliable instruments will generally show that stable patients perform similarly over repeated administrations (Guyatt et al., 1993). For evaluative instruments, responsiveness or the tool's ability to detect change is of utmost importance (Guyatt et al., 1993).

Sensitivity to change over time is essential for QOL instruments if they are to be useful in the clinical setting, especially in clinical trials; therefore, instruments that measure state rather than trait characteristics and instruments that have scaling options sufficiently distinct to measure improvement or deterioration in the attributes being measured are the most useful (Goodwin, Black, Bordeleau, \& Ganz, 2003).

Researchers generally use QOL measures to report group data and compare it with normative data from previous studies while clinicians are interested in the benefit or effect on an individual and use the information for individual clinical decision making (Varricchio, 2006). For a measure to be clinically useful, it must be reliable appropriate, valid, responsive and also simple, quick to complete, easy to score and reflective of useful clinical information (Higginson \& Carr, 2001).

Researchers can also use QOL data to evaluate the impact of an intervention on a population or to determine the success of a program. When applied to a particular population, socioeconomic assessment, including assessment of socioeconomic wellbeing, would be an important consideration when evaluating the outcomes and 
understanding the impact of a program on diverse populations (Guidry, Torrence, \& Herbelin, 2005).

As Calman claimed (Calman, 1984), it is not enough to just measure quality of life. Action or related decisions must follow. Tanaka and Gotay (1998) claimed that clinicians and medical students perceive health-related QOL to be equal to survival in making treatment decisions, yet this is not always evident in practice. Using QOL as an outcome measure is relevant to evaluating cancer nursing practice because nursing should be concerned with not only the patient's survival and limiting undesirable complications but also with patient responses to the disease and treatment (Grant, Padilla, Ferrell, \& Rhiner, 1990).

While quality of life is viewed as valuable patient information, over one-third of clinicians feel the current measurement tools are inadequate, and many cannot find the time to collect and utilize such data (Bottomley, 2002). A survey of oncologists found that $80 \%$ believed that quality of life data should be collected, but only $50 \%$ actually did so (Morris, Perez, \& McNoe, 1998). Major obstacles to collecting such data included time and resource limitations and perceived lack of a suitable tool. Results of this survey revealed that while QOL information could have an important part to play in the management of individual patients, physicians tend to rely on biomedical measuresespecially when care is directed toward cure (as opposed to palliative care).

In their review of the impact of health-related QOL measurement on clinical decision making in breast cancer clinical trials, Goodwin et al. (2003) found that such measures contributed little when deciding between treatment alternatives, especially when biomedical (as opposed to psychosocial) interventions were under consideration. 
They hypothesized that this might be due to several factors: (1) the lack of precision of the measurement instruments; (2) the failure of existing instruments to capture the important domains; (3) or the ability of simpler, less burdensome instruments to provide similar information. When the efficacy of one medical treatment to prolong survival is superior to another, patients may choose the superior treatment regardless of the impact of the treatment on QOL. The authors' conclusion was that "perhaps HRQOL measures should be included in randomized biomedical treatment trials only when equivalency of treatments is likely and when differences in HRQOL will, therefore, become the primary factor influencing treatment decisions" (p. 286).

In a study of physicians in Amsterdam, QOL assessments were integrated into the daily routine of an out-patient oncology clinic (Detmar \& Aaronson, 1998). Both the patient and the physician were given a graphic presentation of previous and current patient scores using the EORTC QLQ-C30 as the measurement instrument. Although the sample population was limited (16 physicians, 18 patients), the results showed that physicians discussed three times as many topics with patients as previously, and both patients and physicians believed the QOL summary facilitated communication and that such utilization of results should continue.

While QOL information has been historically used by medical professionals, this type of information would be an essential part of a social work assessment and could easily be analyzed as part of treatment planning and goal setting especially when psychosocial interventions are planned. QOL data is frequently collected as part of a clinical trial or intervention evaluation in oncology; this data is underutilized in that it could inform the treatment team during the course of care as well as being used in the 
traditional manner as a repeated measure for evaluating treatment impact. Social workers might view QOL data to be more useful to their practice if tools collected meaningful measures of psychosocial well-being including socioeconomic issues.

The fact that QOL measures are often used solely to collect data and are not reviewed or discussed with the patient further limits the potential impact of the instruments. To ask a person about issues of such importance to his/her well-being and not explore possible means of improving negative factors or ameliorating unnecessary suffering would be unethical practice for a clinician, yet researchers do this routinely. Perhaps a partnership between researchers and the clinicians whereby results are shared both among professionals and with patients would result in QOL measures having dual functions as research measures and clinical assessment tools.

Higginson and Carr (2001) list the following uses for QOL measures in clinical practice: identifying and prioritizing problems; facilitating communication; screening for hidden problems; facilitating shared clinical decision making; and monitoring changes or responses to treatment (Higginson \& Carr, 2001). All these potential uses are relevant to social work practice and consistent with the values and ethics driving the profession. See the last section of this chapter for further discussion of the relevance of QOL measurement to the social work profession.

\section{Why a Socioeconomic Dimension?}

The realities of poverty, social injustice, and inequality and the related healthcare disparities in America are evidence that just as persons differ related to the physical, functional, social, emotional, and spiritual aspects of health and illness, there is diversity 
in socioeconomic functioning which impacts the experience of and expectations related to quality of life.

As noted earlier, the U.S. Public Health Service published it first investigation of economic deprivation and ill health in 1916 based upon a study of the experience of garment workers in New York City (Warren \& Sidestroker, 1916). It was then noted that there was little data evaluating the effects of economic conditions on the health of wage earners and their families. Even today, although we know that social class is a key determinant of population health, routine analysis using conceptually coherent and consistent measures of socioeconomic position is rare in U.S. public health research (Krieger, Williams, \& Moss, 1997).

Health researchers are realizing that considering individuals outside of their social context limits understanding of disease etiology, health, and intervention modes.

Because SES is a central feature of the social structure of all complex societies, it is given much consideration when trying to understand social factors in disease and health (Oakes \& Rossi, 2003). Oakes and Rossi (2003) list the following reasons why the number of studies of how disease and health relate to SES is increasing:

(1) Science is cumulative and there is a great deal of precedent proving a strong relationship between SES and disability and disease.

(2) SES is important to agencies interested in understanding and explaining the public's health including such major funders as the National Institute of Health. Funding structures influence research focus and direction.

(3) SES is relevant to social policy concerning public health. Unlike some correlates of disease, SES has the potential of being changed by social policy. 
(4) Socioeconomic structure in the US is changing with economic inequality increasing. Those of lower socioeconomic status are becoming more impoverished, with much of the concentrated poverty existing among racial minorities.

(5) Lack of socioeconomic data can lead to misunderstanding of disparities in health. Such disparities can be blamed on signs of genetic differences or behavioral choices rather than clues about how racial discrimination and structural constraints harm health.

(6) Understanding the linkages between SES and health can provide information about the actual mechanisms involved and can contribute to discovering remedies.

All of these reasons also justify measurement of socioeconomic well-being as a component of QOL measurement. Consistent and broadly comparable measures of SES that can be incorporated into a wide variety of federally and privately sponsored data sets is essential (Krieger et al., 1997). Knowing that QOL instruments are almost always included in studies related to cancer and its treatment, including a socioeconomic dimension and analyzing its impact and relationship with other dimensions of QOL could impact knowledge related not only to the individual but also contribute to understanding of the impact of inequality on health outcomes.

Rather than being built upon theory, most QOL research has been theory generating; inductive, patient-generated approaches have been most often used to define the illustrative domains (Haase \& Braden, 2003). Because the majority of QOL measurements have evolved via medical and nursing research, the focus has been on the 
patient's physical, psychological and intrapersonal well-being (medical model) while environmental and socioeconomic concerns have not been prioritized as contributing factors or domains.

When evaluating QOL, social workers commonly adopt a different perspective that accounts for the individual's environmental context. The life model of social work practice (Germain \& Gitterman, 1996) presents an ecological perspective which could contribute to the conceptualization of QOL. Focusing on the reciprocal relationship between person and environment, ecological theory extends the understanding of the interacting personal, environmental, and cultural factors involved in troubling situations such as a diagnosis of cancer and related treatments. If applied to the concept of QOL, ecological theory would include not only the individual's intra and interpersonal responses to cancer as a life stressor but would also consider the impact of habitat (the person's physical and social settings within a cultural context) and niche (status occupied in a community's social structure) (Germain \& Gitterman, 1996) as essential to evaluation. Knowing that disparate healthcare availability and services seriously impact the poor, assessing the socioeconomic well-being of a person as a domain or dimension of QOL would be important to any social worker involved with clients experiencing cancer and arguably should be important to other health care providers as an integral component of QOL.

The traditional health-related QOL model follows a predominantly individual centered paradigm excluding contextual dimensions or domains and is insensitive to underserved populations including ethnic minorities, those of lower socioeconomic status, socio-political marginalized persons, and rural survivors (Ashing-Giwa, 2005). 
Ashing-Giwa (2005) proposes a contextual model for understanding and measuring health-related QOL including not only micro-contextual variables (general health and comorbidity, health efficacy, cancer-specific medical characteristics, and psychological well-being) but also macro-contextual factors (demographic context, social-ecological context, cultural context, and healthcare context). Such a model would be consistent with the life model of social work practice, the theoretical base of this dissertation described in Chapter II.

\section{Relevance to Social Work}

Since QOL measurement has become the norm in evaluating the whole person response to a disease and related treatments, it would follow that social workers would consider such measures in developing their assessment and understanding of patient needs. In oncology settings, social workers are often called upon when patients experience resource and environmental limitations. Including socioeconomic well-being as a dimension would identify the patient's perceptions of the impact of habitat and niche on their overall functioning. This along with assessment of the other domains of QOL (functional, physical, social and family, emotional, and spiritual) could be an important adjunct to the social work assessment providing not only descriptive, but perhaps predictive and outcome evaluation benefits as well.

Concern with QOL measurement and specifically the measurement of socioeconomic well-being as a dimension of QOL, is aligned with the following ethical principles as put forth by the National Association of Social Workers (1996):

(1) Social workers' primary goal is to help people in need and to address social problems. 
(2) Social workers challenge social injustice.

(3) Social workers respect the inherent dignity and worth of the person.

(4) Social workers recognize the central importance of human relationships.

Inclusion of a socioeconomic well-being dimension would identify client issues and the impact of socioeconomic variables on QOL therefore providing research-based knowledge related to the extent and impact of healthcare disparities on individuals and populations. The dignity and worth of the individual would be respected via provision of a holistic picture of not only physical, emotional, and social factors but also socioeconomic components of QOL.

Denying the impact of socioeconomic well-being on QOL perpetuates our society's indifference to the reality of healthcare disparities and inequality in our nation by assuming that socioeconomic status and related attitudes towards personal well-being do not constitute a domain of significance. This introductory chapter has highlighted the need for such a dimension as justified by the reality of the impact of inequality and injustice (as well as the alternative conditions of affluence and privilege) on the impact and outcomes related to cancer diagnosis, treatment, and prognosis. 


\section{CHAPTER II}

\section{THE LITERATURE}

In this chapter, the literature related to the foundational basis for this study will be explored beginning with a review of the development and psychometric evaluation of the FACT-G, the measure to which the proposed scale of socioeconomic well-being will be added. Theoretical support for inclusion of a socioeconomic dimension in QOL measures will be discussed. Social class theory as a basis for determining measures of socioeconomic status will be explored and linked to the proposed construct of socioeconomic well-being. A conceptual model for development of this measure of socioeconomic well-being will be explained. Lastly, existing measures of socioeconomic well-being in health related quality of life will be described and related to the proposed measure.

\section{The FACT-G}

\section{Background}

The FACT-G is one of many measures included in the Functional Assessment of Chronic Illness Therapy (FACIT) Measurement System, a collection of health-related QOL questionnaires used in chronic illness. The system includes over 400 items and over 30 targeted subscales; selected scales are available in over 40 languages (Cella \& Nowinski, 2002). Initially known as the FACT series of questionnaires, the FACIT title is now used to describe the evolution of what was once a cancer targeted system into a 
system inclusive of other chronic illnesses and conditions including multiple sclerosis, HIV and Parkinson's disease (Lent, Hahn, Eremenco, Webster, \& Cella, 1999).

The system is a hybrid or modular system in that it combines a core general measure (generic measure) with supplemental targeted measures which ask questions focused on a specific disease, condition, or treatment (Cella \& Nowinski, 2002). There are currently 12 FACIT subscales targeting different types of cancer (breast, bladder, brain, central nervous system, cervical, colon, esophageal, head and neck, hepatobiliary, lung, ovarian, prostate). Condition-specific subscales evaluate anorexia and cachexia, anemia, diarrhea, endocrine symptoms, fatigue, fecal incontinence, and urinary incontinence. Subscales related to specific treatment interventions address bone marrow transplant, biologic response modifiers, neurotoxicity, and taxane toxicity (Cella \& Nowinski, 2002).

The FACT-G is the core, generic questionnaire of this system. It assesses health status according to four health related QOL dimensions as follows:

(1) Physical well-being (PWB) - an evaluation of disease symptoms and side effects of treatment

(2) Social well-being (SWB) - an assessment of the quality of relationships with family and friends and social activity

(3) Emotional well-being (EWB) - a measure of coping ability and also the experience of feelings ranging from enjoyment to distress

(4) Functional well-being (FWB) — evaluates the individual's ability to perform basic activities of daily living including self-care, home management, and work. (Cella \& Nowinski, 2002) 


\section{Development of the FACIT Scales and Subscales}

A standardized methodology was used in the development of the FACIT Instruments beginning with the FACT-G using five steps: (1) item generation involving both patients and healthcare providers via interview and a literature review; (2) item review and reduction based upon relevancy, frequency of endorsement, representation of important dimensions, and capacity for meaningful translation; (3) scale construction including review of selected items by original participants; (4) initial evaluation via testing to establish psychometric properties including reliability, item analysis, validity, and sensitivity; and (5) additional evaluation through an iterative process (Cella \& Nowinski, 2002). This methodology has been modified as needed incorporating new advances in psychometric and statistical techniques including item analysis using item response theory to evaluate how well test items fit the underlying concept of healthrelated QOL (Cella \& Nowinski, 2002).

The generic core questionnaire, the Functional Assessment of Cancer-General (FACT-G), was the first of the measurement instruments to be developed. Initial development and validation occurred from October 1987 through February 1992 following the five step process outlined above. Description of the process, populations involved and the findings of this process are outlined in Table 2. The FACT-G was found to meet or exceed requirements for use in oncology clinical trials based upon ease of administration, brevity, reliability, validity, and responsiveness to clinical change (Cella et al., 1993). 
Table 2

Summary of Initial Development/validation Study for FACT-G

\begin{tabular}{|c|c|c|c|}
\hline Phase & Methodology & Population & Results \\
\hline $\begin{array}{l}\text { Phase I - Item } \\
\text { Generation }\end{array}$ & $\begin{array}{l}\text { Items generated } \\
\text { using semi } \\
\text { structured } \\
\text { interviews after } \\
\text { participant } \\
\text { completion of the } \\
\text { Profile of Mood } \\
\text { States and two } \\
\text { QOL scales (the } \\
\text { functional Living } \\
\text { Index-Cancer and } \\
\text { the Quality of Life } \\
\text { Index }\end{array}$ & $\begin{array}{l}45 \text { patients } \\
\text { receiving treatment } \\
\text { for advanced } \\
\text { cancer ( } 15 \text { breast, } \\
15 \text { lung, } 15 \\
\text { colorectal) } \\
15 \text { oncology } \\
\text { specialists (MDs or } \\
\text { RNs with three or } \\
\text { more years of } \\
\text { experience) }\end{array}$ & $\begin{array}{l}\text { Items developed : } \\
137 \text { related to } \\
\text { breast, } 126 \\
\text { colorectal, and } \\
107 \text { lung }\end{array}$ \\
\hline $\begin{array}{l}\text { Phase II - Item } \\
\text { Review and } \\
\text { Reduction }\end{array}$ & $\begin{array}{l}\text { Participants rated } \\
\text { items created in } \\
\text { Phase I on a } 4 \\
\text { point scale. Items } \\
\text { rated as very and } \\
\text { extremely } \\
\text { important were } \\
\text { retained. } \\
\text { Items common } \\
\text { across disease sites } \\
\text { were reviewed for } \\
\text { redundancy by } \\
\text { independent panel } \\
\text { of oncologists, } \\
\text { nurses and social } \\
\text { scientists and } \\
\text { similar items were } \\
\text { deleted. }\end{array}$ & $\begin{array}{l}\text { New sample of } 90 \\
\text { patients receiving } \\
\text { chemotherapy ( } 30 \\
\text { lung, } 30 \text { breast, and } \\
30 \text { colorectal). }\end{array}$ & $\begin{array}{l}\text { Item reduction } \\
\text { resulted in } 38 \\
\text { items retained to } \\
\text { constitute } \\
\text { Version I. }\end{array}$ \\
\hline
\end{tabular}


Table 2 (continued)

\begin{tabular}{|c|c|c|c|}
\hline Phase & Methodology & Population & Results \\
\hline $\begin{array}{l}\text { Phase III - Scale } \\
\text { Construction/Piloting }\end{array}$ & $\begin{array}{l}\text { Item presentation } \\
\text { format developed } \\
\text { based on } \\
\text { investigators' } \\
\text { definition of QOL. } \\
\text { Included actual } \\
\text { functioning and } \\
\text { expected } \\
\text { functioning ratings } \\
\text { in Version I. } \\
\text { Version II } \\
\text { excluded } \\
\text { expectation ratings } \\
\text { but included } \\
\text { patient appraisal of } \\
\text { importance of each } \\
\text { dimension. }\end{array}$ & $\begin{array}{l}\text { Population testing } \\
\text { not described as } \\
\text { part of this } \\
\text { process. } \\
\text { Apparently this } \\
\text { process was } \\
\text { conducted by } \\
\text { investigators } \\
\text { without participant } \\
\text { input. }\end{array}$ & $\begin{array}{l}38 \text { items reduced } \\
\text { to } 28 \text { in Version } \\
\text { II. Experimental } \\
\text { item added to end } \\
\text { of each subscale } \\
\text { to assess patient } \\
\text { appraisal of } \\
\text { extent of affect } \\
\text { on overall QOL } \\
\text { (using 0-10 } \\
\text { numerical analog } \\
\text { scale. }\end{array}$ \\
\hline $\begin{array}{l}\text { Phase IV - Scale } \\
\text { Construction/Piloting }\end{array}$ & $\begin{array}{l}\text { Participants } \\
\text { completed Version } \\
\text { II along with } \\
\text { validation packet } \\
\text { designed to } \\
\text { evaluate } \\
\text { convergent and } \\
\text { divergent validity } \\
\text { Item analysis and } \\
\text { factor analysis } \\
\text { conducted on } \\
\text { results }\end{array}$ & $\begin{array}{l}\text { Previously } \\
\text { untested } \\
\text { heterogeneous } \\
\text { sample of }(\mathrm{n}= \\
545) \text { patients with } \\
\text { cancer recruited } \\
\text { from four sources: } \\
\text { inpatients, } \\
\text { outpatients } \\
\text { receiving } \\
\text { treatment, patients } \\
\text { receiving } \\
\text { supportive } \\
\text { services, and } \\
\text { patients in a } \\
\text { funded } \\
\text { intervention study }\end{array}$ & $\begin{array}{l}\text { Five subscales } \\
\text { created based } \\
\text { upon } \\
\text { identification of } \\
\text { six significant } \\
\text { factors explaining } \\
51 \% \text { of the } \\
\text { variance. } \\
\text { Convergent and } \\
\text { divergent validity } \\
\text { established based } \\
\text { upon correlations } \\
\text { with measure in } \\
\text { the validation } \\
\text { packet. } \\
\text { Differentiation of } \\
\text { sensitivity of } \\
\text { scale established } \\
\text { via correlations } \\
\text { with disease } \\
\text { staging and } \\
\text { performance } \\
\text { rating variables. }\end{array}$ \\
\hline
\end{tabular}


Table 2 (continued)

\begin{tabular}{|l|l|l|l|}
\hline \multicolumn{1}{|c|}{ Phase } & \multicolumn{1}{|c|}{ Methodology } & \multicolumn{1}{c|}{ Population } & \multicolumn{1}{c|}{ Results } \\
\hline $\begin{array}{l}\text { Phase V - } \\
\text { Additional }\end{array}$ & $\begin{array}{l}\text { Test- retest } \\
\text { conducted within 3 } 3 \\
\text { to 7 days } \\
\text { Sensitivity to } \\
\text { change over time } \\
\text { related to } \\
\text { performance status } \\
\text { change over two } \\
\text { month period } \\
\text { evaluated }\end{array}$ & $\begin{array}{l}\text { 70 outpatients with } \\
\text { mixed cancer } \\
\text { diagnoses } \\
\text { completed test- } \\
\text { retest within 3-7 } \\
\text { days }\end{array}$ & $\begin{array}{l}\text { High test/retest } \\
\text { correlations on } \\
\text { each subscale } \\
\text { ranging from .82 - } \\
\text { receiving } \\
\text { chemotherapy } \\
\text { completed } \\
\text { instrument and } \\
\text { performance status } \\
\text { with total score } \\
\text { correlations of .92 } \\
\text { rating twice } \\
\text { censitivity to } \\
\text { changes in } \\
\text { functional status } \\
\text { established- } \\
\text { FACT-G capable } \\
\text { of distinguishing } \\
\text { between three } \\
\text { levels of } \\
\text { functional } \\
\text { performance }\end{array}$ \\
& & & \\
& & &
\end{tabular}

The FACT-G is now in Version 4; the various versions have evolved as a result of the iterative efforts to enhance clarity and precision without threatening established reliability and validity (Webster, Cella, \& Yost, 2003). It is considered to be appropriate for any patient with cancer and extensions of it have been used and validated in other chronic conditions including HIV/AIDS, multiple sclerosis, Parkinson's disease, rheumatoid arthritis, and in the general population (Webster et al., 2003). Adaptations resulting in Version 4 were influenced by the international collaborative work of the FACIT Multilingual Translation Project; Version 4 is cross-culturally relevant and sensitive to cross-cultural psychosocial impact of illness (Lent et al., 1999). The FACT-G has been translated into over 30 non-English languages since 1994. This core questionnaire is the scale under study in this investigation. Investigator rationale for 
selection of the FACT-G to measure QOL include its widespread use in oncology, its availability in multiple languages, its ease of administration, the relatively short amount of time required to complete it (Overcash, Extermann, Parr, Perry, \& Balducci, 2001), reliability, validity and ability to assess responses to clinical changes (Winstead-Fry \& Schultz, 1997; Goodwin et al., 2003). It has been noted to be the most used measure in the United States and has been found to be well-accepted by patient populations (Rodary et al., 2004).

\section{Psychometric Analysis of the FACT-G}

As previously stated, the initial development and validation of the FACT-G was documented in 1993 (Cella et al., 1993) and is detailed in Table 2. Socioeconomic status was not a reported variable in this study. Other validation studies relevant to this dissertation include studies involving rural and elderly populations.

Winstead-Fry and Schultz (1997) completed a systematic replication of the 1993 Cella et al. study utilizing the same validation packet and procedures with a rural population. Such a population is reflective of socioeconomic differences in that rural persons tend to be poorer and have less education, and experience access and availability issues related to the provision of healthcare (Winstead-Fry \& Schultz, 1997). This study found results consistent with Cella's evaluation of the FACT-G. See Table 3 for details of the study. While age, education level, and income were not found to be predictors of QOL in their data analysis, respondents with reported incomes of \$50,000-74,999 had significantly higher QOL scores than those reporting incomes less than $\$ 20,000$ (Schultz \& Winstead-Fry, 2001). 
Table 3

$\underline{\text { Relevant FACT-G Validity and Reliability Studies }}$

\begin{tabular}{|c|c|c|c|}
\hline Authors & Population & Methodology & Results \\
\hline $\begin{array}{l}\text { Winstead-Fry, } \\
\text { Patricia } \\
\text { Schultz, Alyce }\end{array}$ & $\begin{array}{l}\text { Rural cancer } \\
\text { patients } \\
\text { residing in } \\
\text { Maine and } \\
\text { Vermont } \\
\text { diagnosed for at } \\
\text { least one month } \\
850 \text { surveys } \\
\text { mailed, } 344 \\
\text { returned (44\% } \\
\text { response rate) }\end{array}$ & $\begin{array}{l}\text { Systematic } \\
\text { replication using } \\
\text { same validation } \\
\text { packet and } \\
\text { procedures as Cella } \\
\text { (1993) with a } \\
\text { different population } \\
\text { (all rural). All } \\
\text { surveys were mailed. }\end{array}$ & $\begin{array}{l}\text { Consistent with Cella } \\
\text { (1997). Cronbach alpha } \\
\text { range form .68 to } .90 \text { for } \\
\text { subscales, } .93 \text { for total } \\
\text { scale; convergent validity } \\
\text { supported; similar factor } \\
\text { loadings with some } \\
\text { differences as to subscale } \\
\text { assignment; scale found to } \\
\text { be valid and reliable for } \\
\text { use with rural population }\end{array}$ \\
\hline $\begin{array}{l}\text { Overcash, } \\
\text { Janine } \\
\text { Extermann, } \\
\text { Martine } \\
\text { Parr, Joyce } \\
\text { Perry, Judy } \\
\text { Balducci, } \\
\text { Lodovico }\end{array}$ & $\begin{array}{l}112 \text { patients } \\
\text { over } 64 \text { years of } \\
\text { age. Compared } \\
\text { patients with } \\
\text { cancer to } \\
\text { community } \\
\text { dwelling elderly } \\
\text { patients without } \\
\text { cancer }\end{array}$ & $\begin{array}{l}\text { Surveys were mailed } \\
\text { to cancer patients } \\
\text { who returned them to } \\
\text { the clinic. } \\
\text { Community dwelling } \\
\text { groups were visited } \\
\text { and invited. } \\
\text { Validation packet } \\
\text { included the SF-36, } \\
\text { FACT-G, ECOG } \\
\text { performance status, } \\
\text { Charlson } \\
\text { Comorbidity Scale, } \\
\text { Cumulative Rating } \\
\text { Scale-Geriatric }\end{array}$ & $\begin{array}{l}\text { Internal consistency of } \\
\text { subscales using Chonbach } \\
\text { coefficient were similar to } \\
\text { Cella; evaluation of } \\
\text { concurrent validity with } \\
\text { SF-36 showed good } \\
\text { correlations; reliability } \\
\text { almost identical to Cella's } \\
\text { findings; FACT-G unable } \\
\text { to differentiate between } \\
\text { patients with } \\
\text { metastatic/nonmetastatic } \\
\text { cancer, number of } \\
\text { comorbidities but did } \\
\text { discriminate between } \\
\text { patients with and without } \\
\text { cancer. FACT-G found to } \\
\text { be valid, reliable with this } \\
\text { population and } \\
\text { manageable (quick, easy } \\
\text { to use). }\end{array}$ \\
\hline
\end{tabular}

Using a different validation packet, Overcash, Extermann, Parr, Perry, and Balducci studied the validity and reliability of the FACT-G with an elderly population. 
The MOS Short Form Health Survey (SF-36), an instrument known to be a valid and reliable measure of QOL in the elderly, was selected as a comparative measure. Details of this study are included in Table 3. This study found the FACT-G to be a reliable and valid tool when used to assess the older patient with cancer (Overcash et al., 2001).

Socioeconomic variables were not considered in the study analysis, but elderly persons are more likely to have a fixed income lower than other members of the general population, and functional limitations might influence their access to healthcare.

\section{Theoretical Support for Including Socioeconomic \\ Well-Being when Measuring Cancer Related QOL}

\section{Ecological Theory}

Chambers and Wedel (2004) claimed that social work is the only profession with a simultaneous focus on both the person and the environment. The ecological theory of Germain and Gitterman (first published in 1991, most recent edition 1996) has provided a structure for explaining and exploring this interface. Built upon the biological science that studies living creatures and their relationship with their environment, this theory should appeal to both medical and social work professionals. It is comprehensive and holistic and considers both the individual and the context which contributes to his/her being. Key concepts of this theory can illuminate our understanding of the importance of socioeconomic well-being to an individual's quality of life.

\section{Person:Environment Fit}

Person:environment fit is the central tenet of ecological theory. Germain and Gitterman (1996) view the relationship between the person and their environment as circular and inseparable with continuous feedback loops. A colon is placed between the 
words signifying that person:environment is viewed as a unified phenomenon. The fit between the two can be adequate, minimally adequate, or inadequate. If adequate or at least minimally adequate, the person's goals, needs, and desires are satisfied and a state of adaptedness occurs. If the fit is inadequate (as it often is for the poor and marginalized members of society), the person suffers and experiences stress. The person must attempt to make adjustments in the environment - processes known as adaptations-in order to

create a better fit. Such adaptations may be cognitive or behavioral and may occur within the person or in the environment. For example, a person residing in a community with poor air quality resulting in health issues can make a personal adaptation and physically relocate or can work for an adjustment in the environment via higher standards for air quality and related enforcement efforts.

\section{Life Stressors}

Life stressors, according to Germain and Gitterman (1996) are those transitions or events that threaten the person:environment fit. Terkelson (1980) divided such stressors into two orders: first order stressors are those expected life changes that require adjustments but are not overwhelming. Examples would be marriage, going off to college, or having a surgery resulting in a complete recovery. Second order stressors are more serious and require a significant change in identity and reorganization of the self. Examples of a second order stressor might be a terminal cancer diagnosis or a disease resulting in long term disability. While both the rich and the poor suffer life stressors, there is often a difference in the internal and environmental resources available to assist in such adjustments. Disparate healthcare resources in certain neighborhoods would be an example of inadequate environmental resources to deal with a stressor. 
The interpretation of a stressor determines whether it will be viewed as a threat or a challenge (Germain \& Gitterman, 1996). Persons who lack external or internal resources and have poor coping skills are more likely to have a negative response and feel threatened and/or overwhelmed by a stressor, including illness. Those who have been more successful and have access to resources outside themselves may approach a potential crisis with zest and view it as a challenge. The environment influences these attitudes, and, too often, the environment of those in poverty has not provided adequate resources for developing successful coping skills. Stress is the physical or emotional response of a person who feels unable to cope.

Mechanic, Meeker and Eells (1974) listed four ways the environment can and should support the individual; (1) the environment should provide institutions which provide the necessary needs such as family health centers which are easily accessible and provide care to all persons regardless of ability to pay; (2) the environment should provide education related to desired coping skills such as preventive health education; (3) the environment should reinforce appropriate behaviors such as preventive screening or involvement in healthcare decisions; and (4) the environment should provide social support. While great progress has been made in education, screening, and preventive services, there are still many Americans who do not have access to necessary healthcare resources, and their environment does not provide needed support related to restoring or maintaining health.

Gitterman and Germain (1996) also stress the importance of individual coping skills - specifically relatedness, self esteem, self directness, and competence. The life model of social work practice which is built on Ecological Theory assumes that social 
workers work in ways which support, restore, or increase these four attributes. These skills develop in an environment that encourages and rewards such behavior and are the outcomes of adaptive person:environment relationships. Too often the poor are not encouraged to be assertive or self-directed and their environment does not provide supportive resources such as adequate educational resources.

\section{Coercive and Exploitative Power}

Power is another component of this interplay between person and environment. Germain and Gitterman (1996) delineate two types of power: coercive and exploitative. Coercive power is that power that prevents people from involvement in the decisions that affect them while exploitative power is influence that is used to negatively affect the person:environment fit for those with less power. An example of coercive power would be a physician deciding that a poor person cannot possibly understand and decide between two treatment options; this physician might not offer an option to the person but instead chose the cheaper or simpler option for the patient. A blatant example of exploitative power exists in Louisville, Kentucky. In a certain part of that city known as Smoketown, toxic waste dumping has resulted in serious threats to the health of persons living in this lower socioeconomic community. Yet only recently has the city attended to the problem and only as a result of successful neighborhood mobilization and organization calling attention to the situation. Political and economic abuse of power results in a multitude of problems including poverty, poor education and resulting unemployment or underemployment and lack of health insurance, lack of affordable housing, homelessness, healthcare disparities, and ultimately impacts quality of life. 


\section{Habitat and Niche}

Habitat and niche, two terms "borrowed" from the biological sciences, are used by Germain and Gitterman (1996) to further explain their ecological theory. These two concepts are key to conceptualizing socioeconomic well-being. Habitat refers to a person's social and physical environment while niche is used as a metaphor for one's status or position in a community's social structure. Because society allows the abuse of economic and political power (as described in the previous paragraph), many persons are forced to live in physical environments not conducive to good health and satisfactory adaptedness and are classified into "niches" which don't support the realization of human needs and desires including quality healthcare. Habitat and niche are interrelated: one's social status (niche) is frequently related to his/her community (habitat) and vice versa, and both significantly impact on socioeconomic well-being as it relates to health.

Physical habitat can be rural, urban, or suburban and includes not only dwelling but the supportive transportation systems, school, religious structures, social agencies, hospitals, entertainment, and education centers. Supportive habitats contribute to the growth, health, and social functioning of an individual; inadequate habitats produce isolation, disorientation, and helplessness (Germain \& Gitterman, 1996) and, therefore, can negatively impact QOL

Niche can also shape health related QOL and, particularly, socioeconomic wellbeing. An individual's status in his/her social community often determines the availability of growth-supporting, health-promoting opportunities and services. While in the United States, niche is assumed to be shaped by equal opportunity, in reality, many people are in niches that do not support their needs, rights and aspirations due to personal 
characteristics which are devalued by society including those factors placing them in a lower SES (poor or lack of education, limited income/earning ability, disability/illness, professional affiliation).

Germain and Gitterman (1996) move beyond theory to construct a framework for life-modeled social work practice. A key consideration of this model is the pervasive significance of social and physical environments and culture. To ignore the influence of habitat and niche on individual functioning and health related QOL would be inconceivable according to their holistic theory. If measurement of QOL is to include the whole person response to cancer diagnosis and treatment, socioeconomic well-being (the impact of habitat and niche on the person's subjective evaluation of well-being) must be a dimension of concern.

\section{Social Class Theory}

Exploring and understanding social class theory and its contribution to the measurement and interpretation of socioeconomic status provides an important foundation for development of a measure of socioeconomic well-being.

Three sociological traditions have impacted the measurement and understanding of socioeconomic position in regard to health--Marxian, Weberian, and Functionalist (Lynch \& Kaplan, 2000). Lynch and Kaplan summarize and simplify the perspectives of these three theories as follows:

(1) Marxian tradition views society as stratified into classes as a result of the nature of exploitative production relations.

(2) Weberian tradition views stratification as a result of class, status, and political power leading to the unequal distribution of economic resources and skills. 
(3) The Functionalist tradition sees stratification as a natural and necessary feature of complex modern societies (Lynch \& Kaplan, 2000).

\section{Marxism and Social Class}

Any discussion of social class theory would be remiss without acknowledging the theoretical contributions of Karl Marx. Marx focused on social class as the economic dimension of stratification determined predominantly by the material aspects of wealth; in many ways, he seemed to be more an economist than a sociologist (Ritzer, 2000) and has been classified as an economic determinist (Warner, 1960). According to Marx, classes are defined by the relationship between those who own property in the means of productions and those who do not. This results in a dichotomous model of class relations composed of an exploiting ownership class and a subordinate nonpropertied class who are of necessity in conflict (Lynch \& Kaplan, 2000). Marx argued that the problems of modern life can be traced to the structures of capitalism and that solutions would only result from the overthrow of these structures by large numbers of people (Marx \& Engels, 1845/1956). This connection of theoretical insight to potential social action was a unique approach (Burghardt, 1986) which made Marx's work subject to criticism because the revolution he prophesized has not materialized. Criticism of capitalism and commitment to socialism dominated his work. Marx and his followers viewed the class system and ideology as capitalist phenomenon and believed that changing the economic base would lead to a classless society (Warner et al, 1960). Power, according to Marx, was a product of economics; those who control the means of production and the distribution of products process the power and prestige in a society (Warner et al, 1960). 


\section{Weberian Thought}

Max Weber offered a more rounded, less radical approach to understanding the social world making his theory more acceptable to many (Ritzer, 2000). While Marx concentrated on economic determinants of social class, Weber was interested in a wide range of social phenomenon. Weber was neither a critic or a champion of capitalism; he viewed capitalism as creating groups such as the working class, who were at a disadvantage because they had fewer goods, abilities, and skills to exchange for income (Lynch \& Kaplan, 2000). An individual's fate (life chances) could be explained by the distributive forces of the market which were subject to social, political, and economic power. Classes, according to Weber, were groups of people sharing a common set of beliefs, values, and circumstances which he referred to as "life chances" (Weber, 1958). Weber described these groups as being composed of communities of people whose situation could be understood by their "social honor" and "style of life" (Lynch \& Kaplan, 2000). Weber claimed that the distribution of power was not solely determined by material wealth but also by social privilege.

In a more modern context, Oscar Lewis agreed with Marx that capitalism was the culprit at the root of inequality. As discussed in Chapter I, he theorized, based upon his study of poverty and its associated traits, that a culture (or subculture) of poverty develops as a way of life passed down along family lines (Lewis, 1969). This aspect of his theory agrees with Weber's ideas about "life chances." While he views this culture as evolving in a variety of historical contexts, he characterizes certain conditions which enable its development and ongoing existence: 
(1) an economy based on cash, wage labor, and production geared towards profit

(2) a persistent high rate of unemployment and underemployment for skilled labor

(3) low wages

(4) failure to provide social, political, and economic organization for the lowincome population

(5) a dominant set of values that focus on accumulation of wealth and property, the possibility of upward mobility, and thrift and explains the low economic status as a result of personal inadequacy or inferiority. (Lewis, pp. 187-188)

Lewis viewed this subculture of poverty as part of the larger culture of capitalism, an economic system which channels wealth to a few creating sharp class distinctions.

\section{The Functionalist Tradition}

Other theorists, those of the Functionalist persuasion, argue that class is a multifaceted phenomenon necessary in complex modern societies. Talcot Parsons is credited with being the progenitor of this school of thought (Wohlfarth, 1997). Parsons concentrated on the structures of society which he viewed as being mutually supportive, performing a variety of positive functions for each other, and tending towards a dynamic equilibrium (Ritzer, 2000).

W. Lloyd Warner, Marchia Meeker, and Kenneth Eells (1960) studied the significance of social class in America and claimed that social class permeates every aspect of life and is an important determinant of personality development and problem solving. According to these authors, Functionalist theorists may view economic stratification as primary in a complex social system, but it is viewed as only one part of a larger system of rank. After acknowledging that social structures of more complex 
societies must have rank orders to assure performance of the functions necessary for group survival, Warner, Meeker, and Eells (1960) embark on an effort to explain further and evaluate the reality of social class in America. Disputing Marxian theory, these authors claim class order is necessitated by the complexity of society and that the presence of this order does not necessarily mean class conflict. Rank orders result from the need to maintain unity and cohesion within society and make common enterprises successful (Warner et al, 1960).

Men and women in the various strata have families who become identified with their social position and the resulting social matrix provides the structure of our class system (Warner et al, 1960). The class system allows for social mobility through the use of money, education, occupation, talent, skill, philanthropy, sex, and marriage (Warner et al, 1960). Education is the most frequent of these modalities to influence change in social class. Educational advancement may or may not result in notable economic class movement, but it can influence prestige and social acceptance while not necessarily affecting one's income level.

While economic factors and social mobility are significant and important, they are not the sole determinants of social class. An individual or family must also be accepted as equal of others who belong to that class. Economic factors, although significant, are not sufficient to predict the social class of a family or individual (Warner et al, 1960). "Money must be translated into socially approved behavior and possessions and they in turn must be translated into intimate participation with, and acceptance by, members of the superior class" (Warner et al,1960, p. 21). Class often determines social interactions; for instance, the majority of marriages are between members of the same class. 
While education can support social class mobility, Warner also demonstrates how it can limit mobility. For instance, children born into poorer, uneducated families may be stigmatized and ranked low by the teacher who is a product of middle-class values and, therefore, the child does not have a fair chance to succeed. The influence of other children in the same neighborhood related to education and school can also work to keep individuals from advancing educationally. Class values and beliefs transmitted to children in the early years can become ingrained in an individual's personality and become permanent for thoughts, feelings, and actions. Social class, according to Warner et al (1960), influences every aspect of American thought and action, and our status system should be a major consideration in our efforts to study and understand.

\section{Social Class as Social Relationship}

Kreiger, Williams, and Moss (1997) conceptualize class as a social relationship created by societies rather than an a priori property of individual human beings:

We use "social class" to refer to social groups arising from interdependent economic relationships among people. These relationships are determined by a society's forms of property, ownership, and labor, and their connections through production, distribution, and consumption of goods, services, and information. Stated simply, classes - like the working class, business owner, and their managerial class - exist in relationship to and co-define each other. (pp. 344-345)

Conceptualizing class as a social relationship helps to explain the generation, distribution, and persistence of myriad specific pathways leading to social disparities in income, wealth, and health (Krieger et al., 1997). Efforts to advance the economic and social well-being of one class are often linked to the deprivation of others. For instance, efforts of insurance companies to increase premiums in order to improve or maintain profits result in increased inability of 
the lower classes to afford health insurance. Class-related conflicts over taxes, government regulations, and government expenditures also effect the economic and social well-being of persons (usually of the lower socioeconomic strata) who are dependent on publicly financed programs (Krieger et al., 1997).

James Coleman conceptualizes three aspects or dimensions of social class: physical capital, human capital, and social capital (Coleman, 1990). Physical capital is the tangible, observable component of social class, human capital consists of the skills and capabilities of persons, and social capital exists in the relationships among persons that facilitate action. His idea of social capital parallels Krieger, Williams and Moss' conceptualization of social class as a social relationship. According to Coleman, SES is not only a measure of access to resources but is a function of material endowments, skills, abilities and knowledge, and the status, power, truthworthiness, and abilities of the members of one's social network (Oakes \& Rossi, 2003).

Because SES is a central feature of the social structure of all complex societies, it is often the key consideration when studying the relationship between social factors, disease and health (Warner et al, 1960), but, as we have seen through exploring various theories, concentrating on SES alone limits our understanding of the impact of social status on health and disease. According to Warner, "every aspect of American thought and action is powerfully influenced by social class; to think realistically and act effectively; we must know and understand our status system" (p. 32).

Connecting Social Class Theory to

Measurement of Socioeconomic Status 
Theoretical explanations of social class can be linked to variables considered to be relevant in measurement of socioeconomic status and well-being related to socioeconomic factors.

If a Marxian tradition directs measurement, concern would be solely with the dichotomy of relationship to the means of production and delineation to two groups: those with ownership of such means and those without. Measurement would be concerned with economic variables (income, assets) alone.

Viewing measurement from a Weberian tradition would lead to the evaluation of indicators of "life chances" including education, occupation, and income. Skills, knowledge and resources would be considerations because they provide key linkage between social stratification and health (Lynch \& Kaplan, 2000).

Moving to a Functionalist perspective would further expand the variables considered as important to determination of social class. In addition to occupation, occupational prestige would be viewed as a consideration. Contextual socioeconomic affects on healthcare and exposure to certain socioeconomic conditions (the impact of neighborhood) would be seen as relevant, not only in the present, but across the life span. Extraindividual factors, such as the impact of communities and institutions, would merit significance in evaluating socioeconomic status, social class, and health.

The Functionalist approach to understanding socioeconomic status, social class and health and the concept of social class as social relationship will be the foundation for development of the proposed scale of socioeconomic well-being and the related validation tools and variables to be assessed. Such a holistic approach which attempts to 
incorporate environmental as well as individual factors and the interplay between the two is congruent with the previously described ecological theory of Germain and Gitterman.

As stated by Lynch and Kaplan:

While traditional measures of education, occupation, and income are powerful predictors of health, they are limited. We must transform our thinking and analysis from static to dynamic approaches to more fully understand how socioeconomic factors influence health. This means conceptualizing, gathering and analyzing data within a lifecourse perspective. (p. 27)

\section{Defining Socioeconomic Well-Being}

Perhaps a partial reason for excluding socioeconomic factors from quality of life measurement is that there exists no consensus on a nominal definition or widely accepted socioeconomic status measurement tool (Oakes \& Rossi, 2003). The term "socioeconomic" was coined by American sociologist, Lester Ward, in 1883, but conceptualizing and measuring socioeconomic status has remained difficult and controversial according to Oakes and Rossi (2003).

Definitions of SES most often list demographic variables which operationalize one's social position and relationship to resources. Socioeconomic status has been defined as one's relative position in the social hierarchy which is operationalized as level of education, occupation, and/or income (Mackenbach \& Kunst, 1997). Oakes and Rossi (2003) further described socioeconomic status as a conceptually useful proxy for describing access to resources and constructing remedies - thoughts that are particularly relevant to health-related quality of life and the reality of healthcare disparities in our country. SES has been viewed as a "shorthand" expression for variables that characterize the stratification of persons, families, or neighborhoods related to their capacity to consume valued goods (Krieger et al., 1997). 
Demographic variables such as income, assets, poverty level, educational level, are measures often used to assess socioeconomic status. Table 4 summarizes the rationale for such measures and related measurement issues as described by Krieger et al. (1997) in their review of frequently used measures of social class.

\section{Table 4}

\section{Demographic Measures of Socioeconomic Position}

\begin{tabular}{|c|c|c|c|}
\hline \multirow[t]{2}{*}{ Measure } & \multirow{2}{*}{$\begin{array}{l}\text { Rationale for inclusion } \\
\text { as a measure }\end{array}$} & \multicolumn{2}{|c|}{ Measurement issues } \\
\hline & & Pros & Cons \\
\hline Income & $\begin{array}{l}\text { Income level has } \\
\text { important implications } \\
\text { for health } \\
\text { Even simple categorical } \\
\text { measure of annual } \\
\text { income are strongly } \\
\text { associated with myriad } \\
\text { health outcomes }\end{array}$ & $\begin{array}{l}\text { Income has been } \\
\text { proven to have a } \\
\text { strong association } \\
\text { with health status and } \\
\text { outcomes } \\
\text { Most are aware of } \\
\text { their annual or } \\
\text { monthly income }\end{array}$ & $\begin{array}{l}\text { Not a simple } \\
\text { variable-has } \\
\text { multiple } \\
\text { components (not } \\
\text { just salary) } \\
\text { Can fluctuate, be } \\
\text { volatile } \\
\text { Nonresponse to } \\
\text { questions about } \\
\text { income is often } \\
\text { high } \\
\text { May not reflect } \\
\text { purchasing power } \\
\text { or all income } \\
\text { available }\end{array}$ \\
\hline
\end{tabular}


Table 4 (continued)

\begin{tabular}{|c|c|c|c|}
\hline \multirow[t]{2}{*}{ Measure } & \multirow{2}{*}{$\begin{array}{l}\text { Rationale for inclusion } \\
\text { as a measure }\end{array}$} & \multicolumn{2}{|c|}{ Measurement issues } \\
\hline & & Pros & Cons \\
\hline Poverty & $\begin{array}{l}\text { Provides a means for } \\
\text { evaluating income in } \\
\text { relation to need and to } \\
\text { health }\end{array}$ & $\begin{array}{l}\text { U.S. poverty } \\
\text { thresholds are } \\
\text { readily available in } \\
\text { Census Bureau } \\
\text { publications }\end{array}$ & $\begin{array}{l}\text { Determining what } \\
\text { constitutes poverty } \\
\text { involves judgments } \\
\text { about social norms } \\
\text { Focusing solely on } \\
\text { above or below } \\
\text { poverty level } \\
\text { determination does } \\
\text { not reveal the full } \\
\text { range of } \\
\text { inequalities income } \\
\text { distribution and } \\
\text { wealth } \\
\text { Current criteria for } \\
\text { determining is } \\
\text { flawed and was } \\
\text { established in } 1964\end{array}$ \\
\hline Wealth/Assets & $\begin{array}{l}\text { As wealth and assets } \\
\text { provide sources of } \\
\text { economic security and } \\
\text { power, they are } \\
\text { important additional } \\
\text { considerations } \\
\text { Houses with } \\
\text { comparable incomes } \\
\text { can differ vastly in their } \\
\text { net worth }\end{array}$ & $\begin{array}{l}\text { Can be evaluated } \\
\text { related to ownership } \\
\text { of car or home - } \\
\text { questions not subject } \\
\text { to low } \\
\text { nonresponsive bias }\end{array}$ & $\begin{array}{l}\text { Difficult to capture } \\
\text { entirety of assets } \\
\text { accrued through } \\
\text { inheritance } \\
\text { investment, and } \\
\text { savings }\end{array}$ \\
\hline Education & $\begin{array}{l}\text { Is indicative of not only } \\
\text { income but also prestige } \\
\text { Educational level has } \\
\text { been shown to be an } \\
\text { important predictor of } \\
\text { mortality and morbidity } \\
\text { in the United States }\end{array}$ & $\begin{array}{l}\text { Ease of } \\
\text { measurement } \\
\text { Applicability to } \\
\text { persons not in the } \\
\text { active labor force } \\
\text { Is usually stable } \\
\text { over life span } \\
\text { regardless of } \\
\text { changes in health } \\
\text { status } \\
\text { Associated with } \\
\text { numerous health } \\
\text { outcomes }\end{array}$ & $\begin{array}{l}\text { May be less } \\
\text { sensitive measure } \\
\text { than income or } \\
\text { wealth because the } \\
\text { span of educational } \\
\text { levels is far less } \\
\text { than span of income } \\
\text { and wealth } \\
\text { Education does not } \\
\text { have a universal } \\
\text { meaning and the } \\
\text { value related to } \\
\text { educational } \\
\text { obtainment changes } \\
\text { over time }\end{array}$ \\
\hline
\end{tabular}


These measures of social status are based on achieved statuses in that they are gained by the individual via access to opportunity and self-motivation, but the influence of ascribed status as determined by factors inherent to the individual at birth (gender, race-ethnicity, and age) are also contributory factors (Alwin \& Wray, 2005). According to Alwin and Wray (2005), gender inequalities may shape one's life course in ways that have health consequences, and racial and ethnic health differences may result from patterns of discrimination.

Recent studies have focused on the interplay between status and health over the life-span. While there is general agreement that education and income are predictors of poor health outcomes (Lantz et al., 2001), the impact of each may vary over the life course with education playing a greater role relative to income in the onset of functional limitations while income has stronger influence on the progression or course of such limitations.

House, Lantz, and Herd (2005), reporting on the Americans' Changing Lives Study, concluded that:

Socioeconomic disparities in health are neither constant nor continually increasing over the adult life course; rather they are small in early adulthood, growing increasingly large through middle and early old age, and then diminishing in later old. In other terms, compression of morbidity and functional limitations into the last years of life is much greater at higher socioeconomic levels. (p. 24)

While the measures described in Table 4 capture components of socioeconomic status, they are inadequate for measuring social class based upon social relationship or for capturing the social context related to one's socioeconomic status. While subjective social status has been found to be a strong predictor of ill-health, education, occupation, and income do not fully explain the relationship (Singh-Manoux, 
Adler, \& Marmot, 2003). One's networks and environment, skills (which may exist unrelated to education level), abilities and knowledge, and material endowments including those not exclusively self-earned (i.e., family resources, inheritance) are also considerations. Social prestige may be more relevant to one's socioeconomic status than actual income or educational attainment.

\section{From Socioeconomic Status to Socioeconomic Well-being}

Building on Coleman's work (Coleman, 1990), Oakes and Rossi (2003) define socioeconomic status as differential access to desired resources according to three domains: material capital; human capital; and social capital. These three domains are further described as follows:

(1) Material capital - observable, tangible, owned materials including homes, cars, appliances, income stocks, earnings, savings, investments and known expected wealth such as inheritance. Material capital consists of the material endowments under one's control.

(2) Human capital - this refers to the fixed endowments of an individual such as athletic ability, appearance, innate cognitive ability or talents, instinctual motivation or drive as well as acquired attributes such as education, skills, abilities, and knowledge. Human capital can be used to acquire socially valued goods.

(3) Social capital—resources that are a function of the social system are included in this category. Social capital can be viewed as an individual, family, or household-level trait. Obligations to and from others, information channels, norms, and reputation effects are forms of social capital. Social capital can 
impact educational achievement, social mobility, employment opportunities, and decreased welfare dependency, and it provides a means for the generation and maintenance of behavioral norms.

This framework for understanding the various forms of capital influencing SES will be used to explain and measure the factors that influence one's socioeconomic well-being.

Subjective social status, one's beliefs about his location in a status order, is an important adjunct when attempting to understand the relationship between socioeconomic status and health (Singh-Manoux, Adler, \& Marmot, 2003). This subjective social status as envisioned by Singh-Manoux et al. (2003) incorporates one's current social circumstances, assessment of the past and evaluation of future prospects. Subjective social status has a high degree of congruence with objective measures of socioeconomic position, and one's subjective assessment of social status is a powerful predictor of health status (Singh-Manoux et al., 2003).

QOL measures are used to evaluate a specific time frame. In the case of the FACT-G, respondents are asked to reflect on the past seven days and answer items based upon that period of time. This promotes sensitivity or the ability of the measure to reflect change when administered longitudinally at specific intervals (i.e., prior to treatment, during active treatment, subsequent to treatment). Therefore, items assessing the past and future projections of one's socioeconomic well-being are not appropriate for inclusion in QOL measures, but such factors definitely impact one's subjective evaluation of their "here and now" socioeconomic status.

Well-being is defined as the state of being healthy, happy or prosperous (American heritage dictionary of the English language, 2000). Subjective well-being can 
be depicted as a positive evaluation of one's life associated with good feelings such as life satisfaction, happiness, and self-esteem (Pinquart \& Sorensen, 2000). According to Pinquart and Sorenson, socioeconomic status contributes to subjective well-being in the following ways: subjective well-being derives from accomplishments of one's life; socioeconomic status may contribute to subjective well-being by improving quality of life; economic strain when material resources are low contributes to low subjective wellbeing; and socioeconomic status influences coping processes and can prevent certain stressors. Such correlations result in the hypothesis that higher socioeconomic status is associated with higher subjective well-being. Since quality of life measures are subjective measures of well-being, one would also assume that there is a positive correlation between socioeconomic well-being and quality of life scores.

\section{Definition of the Construct}

Considering these definitions and theoretical explanations from the literature, it is apparent that socioeconomic well-being is a complex construct and may not be unidimensional. A composite definition of health-related socioeconomic well-being might be: one's subjective evaluation of and satisfaction with his/her socioeconomic position in society based upon access to resources including material, human and social capital and the impact of such access on health and illness.

In order to effectively measure the above construct, clear definition of the three types of capital, each composing a domain in itself, is necessary. These domains were described earlier (see page 71). The precise definitions to be used in developing the item pool will be as follows: 
(1) Material capital-observable, tangible, owned materials that are under one's control and impact the ability to afford and access healthcare services. Included as material capital would be not only income or earnings but also owned materials (homes, cars), savings, investments and expected wealth such as inheritance.

(2) Human capital - innate and acquired attributes of an individual (i.e., education, skills, motivation, experience) which influence the ability to acquire material goods, purchase and access healthcare services. Included here would be cognitive functioning, instinctual motivation or drive, stamina, as well as acquired abilities, skills, and knowledge. Such human capital is used to acquire valued goods (Oakes \& Rossi, 2003).

(3) Social capital-individual, family, and neighborhood resources that are available based upon one's position in the social system and the related influence, power, prestige and opportunity. Social capital results from relationships with others and includes obligations to and from others, information channels, norms, and reputational effects (Oakes \& Rossi, 2003).

Just as several factors have been historically used to measure SES (i.e., income, education, career), socioeconomic wellbeing can be viewed as multidimensional and based upon the composite of material, human and social capital controlled by the individual.

Table 5 illustrates how the theories and definitions explored in this section are applied in developing a conceptual framework for defining socioeconomic well-being as a dimension of QOL. Figure 1 depicts the conceptual framework for the construct. 
Table 5

Theories and Definitions Contributing to Conceptual Framework

\section{for Construct of Health-Related Socioeconomic Well-being}

\begin{tabular}{|c|c|c|}
\hline $\begin{array}{l}\text { Theory/Definition } \\
\text { Theorist or Source }\end{array}$ & Relevant Concepts & $\begin{array}{l}\text { Related Items for Item } \\
\text { Pool }\end{array}$ \\
\hline $\begin{array}{l}\text { Ecological Theory } \\
\text { Germain \& Gitterman, } \\
1996\end{array}$ & $\begin{array}{l}\text { Focus on both person and } \\
\text { environment and the interface } \\
\text { between the two as explanatory } \\
\text { Concepts of habitat and niche, } \\
\text { coercive and exploitative } \\
\text { power }\end{array}$ & $\begin{array}{l}\text { Items related to } \\
\text { neighborhood and } \\
\text { environmental impact on } \\
\text { health, ability to assess and } \\
\text { receive healthcare }\end{array}$ \\
\hline $\begin{array}{l}\text { Functionalist Tradition } \\
\text { Warner, Meeker\& } \\
\text { Eells, } 1960\end{array}$ & $\begin{array}{l}\text { Multi-faceted character of } \\
\text { social class (not solely } \\
\text { economic) } \\
\text { Stratification as serving a } \\
\text { variety of functions for society } \\
\text { Social class viewed as } \\
\text { permeating all aspects of } \\
\text { thought and action } \\
\text { Consideration of contextual } \\
\text { socioeconomic affects }\end{array}$ & $\begin{array}{l}\text { Items assessing impact of } \\
\text { socioeconomic status and } \\
\text { the related respect and } \\
\text { privilege on health } \\
\text { assessment and care }\end{array}$ \\
\hline $\begin{array}{l}\text { Social Class Theory } \\
\text { Coleman, } 1990 \\
\text { Oakes \& Rossi, } 2003\end{array}$ & $\begin{array}{l}\text { Theory that three domains } \\
\text { compose social class: physical } \\
\text { capital, human capital, and } \\
\text { social capital }\end{array}$ & $\begin{array}{l}\text { Items regarding not only } \\
\text { economic concerns but } \\
\text { also the impact of } \\
\text { education and skills, } \\
\text { prestige, influence and } \\
\text { neighborhood on health } \\
\text { and illness }\end{array}$ \\
\hline $\begin{array}{l}\text { Class as a Social } \\
\text { Relationship } \\
\text { Krieger, Williams \& } \\
\text { Moss, } 1997\end{array}$ & $\begin{array}{l}\text { Classes exist in relationship to } \\
\text { each other, define each other }\end{array}$ & $\begin{array}{l}\text { Items related to reactions } \\
\text { of others (respect, self- } \\
\text { efficacy neighborhood), } \\
\text { ability to get needs met, } \\
\text { occupational prestige and } \\
\text { the impact of such factors } \\
\text { on healthcare }\end{array}$ \\
\hline $\begin{array}{l}\text { Subjective Social } \\
\text { Status } \\
\text { Singh-Manoux, Adler } \\
\& \text { Marmot, 2003 }\end{array}$ & $\begin{array}{l}\text { One's beliefs about his/her } \\
\text { location in a status order }\end{array}$ & $\begin{array}{l}\text { Items addressing beliefs } \\
\text { and satisfaction related to } \\
\text { social status and healthcare } \\
\text { concerns }\end{array}$ \\
\hline
\end{tabular}


Table 5 (continued)

\begin{tabular}{|l|l|l|}
\hline $\begin{array}{l}\text { Theory/Definition } \\
\text { Theorist or Source }\end{array}$ & Relevant Concepts & $\begin{array}{l}\text { Related Items for Item } \\
\text { Pool }\end{array}$ \\
\hline $\begin{array}{l}\text { Contextual Model for } \\
\text { HRQOL }\end{array}$ & $\begin{array}{l}\text { Socioecological dimension } \\
\text { including socioeconomic status } \\
\text { and life burden included in } \\
\text { assessment of QOL }\end{array}$ & $\begin{array}{l}\text { Items addressing } \\
\text { relationship with } \\
\text { healthcare systems, ability } \\
\text { to get medical care, } \\
\text { neighborhood, ability to } \\
\text { get needs met related to } \\
\text { health and illness }\end{array}$ \\
\hline
\end{tabular}




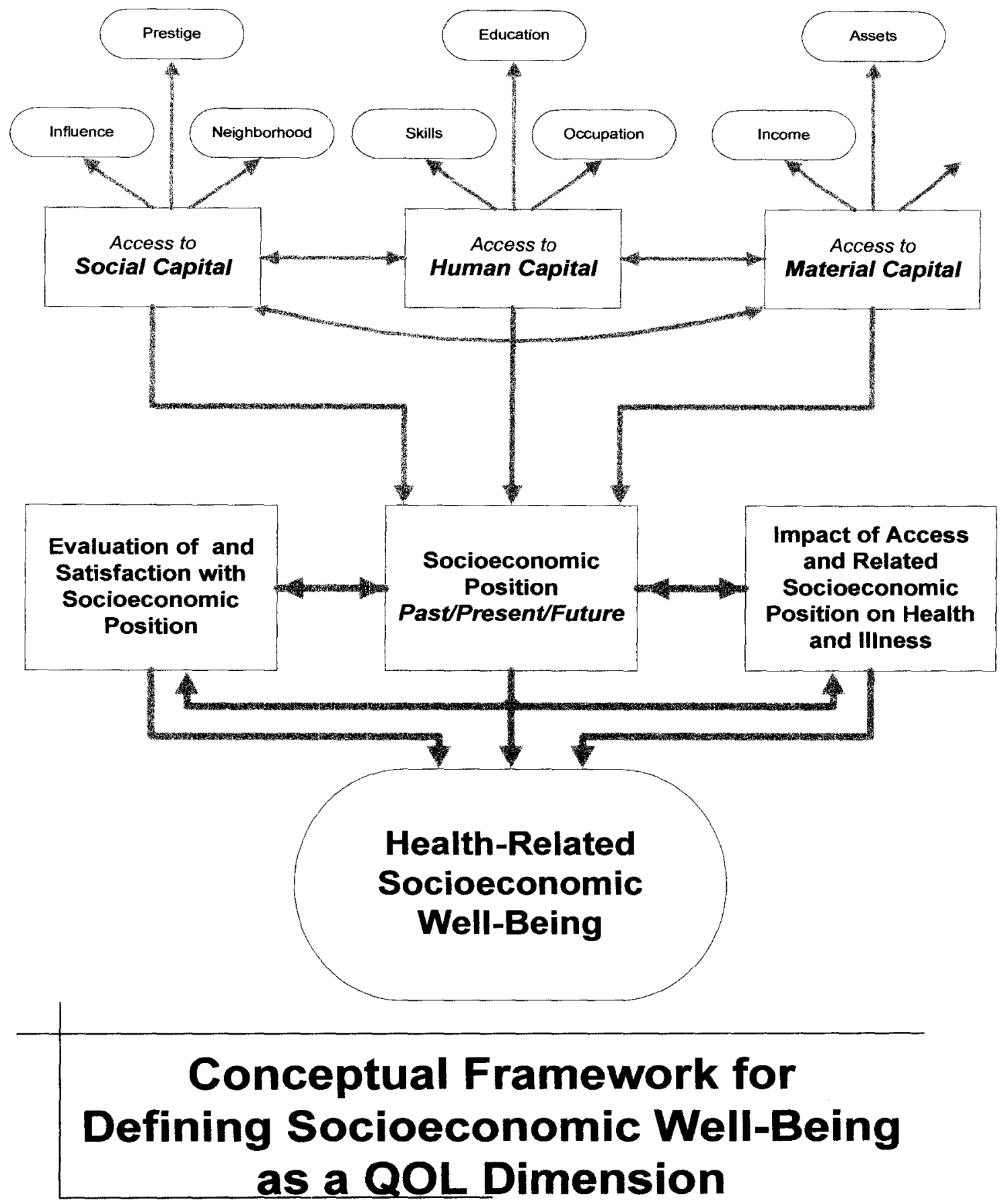

Figure 1. Conceptual framework for defining socioeconomic well-being as a QOL dimension. 


\section{Existing Measures of Socioeconomic Well-Being in}

\section{Health Related Quality of Life Instruments}

Many health related quality of life measures do not address socioeconomic wellbeing as a relevant dimension. This list includes the FACIT tools, the SF-36 Spitzer's quality of Life Index, and the Cancer Rehabilitation Evaluation System (CARES) (McMillan, 1996). Others address economic considerations as a financial well-being dimension (McMillan's Hospice Quality of Life Index) or focus on the financial impact of the diagnosis (EORTC QOL-30) which are both different concepts than socioeconomic well-being as defined earlier.

The Quality of Life Index (QLI) developed by Ferrans and Powers includes a social and economic subscale (Ferrans \& Powers, 1985). This instrument asks subjects to rate a list of life areas in terms of their satisfaction with and the importance of that area in their life. Areas addressed in the Social and Economic subscale of the QLI are: friends, emotional support from people other than your family, neighborhood, home, job/not having a job, education, and financial needs. The FACT-G situates friends and the support received from them in the social/family well-being dimension. The QLI poses questions rather than offering statements for the subject's reaction, and the responses (very dissatisfied to very satisfied) also differ from the FACIT tools.

Singh-Manoux, Adler, and Marmot (2003) developed a simple measure of subjective social status asking respondents to rate their social status in society by placing a large $\mathrm{X}$ on the rung of a 10 rung ladder which best represented their position in society. Their analysis suggested a high degree of congruence between objective measures of socioeconomic position (such as employment grade, education, and income) and 
subjective status therefore suggesting that their measure had good validity (SinghManoux et al., 2003).

Ashing-Giwa (2005) proposed a contextual model of health-related quality of life which includes cultural and socioecological dimensions. Included in the proposed socioecological dimension are socioeconomic status and life burden (e.g., neighborhood characteristics and resources; discrimination). The dimensions of this model include socioecological context, cultural context, demographic context, healthcare system context, cancer related medical factors, general health and comorbidity, health practices and utilization, and psychological well-being. Ashing-Giwa's model is in its formulative stages and an actual instrument is still being evaluated.

While selecting a different instrument inclusive of socioeconomic concerns would be an alternative to using the FACT-G, the FACT-G will continue to be one instrument of choice because of its predominance in past studies (therefore providing normative data to be used in other studies), its established validity and reliability (Cella \& Nowinski, 2002; Cella et al., 1993; Webster et al., 2003; Webster, Odom, Peterman, Lent, \& Cella, 1999) and its applicability to a variety of cancer diagnoses. Other reasons for selection of this instrument when measuring cancer related QOL include widespread use in oncology, availability in multiple languages, ease of administration, the short amount of time needed for completion, and ability to assess response to clinical changes (Overcash et al., 2001; Winstead-Fry \& Schultz, 1997). The addition of a socioeconomic well-being domain to this existing tool would enable it to better address the whole person response and respond to the recommendation that socioeconomic considerations become a relevant variable when studying populations with cancer (Guidry et al., 2005). Such a scale could 
also serve as a model for evaluating the construct of socioeconomic well-being which could be used in developing scales for existing and/or new measures of QOL.

\section{Conclusion}

This chapter has explored the development, validity, and reliability of the FACT$\mathrm{G}$, the established instrument for which a scale measuring socioeconomic well-being is proposed. The Ecological Theory of Germain and Gitterman as well as theories related to socioeconomic status were examined to develop a contextual framework for measuring health-related socioeconomic well-being. A definition for this construct was developed.

Lastly, special considerations in the initial process of scale development were addressed. With this foundation in place, Chapter III delineates the methodology for the study. 


\section{CHAPTER III}

\section{METHODOLOGY}

This chapter details the methodology used to conduct the research and analysis for this study. The study used classical measurement theory to develop, evaluate, and validate a scale for measuring self-reported socioeconomic well-being in persons who have had a diagnosis of cancer.

Classical measurement theory was developed during the 1920 s, is often used in initially developing and validating instruments (Faul \& Van Zyl, 2004), and is the most frequently used theory for such purposes in social work (Spector, 1992). Classical measurement theory distinguishes between true score and observed score with the true score being the theoretical value each subject has on the construct of interest. The observed score is that score actually derived from the measurement process. Each observed score consists of two components: the true score and random error. Errors are assumed to be from a population with a mean of zero; therefore, with multiple observations, errors will tend to average zero. In classical theory, reliability is based on the amount of error in observed scores. If the amount of error is quite small, the scale can be considered to be a highly reliable measurement (Nurious \& Hudson, 1993).

Classical measurement theory considers each individual item to be an observation of the intended trait or construct (Spector, 1992), often called the latent variable because it is not directly observable and is variable as opposed to constant (DeVillis, 2003). This 
latent variable (in this study, socioeconomic well-being) is considered a cause of the item score. A causal relationship between the latent variable and a measure implies certain empirical relationships. In evaluating items assumed to reflect the same latent variable, the relationships (correlations) of these items to each other allows inferences as to how significantly each item correlates with that latent variable (DeVellis, 2003).

Another tenet of classical measurement theory is the domain sampling model which assumes that a particular measure can be composed of responses to a random sample of items from a hypothetical domain of items (Faul \& Van Zyl, 2004). The true score would be the score the subject would obtain if all items in the domain were used. The reliability of a sample of items depends on the extent of the correlation between the score on those items and the true scores (Nunnelly \& Bernstein, 1994).

\section{Purpose of the Study}

The general purpose of this study was to explore the influence of socioeconomic factors upon the self-perceived QOL of persons diagnosed with cancer by (1) developing a theoretical, literature-based instrument to measure socioeconomic well-being, (2) conducting a psychometric evaluation of the proposed measure, and (3) investigating the explanatory power of this measure in predicting quality of life in persons with a diagnosis of cancer (incremental validity).

Specific aims were as follows:

1. To develop and evaluate an item pool for a Socioeconomic Well-being Scale based upon a thorough exploration of the literature, a resulting theory-based definition of the construct, and expert review.

2. To evaluate the psychometric performance of a proposed scale to measure the domain of socioeconomic well-being. 
3. To evaluate the value of adding such a subscale to the FACT-G.

\section{Research Questions}

The research questions driving this study are as follows:

Question 1: Is the proposed scale for evaluating health-related socioeconomic well-being supported by literature, theory, and expert review?

Question 2: Is the proposed scale for evaluating health-related socioeconomic well-being reliable and valid?

Question 3: Is the inclusion of a socio-economic well-being domain to the FACT-G a valuable addition with explanatory power when evaluating QOL in persons with a cancer diagnosis?

\section{Design}

This study utilized a cross-sectional contextual survey design. With this design, data are gathered on a sample or "cross-section" of respondents chosen to represent a particular target population: data are collected over a short period of time (Singleton \& Straits, 1999).

The design was contextual in that it studied individuals and relationships found within the same social context. Contextual designs sample a significant number of cases within a particular group or context with the goal of accurately describing selected characteristics of that context (Singleton \& Straits, 1999).

Study participants shared the social context of having had a cancer diagnosis and having received cancer care. They were recruited using the Tumor Registry of the University of Louisville Hospital and the James Graham Brown Cancer Center (JGBCC) to generate a list of recently diagnosed persons from which a random sample could be chosen. Use of this sampling frame enabled recruitment of an adequate sample for scale validation and reliability procedures. 


\section{Sampling}

\section{Sample Source}

A HIPAA waiver for recruitment purposes was secured from the University of Louisville Human Subjects Protection Program to allow the investigator to receive names and addresses of the most recently diagnosed and still surviving entries to the before mentioned Tumor Registry. Permission to use the Tumor Registry was secured from the University of Louisville Hospital Research Integrity Committee.

This sampling frame allowed for sampling of a wide variety of potential participants with varying demographic (age, race, income, education, etc.) and disease characteristics (site, stage, outcome of treatment, etc.). Having such a diverse, variable population is desired in validation studies as it permits reliability and validity evaluation of the new tool. Cronbach's coefficient alpha, used to evaluate reliability, is based on interitem correlations and its value can be affected by homogeneity of subject responses to scale items (Faul \& Van Zyl, 2004). If the population were homogeneous, reliability and validity would be artificially affected by small standard deviations and interitem correlations within the scale (Hudson \& Pike, 1995).

\section{Sampling Procedures}

One thousand two hundred surviving individuals were randomly selected using SPSS software (SPSS, 2005) from all persons $(\mathrm{n}=1700)$ listed on the Tumor Registry as being diagnosed with cancer between January 2004 and December 2005. Bryant and Yarnold (1995) state that the subject to variables (STV) ratio should be five to one if the results of one's analysis is to be considered reliable. For most validation studies it is desirable to have sample sizes greater than or equal to 10 participants per item in the original pool (Springer, Abell, \& Hudson, 2002). The proposed item pool for the validation study included 23 items. 
Therefore, it was hoped that a sample of at least 230 (or approximately $20 \%$ ) could be recruited so that both of the previously stated requirements for the number of participants would be met.

In an effort to increase the mailed survey response, an embossed pencil (given as a small incentive) and a business reply envelope were included in the survey packet and a reminder postcard was sent approximately three weeks after the first mailing. Dillman (2007) recommends enclosing a token incentive and sending a thank you/reminder postcard as means of increasing mailed survey response rates.

\section{Measures}

Copies of all measures included in the validation packet are included in Appendix A: Validation Packet. The first item included in this packet was the preamble consent which received approval by the University of Louisville, Human Subjects Protections Program prior to including it in the packet.

\section{Demographic Questionnaire}

Immediately following the preamble consent were a series of demographic questions to be answered by the participant. Since subjective social status has been demonstrated to correlate with objective measures of socioeconomic position (Singh-Manoux et al., 2003), the variables relating to socioeconomic status were used in assessing convergent construct validity of the scale (i.e., monthly income, years of education). Other demographic variables not shown in the literature to be correlated with socioeconomic status (i.e., number of children, number in household and years since cancer diagnosis) were used in assessing discriminant construct validity.

The demographics of the sample were compared to the demographics available on the total population of persons entered into the Tumor Registry for the same period of time who 
were still presumed to be alive. The performance of the sample on the FACT-G was compared to normative data for a cancer population and a previous psychometric study of the FACT-G.

\section{The FACT-G}

The FACT-G, including the four dimensions of Physical Well-Being, Social/Family Well-Being, Emotional Well-Being and Functional Well-Being, followed the preamble consent. The FACT-G and studies of its validation and reliability were detailed in Chapter II. It is considered to be a reliable and valid measure and is frequently used to measure QOL in oncology.

\section{Socioeconomic Well-Being Scale (SEWBS)}

The proposed item pool for the scale of Socioeconomic Well-being was included following the four dimensions of the FACT-G. It was formatted similar to the FACT-G to facilitate the participant's comfort and ease as they completed the included instruments, and to insure ease of comparison with the existing four subscales.

The proposed scale was intended for use as a subscale within the multidimensional FACT-G for the purpose of measuring the dimension of socioeconomic well-being. Therefore, the item stems were statements worded similar to other scales within the FACT-G and the response options were the same (not at all, a little bit, somewhat, quite a bit, and very much). Such items are referred to as agreement items or declarative statements that one can agree with or not (Spector, 1992).

The respondents were persons having been diagnosed with cancer at either the James Graham Brown Cancer Center (JGBCC) or the University of Louisville Hospital and therefore listed in the Tumor Registry. As great variability in reading level was expected, the scale items were written as simply as possible to include subjects of lower educational 
standing and literacy. The scale was administered along with the FACT-G which is often used to compare quality of life before and after an intervention or longitudinally to describe quality of life throughout the course of cancer. The scale required approximately 5-10 minutes to complete. The other components of the FACT-G require approximately 15 minutes bringing the total administration time to 20-25 minutes. The current unidimensional scales within the FACT-G have 7-12 items each and it was anticipated that the new subscales would be of similar length after adjustment of items based upon reliability and validity analysis.

Hudson (1994) recommends the list method for generating items. First an attribute of the defined construct is delineated, and then an item based on that attribute is generated. These two steps are repeated to build the item pool. A large pool of items inclusive of the domain is recommended when developing a new measure (Netemeyer, Bearden, \& Sharma, 2003).

Based upon the previous cited theories and definition of health related socioeconomic well-being, the construct of socioeconomic well-being was composed of three subscale domains measuring past, present and future influences and defined as follows:

\section{(A) Human capital - innate and acquired attributes of an individual} which influence the ability to acquire material goods, purchase and access healthcare services. Examples include: innate cognitive ability, education, skills and abilities, motivation and drive.

(B) Material capital-observable, tangible, owned materials that are under one's control and impact the ability to afford and access healthcare services. Examples include: earnings, disposable income, savings, assets, insurance coverage. 


\section{(C) Social capital—individual, family and neighborhood resources}

\section{that are available based upon one's position in the social system.}

Examples include: norms, reputation, influence, prestige, information

channels, obligations to and from others.

The initial item pool consisting of 33 items was sent to expert reviewers for

evaluation and refinement. These original items grouped according to subscales were as follows:

Material Capital Subscale:

I am able to pay my bills on time.

I cannot afford the food I need to stay healthy.

I don't have good credit.

I have to pay more for my medical care than I can afford.

Growing up, my family was able to buy what we needed.

I get medical check-ups even when I am not sick.

I need financial help to pay my bills.

I cannot afford the medicine I need.

I am sure I will be able to handle the costs of my illness.

I have what I need to get by in my home.

I worry about having enough money in the future.

Growing up, I went to the doctor for check-ups.

Growing up, I got healthcare when I needed it.

My health insurance is good enough.

I have money saved for emergencies.

I worry about how having cancer will affect my income. 
Social Capital Subscale:

I am happy with the place I live.

I grew up in a good neighborhood.

My neighborhood is a healthy place to live.

My doctors treat me with respect.

My family is able to get everything we really need.

I am treated the same as other patients when I go for medical care.

Most people look down on me.

My family is respected in our community.

Human Capital Subscale:

I am satisfied with my education.

I have valuable skills.

I hope to better my living situation.

I am proud of the work I do (including work at home).

Growing up, my family thought education was important.

I can find a way to get what I really need.

I am not happy with the kind of work I do.

I plan to get more education.

My family has the ability to earn a good living.

\section{Subjective Social Status Ladder Rating (SSSLR)}

This self-anchoring scale was used to measure subjective social status by SinghManoux, Adler, and Marmot (2003). Participants are asked to place an X on the rung of a 10-rung ladder based upon where they believe they stand in society (see Appendix A for the measurement tool). This simple subjective assessment of social status was found to be a 
powerful predictor of health status and showed strong and significant correlation with conventional measures of objective status (employment grade, education, and income) demonstrating good validity (Singh-Manoux et al., 2003a).

\section{Quality of Life Index-Cancer Version (QLI-CV) Quality of Life Index}

This self-administered instrument was first developed using extensive literature review and factor analysis on data from patients on hemodialysis (Ferrans, 1985; Ferrans \& Powers, 1985) and was subsequently modified for use in patients with cancer (Ferrans \& Ferrell, 1990). This instrument was chosen because it includes a socioeconomic domain which can be correlated with the proposed domain of socioeconomic well-being to evaluate convergent construct validity. See Chapter II for further description of this instrument.

\section{Data Collection Procedures}

A mailed survey approach was used in an effort to recruit an adequate sample of mixed cancer diagnoses, stages, gender, age, and socioeconomic status. A preamble consent approved by the University of Louisville Human Subjects Committee preceded study questions. Participants were encouraged to call the investigators if help in completing the instruments was needed, but all were able to self-administer the validation packet of measures. Interviews or self-administration are both acceptable and validated means of administering the FACT-G (Cella, 1998).

During the data collections period, participants' surveys remained linked by number to the Tumor Registry data base. This linkage allowed collection of data related to certain variables directly from the Cancer Registry including race, gender, date of diagnosis, age at diagnosis, cancer site, and stage of cancer. This improved accuracy and completion of such data fields and also decreased the respondent's burden. This linkage to the Cancer Registry 
was eliminated as soon as data collection was complete and all data was entered into a secure data base protecting confidentiality of the participants.

\section{Analysis Plan}

The analysis plan corresponding to the questions guiding the study is described below:

Question 1: Is the proposed scale for evaluating health-related socioeconomic well-being supported by literature, theory, and expert review?

The literature review and resulting theoretical basis for the scale were described in Chapter II. The initial pool of items was sent to 8 expert reviewers and their feedback was utilized to conduct cognitive testing and to revise the items before including them in the validation packet. It is recommended that at least five expert judges review a proposed instrument to detect bad or marginal items (Netemeyer, Bearden, \& Sharma, 2003). Experts rated each item in terms of its relevance to the construct, clarity of the item, and conciseness of the item (low, moderate, or high). Comments on each item and the overall scale were invited and were considered as the item pool was revised. A copy of the Expert Review Packet can be found in Appendix B: Expert Review Packet.

Question 2: Is the proposed scale for evaluating health-related socioeconomic well-being valid and reliable?

Psychometric analysis of the proposed socioeconomic well-being scale was based on classical measurement theory (Nunnally \& Bernstein, 1994) and followed a step-wise, iterative procedure (Faul \& Van Zyl, 2004; Nunnally \& Bernstein, 1994; Springer, Abell, \& Hudson, 2002)

Analysis began with investigating the reliability of the three domains within the proposed scale (material, human, and social capitol), via the alpha coefficient and standard 
error of measurement (SEM). Alpha reliabilities of .80 and greater and smaller SEM are indicative of a reliable measurement tool (Faul \& Van Zyl, 2004; Springer et al., 2002). Reliability concerns "the extent to which an experiment, test or any measuring procedure yields the same results on repeated trials" (Carmines \& Zeller, 1979,p. 11). In classical measurement theory, reliability is based on the amount of error in observed scores (Faul \& Van Zyl, 2004). Cronbach's alpha coefficient, the most widely used measure of internal consistency (Faul \& Van Zyl, 2004), will be used in this study. A measure of internal consistency requires only a single test administration and does not require either the splitting or repeating of items that other methods used to assess reliability demand (Carmines \& Zeller, 1979).

Because the value of the alpha coefficients can be affected by homogeneity of subject responses to scale items (Carmines \& Zeller, 1979; Hudson, 1991), the standard error of measurement (SEM) was also computed prior to final reliability conclusion. If the SEM is small, the measurement tool can be claimed as reliable in terms of measurement error characteristics; a sound measurement tool has both a large coefficient of reliability and a relatively small SEM compared to the overall range of possible scores (Faul \& Van Zyl, 2004).

Content and construct validity, at the item level, for each subscale was established with the following procedures: (1) examination of the inter-item correlation matrix (correlations need to be $>.30$ ); (2) examination of corrected item-total correlations (correlations must be $>.45$ ); and (3) determination of the mean of all corrected item-total correlations reflects the content validity (the mean should be >.50). At each step in the validation procedure, items were discarded if they failed to meet standards for inclusion in the subscale (Faul \& Van Zyl, 2004). 
Next, content and construct validity, at the subscale level, were established via principal factor analysis. Such confirmatory factor analysis allows the investigator to find clusters of related variables; each cluster or factor consists of those variables whose members correlate more highly with each other than variables outside the cluster (Faul \& Van Zyl, 2004). Confirmatory factor analysis is a tool for theory testing as a factor model is developed a priori and the fit of the data to that model is evaluated (Bryant \& Yarnold, 1995).

Items were eliminated based on the analysis described thus far. The remaining items composed the final subscales and overall measure of socioeconomic well-being.

Convergent and discriminant construct validity, at the subscale level of analysis, were then assessed by comparing the new subscales and total scale to three sets of variables (i.e., Class I, II, and III criterion variables). Class I variables were represented by demographic variables such as number of children, number in household, and years since cancer diagnosis having no apparent correlation with socioeconomic well-being. Class I variables provide an indication of discriminant construct validity; theoretically, there should be little relationship between the subscales, the total scale and the Class I variables.

Class II and III variables provide an indication of convergent construct validity. Class II variables such as age, education, insurance coverage (yes or no), home ownership (yes or no) and subscales of the FACT-G and QLI not thought to be strongly associated with the SEWBS should have a more significant correlation with the new subscales and the total scale than the Class I variables cited above. Class III variables should have an even higher correlation with the subscales and total scales. These variables include items such as monthly income, subjective rating of social status, scores on the Fact-G and the QLI and subscales of those measures hypothesized to have high correlations with the new measures. 
Question 3: Is the inclusion of a socioeconomic well-being domain to the FACT-G a valuable addition with explanatory power when evaluating QOL in persons with a cancer diagnosis?

The value of the addition of a Socioeconomic Well-Being domain to the FACT-G was assessed by measuring its incremental validity. A measure has incremental validity if it provides explanatory power over and above another measure. This is most often assessed using the multivariate procedure of hierarchical multiple regression (Bryant, 2000). This involves three steps:

(1) Proportion of variance explained in the criterion $Y$ (i.e., $R^{2}$ ) by measure $X$ is determined.

(2) The $\mathrm{R}^{2}$ obtained in step one is contrasted with the $\mathrm{R}^{2}$ obtained using an expanded regression model including both measures $\mathrm{X}$ and $\mathrm{Z}$.

(3) The statistical significance of the change in $\mathrm{R}^{2}$ between the baseline and expanded models is examined to test the incremental validity of measure $\mathrm{Z}$ (Bryant, 2000).

$\mathrm{R}^{2}$ indicates the amount of variance in the criterion shared by the weighted combination of predictors or the degree to which differences among individuals are predictable from a set of predictors when those predictors are combined as specified in the multiple regression model (Licht, 1995).

To evaluate the incremental validity of the SEWBS, two hierarchical regression models were evaluated. In the first regression analysis, socioeconomic indicators including monthly income and subjective evaluation of social status were entered into the model in the first block, and then SEWBS was entered into the model in the second block. This regression model was tested twice using two different measures of QOL, overall scores on the FACT-G 
and the QLI, as the criterion measures. In the second regression analysis, a model including the existing subscales of the FACT-G (physical, functional, social/family and emotional) was entered in the first block to predict overall QOL as measured by the QLI. In the second block, the score on the SEWBS was added to determine if SEWBS had predictive ability above and beyond the existing subscales and therefore had incremental validity.

SPSS software, version 15, was used to perform the statistical analysis.

\section{Conclusion}

This chapter has described the methodology used to conduct the study. The purpose, research questions and design, sampling source and procedures, measures included in the survey packet, and data collection procedures were explained. The analysis plan related to each of the research questions was described. 


\section{CHAPTER IV}

\section{RESULTS}

This chapter presents the results of the study beginning with a description of the sample followed by findings related to each of the three study questions.

\section{Sample}

A total of 289 persons responded to the survey packet in some manner making the response rate $24 \%$. Fifteen family members responded that the addressee was deceased. The lag time in data entry by the Tumor Registry staff and inadequate reporting of patient's deaths to the Registry explains this occurrence which can be, none the less, distressing to the family member. Three persons called saying they did not know they had had cancer, and two persons responded that they did not want to receive any further inquiries related to their diagnosis with one being extremely concerned that anyone was allowed to know of her diagnosis (this complaint was reported to the Internal Review Board). All these reports were conveyed to the Tumor Registry so that the records could be updated accordingly and persons desiring no further research inquiries could be eliminated from future studies. Another three persons returned packets which were missing all or the major part of one or more of the instruments and those cases were disqualified. A total of $266(22 \%)$ returned useable data.

Invasion of privacy is the primary risk associated with research recruitment through cancer registries and one reason why approximately $23 \%$ of all registries do not allow contact with patients for the purposes of research recruitment (Beskow, Sandler, \& 
Weinberger, 2006). Difficulty accessing the population sample required for scale validation makes use of the Tumor Registry almost essential for such a study.

The relatively low response rate can be attributed to multiple factors including the following: (1) the personal nature of the questions asked may have made potential respondents decide against participation; (2) this tumor registry includes many persons of lower socioeconomic status because the hospital and the James Graham Brown Cancer Center serve all persons regardless of ability to pay and provide a significant amount of indigent care. Many of these persons are less well-educated and may have been intimidated by a preamble consent and a 12-page survey; (3) because the registry includes many persons of lower socioeconomic status, the population is more transient and many of the survey packets may not have reached the addressee (items sent bulk mail are not usually returned when the address is incorrect).

\section{Demographics}

The mean age of the sample participants was $59.6(\mathrm{SD}=12.72)$ with a median age of 59 and a range of 77 years from 19-96. The national median age at diagnosis for all cancer sites from 2000-2003 was 67 years (Ries et al., 2006). The fact that this sample was younger is reflective of the younger age of the total population of persons on the Tumor Registry. Also, younger patients are more likely to survive several years past their diagnosis. Breast cancer patients composed $27 \%$ of the sample. Breast cancer has a relatively early onset and is often developed before age 60 with the median age of diagnosis being 61 (Jemal, Siegel, Ward, Murray, Xu, Smigal, \& Thun, 2006).

The mean monthly income of respondents was $\$ 3,534(\mathrm{SD}=\$ 3,151.74)$ with a median of $\$ 2,500$ and a rather large range of $0-\$ 20,000$. The average years of education was $14(\mathrm{SD}=3.16)$ with the median being 13 and the range spanning from eight to 30 years. The 
mean and median time since diagnosis was 2 years $(\mathrm{SD}=1.07)$ with a range from .50 to 8 years. The average rating of subjective social status was $5.8(\mathrm{SD}=1.86)$ with a median of 5.5 and a range from 1 to 10 . The results of these continuous variables are shown in Table 6 .

Table 6

Demographics of Sample: Age, Income, Education, and Subjective Rating of Social $\underline{\text { Status }}$

\begin{tabular}{|l|r|r|r|r|r|r|}
\hline & Number & Mean & \multicolumn{1}{c|}{ SD } & Median & Min. & \multicolumn{1}{c|}{ Max. } \\
\hline Age in Years & 265 & 59.6 & 12.72 & 59.0 & 19 & 96 \\
\hline Monthly Income & 200 & $\$ 3534$ & 3151.74 & $\$ 2500$ & 0 & 20,000 \\
\hline Years of Education & 255 & 14.0 & 3.16 & 13.0 & 8 & 30 \\
\hline Years Since Diagnosis & 265 & 2.0 & 1.07 & 2.0 & 0.50 & 8 \\
\hline $\begin{array}{l}\text { Subjective Rating of Social } \\
\text { Status (on scale of 0-10) }\end{array}$ & 248 & 5.8 & 1.86 & 5.5 & 1 & 10 \\
\hline
\end{tabular}

Other demographic variables are summarized in Table 7. The sample was approximately two-thirds women, $85 \%$ Caucasian, with the vast majority covered by health insurance (88\%). Fifty-eight percent were married.

Nearly one-half of the sample earned over $\$ 30,000$ per year. Seventy percent rated their subjective socioeconomic status at five or above on a scale of one to ten. Seventy-nine percent owned a home and $86 \%$ owned a car. The fact that so many were of middle to higher socioeconomic status in terms of income and self-perceived socioeconomic status may be a reflection of the reading ability and interest required to complete a twelve-page written survey packet introduced by a preamble consent. Also, because those of lower 
socioeconomic status have a less stable housing situation, many of the mailed packets may never have reached potential participants.

Table 7

General Demographics: Gender, Race, Income, Marital Status, Education

\begin{tabular}{|c|c|c|}
\hline & Number & $\begin{array}{c}\text { Valid } \\
\text { Percentage }\end{array}$ \\
\hline$N=266$ & & \\
\hline Male & 96 & 35.7 \\
\hline Female & 170 & 64.3 \\
\hline$N=266$ & & \\
\hline Caucasian & 226 & 85.0 \\
\hline African-American & 36 & 13.5 \\
\hline Asian & 1 & 0.4 \\
\hline Other & 3 & 1.1 \\
\hline Marital Status & & \\
\hline Single & 74 & 28.0 \\
\hline Married & 152 & 58.0 \\
\hline Widowed & 35 & 12.9 \\
\hline Other & 3 & 1.1 \\
\hline Years of Education & & \\
\hline Less than high school completion & 26 & 10.2 \\
\hline High school graduate & 88 & 34.5 \\
\hline Some college/college graduate & 90 & 35.4 \\
\hline Post graduate work/degree & 39 & 15.1 \\
\hline 20 years of education and Above & 12 & 4.8 \\
\hline \multicolumn{3}{|l|}{ Insurance Status } \\
\hline Medicare & 102 & 40.0 \\
\hline Medicaid & 23 & 9.0 \\
\hline Private Insurance & 147 & 57.6 \\
\hline No Insurance & 30 & 11.8 \\
\hline \multicolumn{3}{|l|}{ Car/Home Ownership } \\
\hline Own Car & 225 & 86.2 \\
\hline Own Home & 203 & 79.4 \\
\hline
\end{tabular}

Disease related demographics are summarized in Table 8. The prevalence of specific sites in this sample is reflective of the practice specialties at the JGBCC (where interdisciplinary teams focus on cancers of the breast, melanoma, and head and neck cancers) 
and the survival patterns of the specific diagnoses. Breast, melanoma, and prostate cancers are more likely to be diagnosed early and treated successfully and, therefore, have longer survival trajectories, whereas, cancers of the lung and pancreas are often diagnosed late and would have fewer survivors several years post diagnosis. The majority of respondents had been diagnosed during the early stages of their cancer and were no longer receiving treatment.

\section{Table 8}

Disease Related Demographics

\begin{tabular}{|r|r|r|}
\hline & Number & $\begin{array}{c}\text { Valid } \\
\text { Percentage }\end{array}$ \\
\hline Most Frequent Diagnoses (Data from Tumor Registry) & & \\
\hline Breast & 73 & 26.5 \\
\hline Melanoma & 28 & 10.4 \\
\hline Head and Neck Cancers & 28 & 10.4 \\
\hline Prostate & 20 & 7.4 \\
\hline Rectum/Anus & 17 & 6.4 \\
\hline Colon & 13 & 4.9 \\
\hline Endometrium & 13 & 4.9 \\
\hline Lung/Tracheal/Bronchus & 9 & 3.4 \\
\hline Non-Hodgkin's Lymphoma & 7 & 2.6 \\
\hline Early stage & 104 & 45.4 \\
\hline Locally advanced & 20 & 8.7 \\
\hline Spread to lymph nodes & 44 & 19.2 \\
\hline Spread to other part of body & 15 & 6.6 \\
\hline Don't know & 46 & 20.1 \\
\hline of Cancer (According to respondent) & & \\
\hline Current Treatment Status (According to respondent) & 184 & 71.3 \\
\hline Not getting treatment & 74 & 28.7 \\
\hline Getting treatment & 8.5 \\
\hline Radiation & 22 & 12.8 \\
\hline Chemotherapy & 32 & 11.6 \\
\hline Hormone treatment & 30 & 1.6 \\
\hline Other & 4 & \\
\hline & & \\
\hline
\end{tabular}




\section{Comparison of Sample to Total Population}

To ascertain if the sample was representative of the total population of patients (cancer survivors entered into the Tumor Registry between January 2003-December 2005), demographic variables were compared and are displayed in Table 9. A one sample $t$-test was conducted to compare the mean age of the sample to the mean age of the total population drawn from the Tumor Registry, finding that there was a significant difference in the ages of the two groups $(t=4.894, d f=265, p<.001)$. The sample population was older, included a slightly larger percentage of females and patients with breast cancer and had a smaller percentage of blacks than the Tumor Registry population from which it was drawn.

However, the sample population had a younger median age at diagnosis than the national median diagnosis age for cancer patients meaning that patients on the Tumor Registry are even younger than this sample when compared nationally. Because the University of Louisville Hospital and the JGBCC are the community facilities seeing patients without insurance, they may attract younger, uninsured patients who are not yet eligible for Medicare.

\section{Table 9}

\section{Comparison of Sample to Total Population}

\begin{tabular}{|c|c|c|}
\hline & Sample & Total Population \\
\hline \multicolumn{3}{|l|}{ Age } \\
\hline Mean & 59.61 & 55.79 \\
\hline Standard Deviation & 12.69 & 14.89 \\
\hline \multicolumn{3}{|l|}{ Gender } \\
\hline Male & $36.0 \%$ & $41.0 \%$ \\
\hline Female & $64.0 \%$ & $59.0 \%$ \\
\hline \multicolumn{3}{|l|}{ Race } \\
\hline White & $85.0 \%$ & $83.0 \%$ \\
\hline Black & $14.0 \%$ & $17.0 \%$ \\
\hline Asian & $0.4 \%$ & $0.5 \%$ \\
\hline
\end{tabular}


Table 9 (continued)

\begin{tabular}{|r|r|r|}
\hline & \multicolumn{1}{|c|}{ Sample } & Total Population \\
\hline Diagnosis & \multicolumn{2}{|c|}{} \\
\hline Breast & $26.5 \%$ & $20.3 \%$ \\
\hline Malignant Melanoma & $10.4 \%$ & $8.6 \%$ \\
\hline Head and Neck & $10.4 \%$ & $19.8 \%$ \\
\hline Prostate & $7.4 \%$ & $6.3 \%$ \\
\hline Rectum/Anus & $6.4 \%$ & $6.3 \%$ \\
\hline Endometrium & $4.9 \%$ & $6.0 \%$ \\
\hline Lung/Tracheal/Bronchus & $3.4 \%$ & $6.6 \%$ \\
\hline Colon & $4.9 \%$ & $4.1 \%$ \\
\hline
\end{tabular}

The chi square goodness of fit test was used to compare the gender and racial composition of the sample to the total population, and no statistically significant difference was found.

The fact that the sample was older may be reflective of the fact that older, retired persons have more time and interest in completing a survey. The fact that more females responded may explain the higher concentration of persons with breast cancer in the sample, or it could be that persons with breast cancer are more amenable to this type of research and more likely to respond.

\section{Demographic Summary}

Overall, the sample was largely female and Caucasian, middle- to upper-class, mostly educated beyond high school, covered by medical insurance, Medicare or Medicaid, and 2 years beyond their initial diagnosis. The median age of the sample at time of diagnosis (59 years) was lower than the national median age at cancer diagnosis ( 67 years). The majority was diagnosed in the early stages of their disease and were not currently receiving treatment. The most frequent cancer diagnoses were breast, head and neck, and melanoma. 


\section{Comparison of Sample Performance on the FACT-G}

\section{Relative to Normative Data}

Overall sample performance on the FACT-G compared to published reliability and validity data and normative data on the FACT-G is shown in Table 10. This sample demonstrated higher alphas on all subscales and the FACT-G total scores, but SEMs were higher in this sample with the exception of the Functional Well-being Subscale. Means and standard deviations were similar.

The sample for Cella's original Fact-G validation study (Cella et al., 1993) was a heterogeneous sample of 545 patients with cancer receiving inpatient or outpatient treatment. Cancer sites included breast (39\%), lung (15\%), colorectal (12\%), leukemia/lymphoma (8\%), head and neck (8\%), prostate (6\%), ovarian (2\%), and other $(10 \%)$. Other demographic data was not described in the article.

FACT-G normative data was based on a sample of 2,236 adult cancer patients ranging in age from 18 to 92 years. Fifty-seven per cent were female, $69 \%$ were white, $27 \%$ black, and 3\% Hispanic. Cancer sites included breast (29\%), colorectal (13\%), head and neck $(11 \%)$, lung $(17 \%)$, prostate $(8.5 \%)$.

The three samples were all somewhat similar in terms of heterogeneity of diagnoses. They differed in that participants in this study were most often survivors not receiving treatment while the other samples were composed of patients in treatment. 
Table 10

Sample Data Compared to Normative FACT-G Data

\begin{tabular}{|c|c|c|}
\hline Alphas & Study Sample & $\begin{array}{l}\text { FACT-G Reliability } \\
\text { Study }(\mathbf{N}=\mathbf{4 6 6}) \\
\text { (Cella et al., 1993) }\end{array}$ \\
\hline PWB & 0.90 & 0.82 \\
\hline SWB & 0.79 & 0.69 \\
\hline EWB & 0.81 & 0.74 \\
\hline FWB & 0.90 & 0.80 \\
\hline FACT-G & 0.93 & 0.89 \\
\hline SEM & Study Sample & $\begin{array}{l}\text { FACT-G Reliability } \\
\text { Study (N = 466) } \\
\text { (Cella et al, 1993) }\end{array}$ \\
\hline PWB & 2.20 & 1.91 \\
\hline SWB & 2.53 & 2.04 \\
\hline EWB & 2.34 & 1.65 \\
\hline FWB & 2.10 & 2.44 \\
\hline FACT-G & 5.05 & 4.50 \\
\hline Mean/Standard Deviation & Study Sample & $\begin{array}{c}\text { Normative Data - } \\
\text { Cancer Population } \\
(\mathbf{N}=\mathbf{2 2 3 6}) \\
\text { (Brucker et al., 2005) }\end{array}$ \\
\hline PWB & $20.9(6.9)$ & $21.3(6.0)$ \\
\hline SWB & $21.7(5.5)$ & $22.1(5.3)$ \\
\hline EWB & $17.7(5.4)$ & $18.7(4.5)$ \\
\hline FWB & $19.5(6.6)$ & $18.9(6.8)$ \\
\hline FACT-G & $80.1(19.0)$ & $80.9(17.0)$ \\
\hline
\end{tabular}

SEM = Standard Error of Measurment

Research Question 1: Is the proposed scale for evaluating health-related socioeconomic well-being supported by literature, theory, and expert review?

The theoretical support for the proposed Socioeconomic Well-being Scale was detailed in Chapter II. Based upon the definitions, an item pool was generated as described in Chapter III. Using Hudson's list method (Hudson, 1994), 33 items were generated in an effort to explore the assessment of each domain. 
The Expert Review Packet was sent to the six members of this Dissertation

Committee plus the following three experts on the subject content:

(1) Carol Ferrans, PhD, author of the Quality of Life Index

(2) Christine Ritchie, MD, Geriatrician and Palliative Care Physician, Director of Palliative Care Program, University of Alabama, Birmingham

(3) Deepa Rao, PhD, Postdoctoral Research Fellow, Institute for Healthcare Studies, Northwestern University (member of Dr. Cella's staff experienced with the FACIT instruments).

Expert reviewers were asked to rate each item [low (1), moderate (2), or high (3)] in terms of relevance to the construct, clarity of the item, and conciseness of the item and were asked to comment on the item and scale in general. Results were tabulated and weak items were re-evaluated, reworded or eliminated. The majority of reviewers believed that items related to the past or the future were not appropriate to a QOL measure as QOL is a temporal concept. Therefore, all items with a past or future orientation were eliminated. As suggested by the expert reviewers, all items were also made specific to healthcare rather than general as to socioeconomic status. Items were revised and some deleted resulting in a 23 -item pool which focused on the health-related aspects of socioeconomic well-being.

Average scores on items related to relevance, clarity and conciseness as rated by the expert reviewers and the decisions made related to each item are displayed in Table 11. Items are listed by number as they were sent out in the Expert Review Packet (see Appendx B). Elimination and rewriting of items was based more on qualitative input from the dissertation committee related to the construct of socioeconomic well-being than the scores related to relevance, clarity and conciseness. 
Table 11

\section{Results of Expert Review and Related Decisions}

\begin{tabular}{|c|c|c|c|c|}
\hline $\begin{array}{c}\text { Item } \\
\text { Number }\end{array}$ & $\begin{array}{c}\text { Mean } \\
\text { Relevance } \\
\text { Rating }\end{array}$ & $\begin{array}{l}\text { Mean } \\
\text { Clarity } \\
\text { Rating }\end{array}$ & $\begin{array}{c}\text { Mean } \\
\text { Concise- } \\
\text { ness } \\
\text { Rating } \\
\end{array}$ & Decision Made Related to Item \\
\hline 1 & 2.7 & 2.6 & 2.7 & $\begin{array}{l}\text { Rewritten-I know how to take care of } \\
\text { my health. }\end{array}$ \\
\hline 2 & 2.7 & 2.7 & 2.9 & $\begin{array}{l}\text { Rewritten-I can easily get information } \\
\text { about healthcare. }\end{array}$ \\
\hline$\overline{3}$ & 2.3 & 2.7 & 2.9 & $\begin{array}{l}\text { Rewritten-I live in a healthy } \\
\text { neighborhood. }\end{array}$ \\
\hline 4 & 2.4 & 2.6 & 2.9 & $\begin{array}{l}\text { Rewritten-I know people who will help } \\
\text { me out when I am sick. }\end{array}$ \\
\hline 5 & 2.3 & 2.4 & 2.4 & $\begin{array}{l}\text { Rewritten-I am able to pay my medical } \\
\text { bills. }\end{array}$ \\
\hline 6 & 2.0 & 2.3 & 2.3 & $\begin{array}{l}\text { Rewritten-I have enough money to take } \\
\text { care of my healthcare needs. }\end{array}$ \\
\hline 7 & 2.1 & 2.6 & 2.7 & Eliminate-wasn't specific to healthcare \\
\hline 8 & 2.1 & 1.9 & 2.0 & $\begin{array}{l}\text { Rewritten-I have to pay more for my } \\
\text { medical care than I can afford. }\end{array}$ \\
\hline 9 & 2.4 & 2.7 & 2.7 & Eliminate - past orientation \\
\hline $\mathbf{1 0}$ & 3.0 & 2.9 & 2.7 & $\begin{array}{l}\text { Rewritten-Healthcare services are easy } \\
\text { to get in my neighborhood. }\end{array}$ \\
\hline 11 & 2.7 & 2.7 & 3.0 & $\begin{array}{l}\text { Rewritten-I can afford medical check- } \\
\text { ups even when I am not sick. }\end{array}$ \\
\hline 12 & 2.7 & 2.9 & 2.9 & $\begin{array}{l}\text { Rewritten-I have enough money to take } \\
\text { care of my healthcare needs. }\end{array}$ \\
\hline 13 & 2.9 & 2.7 & 2.7 & Eliminated - future orientation \\
\hline 14 & 2.9 & 2.9 & 3.0 & $\begin{array}{l}\text { Retained as written-My doctors treat } \\
\text { me with respect. }\end{array}$ \\
\hline 15 & 3.0 & 2.3 & 2.6 & $\begin{array}{l}\text { Rewritten-The medicine I need is too } \\
\text { expensive for me. }\end{array}$ \\
\hline 16 & 2.9 & 2.7 & 2.7 & $\begin{array}{l}\text { Rewritten-I can get the health } \\
\text { insurance need. }\end{array}$ \\
\hline 17 & 3.0 & 3.0 & 2.9 & $\begin{array}{l}\text { Rewritten-My family thinks good } \\
\text { healthcare is important. }\end{array}$ \\
\hline 18 & 2.9 & 2.6 & 2.7 & $\begin{array}{l}\text { Rewritten-People like me are able to } \\
\text { get the healthcare they need. }\end{array}$ \\
\hline 19 & 2.0 & 2.0 & 2.3 & $\begin{array}{l}\text { Rewritten-I am treated the same as } \\
\text { other patients when I go for medical } \\
\text { care. }\end{array}$ \\
\hline 20 & 2.3 & 2.1 & 2.4 & $\begin{array}{l}\text { Rewritten-I do my best to take care of } \\
\text { my body. }\end{array}$ \\
\hline
\end{tabular}




\begin{tabular}{|c|c|c|c|c|}
\hline $\begin{array}{c}\text { Item } \\
\text { Number }\end{array}$ & $\begin{array}{c}\text { Mean } \\
\text { Relevance } \\
\text { Rating }\end{array}$ & $\begin{array}{l}\text { Mean } \\
\text { Clarity } \\
\text { Rating }\end{array}$ & $\begin{array}{c}\text { Mean } \\
\text { Concise- } \\
\text { ness } \\
\text { Rating }\end{array}$ & Decision Made Related to Item \\
\hline 21 & 2.3 & 2.3 & 2.6 & $\begin{array}{l}\text { Rewritten-I have always taken good } \\
\text { care of myself. }\end{array}$ \\
\hline 22 & 2.6 & 2.7 & 2.9 & Eliminated-not specific to healthcare \\
\hline 23 & 2.1 & 2.1 & 2.6 & $\begin{array}{l}\text { Rewritten-I know how to get the } \\
\text { healthcare services I need. }\end{array}$ \\
\hline 24 & 2.9 & 3.0 & 3.0 & $\begin{array}{l}\text { Rewritten-I believe that being sick will } \\
\text { hurt me financially. }\end{array}$ \\
\hline 25 & 3.0 & 3.0 & 2.9 & Eliminated-not related to healthcare \\
\hline 26 & 2.6 & 2.7 & 2.7 & $\begin{array}{l}\text { Rewritten-I am treated the same as } \\
\text { other patients when I go for medical } \\
\text { care. }\end{array}$ \\
\hline 27 & 2.1 & 2.3 & 2.4 & $\begin{array}{l}\text { Rewritten-I understand the healthcare } \\
\text { system. }\end{array}$ \\
\hline 28 & 2.01 & 2.1 & 2.4 & $\begin{array}{l}\text { Rewritten-I know people who will help } \\
\text { me out when I'm sick. }\end{array}$ \\
\hline 29 & 2.3 & 2.1 & 2.4 & Eliminated -past orientation \\
\hline 30 & 2.6 & 2.7 & 2.7 & $\begin{array}{l}\text { Rewritten-I can get the health } \\
\text { insurance I need. }\end{array}$ \\
\hline 31 & 2.4 & 2.1 & 2.4 & $\begin{array}{l}\text { Rewritten-I believe that being sick will } \\
\text { hurt me financially. }\end{array}$ \\
\hline 32 & 2.9 & 3.0 & 3.0 & $\begin{array}{l}\text { Rewritten-I believe that being sick will } \\
\text { hurt me financially. }\end{array}$ \\
\hline 33 & 2.3 & 2.1 & 2.4 & Eliminated - not specific to healthcare \\
\hline
\end{tabular}

The final-item pool sorted according to subscale and related attributes of the construct was as follows:

\section{(A) Human capital—innate and acquired attributes of an individual}

which influence the ability to acquire material goods, purchase and

access healthcare services. Examples include: innate cognitive ability,

education, skills and abilities, motivation and drive.

Items and related concepts: 
(1) I know how to take care of my health. (cognitive ability, education, knowledge)

(2) I am able to make enough money to pay for my healthcare. (ability, skills)

(3) I do my best to take care of my body. (motivation, drive)

(4) I have always taken good care of myself. (experience)

(5) I know how to get the healthcare services I need. (knowledge, experience, ability)

(6) I understand the healthcare system. (cognitive ability, knowledge, experience)

(7) I want to get the best healthcare possible. (motivation, drive) (B) Material capital-observable, tangible, owned materials that are under one's control and impact the ability to afford and access healthcare services. Examples include: earnings, disposable income, savings, assets, insurance coverage.

Items (all relate to income, earnings, and/or assets):

(1) I have to pay more for my medical care than I can afford.

(2) I am able to pay my medical bills.

(3) I believe that being sick will hurt me financially.

(4) I have enough money to take care of my healthcare needs.

(5) I can afford medical check-ups even when I am not sick.

(6). I can get the health insurance I need.

(7) The medicine I need is too expensive for me. 
(C) Social capital-individual, family and neighborhood resources

that are available based upon one's position in the social system.

Examples include: norms, reputation, influence, prestige, information channels, obligations to and from others.

Items and related concepts:

(1) People like me are able to get the healthcare they need. (norms, obligations from others)

(2) I live in a healthy neighborhood. (neighborhood norms)

(3) Healthcare services are easy to get in my neighborhood. (neighborhood, opportunity)

(4) My doctors treat me with respect. (prestige, obligations from others, reputational effects)

(5) I am treated the same as other patients when I go for medical care. (prestige, reputational effects)

(6) People I know best have healthy habits. (norms)

(7) My family thinks good healthcare is important. (family norms, expectations)

(8) I know people who will help me out when I'm sick. (obligations from others)

(9) I can easily get information about healthcare. (information channels) 


\section{Research Question 2: Is the proposed scale for evaluating health-related socioeconomic well-being valid and reliable?}

Psychometric analysis of the proposed scale was conducted based upon classical measurement theory as described in Chapter III. This section describes results of the iterative process used to develop two subscales and a final Socioeconomic Well-being Scale (SEWBS) including 17 items and the reliability and validity of that scale and each of the included domains.

The SEWBS included in the scale validation packet sent to participants consisted of 23 items measuring three different domains based on the theoretical basis for the scale: (a) material capital, 7 items; (b) social capital, 9 items; and (c) human capital, 7 items.

\section{Reliability and Content Validity at the Scale Level}

After recoding negative items, content and construct validity at the item level for each domain was evaluated using factor analysis and examining corrected item total correlations. Reliability for each domain subscale was examined using the Cronbach Alpha.

Four items which demonstrated poor corrected item correlations and factor loadings were identified immediately. Three of these were from the Human Capital Subscale ("I do my best to take care of my body," "I have always taken good care of myself," and "I want to get the best healthcare possible") and one was from the Social Capital Subscale ("I live in a healthy neighborhood"). Another poorly performing item ("My doctors treat me with respect") was removed as it was very similar in meaning to the item "I am treated the same as other patient when I go for medical care" which remained in the Social Capital Subscale.

When content validity on the item level was evaluated, all items left in the Human Capital Subscale loaded higher onto other subscales. Therefore, a decision was made to 
eliminate one of the items which was weak overall ("I know how to take care of my health") and move the two other remaining items into the Social Capital subscale where they demonstrated stronger factor correlations. The items moved were "I understand the healthcare system" and "I know how to get the healthcare services I need." Also, one item was moved from the Human Capital subscale to the Material Capital subscale based on the factor loadings. This item was "I am able to make enough money to pay for my healthcare." Springer, Abell, and Hudson (2002) suggest the scale developer consider collapsing multiple dimensions into simplified composite constructs when planned patterns do not emerge in the analysis. Similarly, Bryant and Yarnold (1995) state that the goodness of fit of various models to the data can be used to assess the plausibility of alternative hypothesized structural models. The Human Capital subscale items did not perform in a manner supportive of the construct. There may be several possible reasons for this including:

- The difficulty of developing items which measure a more nebulous construct. This domain was intended to measure innate and acquired attributes influencing the ability to acquire material goods, purchase and access healthcare services. Such attributes may be seen as resulting in material and social components which can be more directly measured.

- Human capital may be imbedded in the other two domains and may contribute to the outcomes of material capital and social influence.

- Human capital may not be viewed as a present factor in determining QOL. As QOL is temporal, constructs that are not viewed as present contributors may not appear relevant to the person's current functioning.

Items deleted are summarized in Table 12. 
Table 12

\section{Items Deleted from SEWBS}

\begin{tabular}{|l|l|r|r|}
\hline \multicolumn{1}{|c|}{ Item } & \multicolumn{1}{|c|}{ Subscale } & \multicolumn{1}{c|}{ ITC } & \multicolumn{1}{c|}{ FL } \\
\hline I know how to take care of my health & Human Capital & 0.46 & 0.52 \\
\hline I live in a healthy neighborhood. & Social Capital & 0.39 & 0.41 \\
\hline I do my best to take care of my body. & Human Capital & 0.23 & 0.22 \\
\hline I have always taken good care of myself. & Human Capital & 0.33 & 0.32 \\
\hline My doctors treat me with respect. & Social Capital & 0.42 & 0.47 \\
\hline I want to get the best healthcare possible. & Human Capital & 0.18 & 0.20 \\
\hline
\end{tabular}

ITC $=$ Item total correlation $\quad \mathrm{FL}=$ Factor loading

Cronbach Alphas for the final subscales and total scale were as followed: Material Capital 0.90; Social Capital 0.85; and total SEWB Scale 0.92. Carmines and Zeller (1979) state that reliabilities should not be below .80 for widely used scales, while others state that a value greater than .70 is a good indicator that the scale is measuring one attribute or concept and is helpful evaluation in development of a new scale (Grant et al., 1990; Jacobson, 1988). Springer, Abell, and Hudson (2002) propose an even higher value of 0.80 for instruments used to make decisions about a single individual. The proposed measure of Socioeconomic Well-being and the two subscales exceed these specifications for reliability.

The change in the Cronbach's Alpha if item deleted was assessed for each item both in the subscale and full scale analysis. Except for negatively worded items, all items if deleted would have decreased the Alpha. The Alpha on the Material Capital subscale would have increased by only .007 if the item, "I believe that being sick will hurt me financially," were dropped and by .004 if the item, "the medicine I need is too expensive for me," were dropped. The poorer functioning of these two items was attributed to response patterns rather 
than content issues, and it was felt that these items were valuable from a theoretical perspective and should remain.

Because homogeneous samples can affect the reliability coefficients by giving lower estimates of reliability, it is recommended that the standard error of measurement (SEM) also be computed before drawing final conclusions about the reliability of a measurement tool (Faul \& van Zyl, 2004). The SEMs of the subscales and total scale were as follows: Material Capital, 3.04; Social Capital, 2.33; and Socioeconomic Well-being, 4.05. In terms of measurement error, a sound measurement tool is one with a large coefficient of reliability and a small SEM compared to the overall range of possible scores (Hudson, 1992; Faul \& Van Zyl, 2004). Hudson's (1992) stated that as a rule, the SEM should be approximately $5 \%$ or less of the range of instruments scored over a range of $0-100$. Using this standard, the results related to SEMs on the proposed scales are displayed in Table 13. While the SEMS do not meet Hudson's standard, they are still relatively low and not out of range when compared to the SEMs reported by Cella in his validation of the FACT-G (see Table 10).

Corrected item-scale correlations were used to assess correlations between the items in each subscale. The corrected item-scale correlation correlates the item with all the scale items excluding itself as the item's inclusion in the scale can inflate the correlation 
Table 13

SEMs of the Proposed Subscales and SEWB Scale

\begin{tabular}{|l|r|r|r|}
\hline & $\begin{array}{c}\text { Range of Possible } \\
\text { Scores }\end{array}$ & $\begin{array}{c}\text { Desired SEM } \\
\text { (Range X .05) }\end{array}$ & \multicolumn{2}{c|}{$\begin{array}{c}\text { SEM for this } \\
\text { Study }\end{array}$} \\
\hline Material Capital & 37 & 1.85 & 3.04 \\
\hline Social Capital & 33 & 1.65 & 2.33 \\
\hline Total SEWB Scale & 69 & 3.45 & 4.05 \\
\hline
\end{tabular}

SEM $=$ Standard Error of Measurement

coefficient (DeVellis, 2003). These correlations need to be $>0.45$ with a mean $>0.50$, and the mean can be treated as a coefficient of content validity (Faul \& Van Zyl, 2004). For the Material Capital subscale, this mean was 0.67 ; for the Social Capital subscale, it was 0.59; and for the total Socioeconomic Well-being subscale, it was 0.62 . Therefore, both subscales and the total scale met specifications for the coefficient of content validity. According to Faul and Van Zyl (2004), the coefficient of content validity can also be viewed as an indication of convergent and discriminant construct validity at the item level of analysis.

Confirmatory factor analysis was conducted using principle axis factoring rather than principle components analysis as the type of factoring. This method was chosen as it allows for the confirmation of a predicted model by examining predicted factor loadings of indicator variables on a latent variable. For the Material Capital subscale, principal axis factoring resulted in one factor explaining $53 \%$ of the variance. For the Social Capital Subscale, principal axis factoring resulted in one factor explaining $42 \%$ of the variance.

The results of the reliability, content validity, and factorial validity for the two subscales are presented in Table 14. 
Table 14

Subscale Analysis of the SEWBS

\begin{tabular}{|c|l|c|c|}
\hline Item \# & Material Capital $\quad \mathbf{a = . 9 0}$ & ITC & FL \\
\hline 2 & I believe that being sick will hurt me financially & 0.48 & 0.49 \\
\hline 3 & People like me are able to get the healthcare they need & 0.62 & 0.65 \\
\hline 4 & I am able to make enough money to pay for my healthcare & 0.72 & 0.77 \\
\hline 5 & I have to pay more for my medical care than I can afford & 0.61 & 0.62 \\
\hline 8 & I am able to pay my medical bills & 0.77 & 0.83 \\
\hline 11 & I can afford medical check-ups even when I am not sick & 0.78 & 0.84 \\
\hline 13 & I have enough money to take care of my healthcare needs & 0.85 & 0.91 \\
\hline 14 & I can get the health insurance I need & 0,76 & 0.81 \\
\hline 20 & The medicine I need is too expensive for me & 0.53 & 0.54 \\
\hline & & $\mathbf{0 . 6 7}$ & $\mathbf{0 . 7 2}$ \\
\hline Item \# & Social Capital & ITC & FL \\
\hline 9 & I can easily get information about healthcare & 0.63 & 0.70 \\
\hline 15 & My family thinks good healthcare is important & 0.46 & 0.50 \\
\hline 16 & I know how to get the healthcare services I need & 0.75 & 0.83 \\
\hline 17 & I know people who will help me out when I am sick & 0.68 & 0.74 \\
\hline 18 & People I know best have healthy habits & 0.49 & 0.53 \\
\hline 19 & I understand the healthcare system & 0.64 & 0.70 \\
\hline 21 & $\begin{array}{l}\text { I am treated the same as other patients when I go for medical } \\
\text { care }\end{array}$ & 0.44 & 0.48 \\
\hline 23 & Healthcare services are easy to get in my neighborhood & 0.61 & 0.67 \\
\hline & & $\mathbf{0 . 5 9}$ & $\mathbf{0 . 6 4}$ \\
\hline
\end{tabular}

ITC $=$ Item total correlation $\quad \mathrm{FL}=$ Factor loading

Subsequently, the two separate subscales were examined as one scale with two dimensions. Results for the full scale are displayed in Table 15. 


\section{Table 15}

The Reliability, Content Validity, and Factor Loadings of the SEWBS

\begin{tabular}{|c|c|c|c|}
\hline Item \# & Socioeconomic Well-being Scale & ITC & FL \\
\hline 2 & I believe that being sick will hurt me financially & 0.48 & 0.48 \\
\hline 3 & People like me are able to get the healthcare they need & 0.65 & 0.68 \\
\hline 4 & I am able to make enough money to pay for my healthcare & 0.72 & 0.75 \\
\hline 5 & I have to pay more for my medical care than I can afford & 0.58 & 0.58 \\
\hline 8 & I am able to pay my medical bills & 0.74 & 0.78 \\
\hline 9 & I can easily get information about healthcare & 0.66 & 0.70 \\
\hline 11 & I can afford medical check-ups even when I am not sick & 0.78 & 0.81 \\
\hline 13 & I have enough money to take care of my healthcare needs & 0.82 & 0.85 \\
\hline 14 & I can get the health insurance I need & 0.79 & 0.83 \\
\hline 15 & My family thinks good healthcare is important & 0.43 & 0.45 \\
\hline 16 & I know how to get the healthcare services I need & 0.78 & 0.82 \\
\hline 17 & I know people who will help me out when I am sick & 0.57 & 0.60 \\
\hline 18 & People I know best have healthy habits & 0.43 & 0.45 \\
\hline 19 & I understand the healthcare system & 0.61 & 0.64 \\
\hline 20 & The medicine I need is too expensive for me & 0.46 & 0.46 \\
\hline 21 & $\begin{array}{l}\text { I am treated the same as other patients when I go for medical } \\
\text { care }\end{array}$ & 0.40 & 0.42 \\
\hline 23 & Healthcare services are easy to get in my neighborhood & 0.64 & 0.68 \\
\hline & Mean & 0.62 & 0.64 \\
\hline
\end{tabular}

ITC $=$ Item total correlation $\quad \mathrm{FL}=$ Factor loading 


\section{Construct Validity at the Item Level}

To establish construct validity at the item level, the 17 items were correlated with the two SEWB subscales (Material and Social Capital) and the four subscales of the FACT-G (Physical, Social/Family, Emotional, and Functional). Construct validity of an item is proven if the item has a higher corrected item-total correlation with its own total than with the total score of any other subscale (Faul, 1995; Hudson, 1991). All items on each subscale demonstrated higher correlations with the designated subscale than with the other subscales. The results of this analysis are shown in Table 16. The final items all loaded more strongly onto their designated subscale with no factor loading failures.

While there may be overlap of items with other subscales in which the correlations approached the correlation of the item with its intended subscale, one must be cautious in deleting items when constructing a theory-based scale. Because scale validation is sample specific and descriptive only of the participants actually included (Springer et al., 2002), trimming items unnecessarily may eliminate items potentially reflective of the theory that could perform well in other samples. 
Table 16

Correlation Matrix Showing Construct Validity of the SEWB Subscales

\begin{tabular}{|c|c|c|c|c|c|c|}
\hline $\begin{array}{c}\text { MCS } \\
\text { ITEMS }\end{array}$ & Mas & SCS & PWB & SWB & EWB & FWB \\
\hline 2 & 0,8 & 0.35 & 0.40 & 0.26 & 0.44 & 0.38 \\
\hline 3 & 0.62 & 0.59 & 0.31 & 0.27 & 0.28 & 0.38 \\
\hline 4 & 0,12 & 0.58 & 0.41 & 0.24 & 0.23 & 0.47 \\
\hline 5 & 501 & 0.39 & 0.28 & 0.16 & 0.25 & 0.26 \\
\hline 8 & 077 & 0.57 & 0.38 & 0.27 & 0.29 & 0.45 \\
\hline 11 & 078 & 0.63 & 0.46 & 0.30 & 0.32 & 0.49 \\
\hline 13 & 048 & 0.64 & 0.46 & 0.28 & 0.33 & 0.49 \\
\hline 14 & 076 & 0.69 & 0.37 & 0.28 & 0.27 & 0.44 \\
\hline 20 & 058 & 0.31 & 0.30 & 0.16 & 0.27 & 0.29 \\
\hline $\begin{array}{c}\text { SCS } \\
\text { ITEMS }\end{array}$ & SCS & No8 & PWB & SWB & EWB & FWB \\
\hline 9 & 0.63 & (1) & 0.34 & 0.38 & 0.28 & 0.44 \\
\hline 15 & 0.46 & 98 & 0.23 & 0.34 & 0.12 & 0.30 \\
\hline 16 & 0.75 & 0.11 & 0.37 & 0.29 & 0.25 & 0.49 \\
\hline 17 & 0.68 & 6. & 0.29 & 0.61 & 0.20 & 0.49 \\
\hline 18 & 0.49 & 50 & 0.26 & 0.44 & 0.23 & 0.43 \\
\hline 19 & 0.64 & 158 & 0.27 & 0.27 & 0.16 & 0.44 \\
\hline 21 & 0.44 & 055 & 0.19 & 0.33 & 0.16 & 0.40 \\
\hline 23 & 0.61 & Ors & 0.00 & 0.23 & -0.11 & 0.10 \\
\hline
\end{tabular}

MCS = Material Capital Subscale SCS = Social Capital Subscale PWB $=$ Physical Well-being Subscale
PWB $=$ Physical Well-being Subscale SWB $=$ Social/Family Well-being Subscale EWB $=$ Emotional Well-being Subscale FWB $=$ Functional Well-being Subscale

\section{Discriminant and Convergent Validity}

To explore discriminant and convergent validity at the scale level, a priori hypotheses based upon the theory of socioeconomic well-being underlying the new measure 
were developed. According to Carmines and Zeller (1979), the social scientist is able to assess the construct validity of a measure if the measure can be placed in theoretical context.

The first hypothesis tested is that the newly developed subscales and total scale will have a low correlation with certain social background variables (Class I predictors), specifically number of children, number in household, and years since cancer diagnosis since these factors seem relatively unrelated to socioeconomic well-being. Results of these correlations are displayed in Table 17.

\section{Table 17}

\section{Correlation Matrix with Class I Criterion Variables}

\begin{tabular}{|l|r|r|r|r|}
\hline & \multicolumn{1}{|c|}{$\begin{array}{c}\text { Number of } \\
\text { Children }\end{array}$} & $\begin{array}{c}\text { Number in } \\
\text { Household }\end{array}$ & \multicolumn{1}{c|}{$\begin{array}{c}\text { Years since } \\
\text { Diagnosis }\end{array}$} & \multicolumn{1}{c|}{ Mean } \\
\hline MCS & 0.04 & 0.01 & -0.10 & 0.05 \\
\hline SCS & 0.02 & -0.03 & -0.10 & 0.05 \\
\hline SEWBS & 0.03 & 0.02 & -0.12 & 0.06 \\
\hline
\end{tabular}

The second hypothesis is that certain variables will have moderate correlations with the new scale (Class II predictors). This was tested by examining the correlations between the new subscales and total SEWB scale and certain demographic variables thought to be somewhat related to socioeconomic well-being including age, years of education, having no insurance (yes [1] or no [2]), and home ownership (yes [1] or no [2]) as well as correlations with subscales on the FACT-G and the QLI measuring domains outside of or less affected by socioeconomic well-being. These correlations are shown in Table 18. 
Table 18

Correlation Matrix with Class II Criterion Variables

\begin{tabular}{|l|r|r|r|r|r|r|r|l|}
\hline & \multicolumn{1}{l|}{ Age } & \multicolumn{1}{l|}{ Ed } & \multicolumn{1}{l|}{ Ins } & \multicolumn{1}{l|}{ Home } & EWB & PSPSUB & FAMSUB & Mean \\
\hline MCS & 0.29 & 0.29 & 0.51 & -0.38 & 0.39 & 0.46 & 0.38 & 0.38 \\
\hline SCS & 0.19 & 0.21 & 0.37 & -0.32 & 0.29 & 0.47 & 0.49 & 0.33 \\
\hline SEWBS & 0.26 & 0.27 & 0.49 & -0.36 & 0.37 & 0.49 & 0.45 & 0.38 \\
\hline
\end{tabular}

Age $=$ age in years

$\mathrm{Ed}=$ years of education

Ins = has no health insurance

Home $=$ owns home
EWB $=$ Emotional well-being subscale $(\mathrm{QLI})$

PSPSUB $=$ Psychological/Spiritual Subscale (QLI)

FAMSUB $=$ Family Subscale $(\mathrm{QLI})$

The third hypothesis is that certain variables will have high correlations with the new scale (Class III predictors). This was tested by examining the correlations between the new subscales and total SEWB scale and monthly income, subjective rating of social status using the ladder instrument (SSSLR), subscales thought to strongly relate to or be affected by socioeconomic well-being and overall scores on the FACT-G and the QLI. The results of these correlations are displayed in Table 19.

\section{Table 19}

Correlation Matrix with Class III Criterion Variables

\begin{tabular}{|l|l|l|l|l|l|l|l|l|l|l|}
\hline & $\begin{array}{l}\text { Mo } \\
\text { Inc }\end{array}$ & $\begin{array}{l}\text { Subj } \\
\text { SS }\end{array}$ & PWB & SWB & $\begin{array}{l}\text { FW } \\
\text { B }\end{array}$ & $\begin{array}{l}\text { FACT } \\
\text {-G }\end{array}$ & QLI & $\begin{array}{l}\text { HF } \\
\text { SUB }\end{array}$ & $\begin{array}{l}\text { SOC } \\
\text { SUB }\end{array}$ & Mean \\
\hline MCS & 0.52 & 0.62 & 0.50 & 0.32 & 0.54 & 0.56 & 0.54 & 0.54 & 0.51 & 0.52 \\
\hline SCS & 0.30 & 0.52 & 0.40 & 0.53 & 0.60 & 0.57 & 0.61 & 0.61 & 0.60 & 0.53 \\
\hline $\begin{array}{l}\text { SEWB } \\
\text { S }\end{array}$ & 0.47 & 0.62 & 0.48 & 0.45 & 0.59 & 0.59 & 0.60 & 0.60 & 0.58 & 0.55 \\
\hline
\end{tabular}

Subj SS = Subjective Social Status rating SWB $=$ Social Well-being HFSUB $=$ Health and Functioning Subscale (QLI) SOCSUB $=$ Socioeconomic Subscale $(\mathrm{QLI})$
PWB $=$ Physical Well-being FWB $=$ Functional Well-being FACT-G = total FACT-G score QLI = total Quality of Life Index 


\section{Summary of Reliability and Validity Analysis}

Initially, content and construct validity was developed for each subscale using the theory and definitions described in Chapter II. Content validity was further evaluated via expert review of the proposed item pool. An iterative analysis process was then employed to assess reliability, content and construct validity. The Cronbach Alpha was used to investigate reliability of the items in the scale. Corrected item-total correlations were investigated and a coefficient of content validity was determined using the mean of the corrected item total correlations.

Confirmatory factor analysis was then used to confirm the dimensionality of the each subscale. Principal factor analysis using principle axis factoring was performed.

During this process, six items were deleted due to overall poor performance, and the remaining items were assigned to two subscales, Material Capital and Social Capital, based upon their factor loadings. See Appendix $\mathrm{C}$ for a tracking of the final disposition of each item. The final subscales met statistical criteria for reliability, content validity and factorial validity.

Convergent and discriminant validity were tested on the scale level using Class I, II, and II criterion variables. Springer, Abell, and Hudson (2002) suggest that one should not evaluate validity on the basis of isolated characteristics but rather look at the composite of complementary evidence. A composite consideration of all aspects of the validity assessment of the three scales (Material Capital, Social Capital, and Socioeconomic Well-being Scales) was suggestive of an instrument with favorable psychometric properties (reliability and validity). 


\section{Research Question 3: Is the inclusion of a socio-economic well-being domain to}

\section{the FACT-G a valuable addition with explanatory power when evaluating}

\section{QOL in persons with a cancer diagnosis?}

As described in the previous chapter, hierarchical multiple regression was used to assess incremental validity (Bryant, 2000). Variables selected as potential socioeconomic predictors of QOL besides the SEWBS were monthly income, years of education and subjective rating of social status. Income and years of education have been shown to be predictive of poor health outcomes (Lantz et al., 2001) and related QOL. The Subjective Social Status Ladder Rating has been shown to be a powerful predictor of health status and has demonstrated significant correlation with conventional measures of objective status such as employment grade, education, and income (Singh-Manoux et al., 2003). For the SEWBS to have incremental validity, it should explain unique variance in QOL above and beyond the variance explained by these variables. Otherwise, one could rely on one or more of these rather than including the SEWBS to determine the impact of socioeconomic influences on QOL.

In any regression analysis, it is important that the independent variables are correlated with the dependent variable (Abu-Bader, 2006). To assess this, a bivariate correlation matrix was generated. Results are shown in Table 20.

This correlation matrix was also used to assess for multicollinearity, the possibility that variables measure the same construct. A Pearson correlation coefficient that is greater than .85 indicates a multicollinearity problem (Abu-Bader, 2006). All 
Table 20

Correlation Matrix_-Potential Socioeconomic Predictors of QOL

\begin{tabular}{|l|r|r|r|r|r|}
\hline & $\begin{array}{c}\text { Monthly } \\
\text { Income }\end{array}$ & $\begin{array}{c}\text { Subj. Social } \\
\text { Status }\end{array}$ & SEWBS & FACT-G & QLI \\
\hline $\begin{array}{l}\text { Yrs of } \\
\text { Education }\end{array}$ & $0.46^{*}$ & $0.48^{*}$ & $0.27^{*}$ & 0.08 & 0.10 \\
\hline $\begin{array}{l}\text { Monthly } \\
\text { Income }\end{array}$ & - & $0.59^{*}$ & $0.47^{*}$ & $0.33^{*}$ & $0.28^{*}$ \\
\hline $\begin{array}{l}\text { Subj. Social } \\
\text { Status }\end{array}$ & - & - & $0.62^{*}$ & $0.46^{*}$ & $0.53^{*}$ \\
\hline SEWBS & - & - & - & $0.59^{*}$ & $0.60^{*}$ \\
\hline
\end{tabular}

* correlation significant at the 0.01 level (2-tailed)

correlations in this analysis were below this threshold; therefore, multicollinearity was not detected. Because years of education was not significantly correlated with either the total score on the FACT-G and the QLI, it was eliminated from the model.

Results of the hierarchical regression analyses are displayed in Tables 21 and 23 and changes between models are shown in Tables 22 and 24 . In both analyses, the $\mathrm{R}^{2}$ change indicates that the SEWBS has predictive ability above and beyond the other potential socioeconomic indicators. 
Table 21

Results of Hierarchical Regression Analysis-Socioeconomic Predictors of QOL with

FACT-G Score as Dependent Variable

\begin{tabular}{|l|c|c|c|}
\hline \multicolumn{1}{|c|}{ Variable } & B & SE B & $\beta$ \\
\hline Step 1 & & & \\
\hline Monthly Income & 0.00 & 0.00 & 0.09 \\
\hline Subjective Social Status (SSS) & 4.28 & 0.96 & 0.40 \\
\hline Step 2 & & & \\
\hline Monthly Income & $5.78 \mathrm{E}-005$ & 0.00 & 0.09 \\
\hline Subjective Social Status (SSS) & 1.33 & 0.98 & 0.12 \\
\hline SEWBS & 0.66 & 0.11 & 0.52 \\
\hline
\end{tabular}

Table 22

Changes Resulting from Hierarchical Regression Analysis-Socioeconomic Predictors of QOL with FACT-G Score as Dependent Variable

\begin{tabular}{|l|r|r|r|r|r|}
\hline \multicolumn{1}{|c|}{ Models } & \multicolumn{1}{|c|}{$\boldsymbol{R}$} & \multicolumn{1}{|c|}{$\boldsymbol{R}^{2}$} & \multicolumn{1}{c|}{$\begin{array}{c}\boldsymbol{R}^{2} \\
\text { change }\end{array}$} & $\begin{array}{c}\boldsymbol{F} \\
\text { change }\end{array}$ & $\begin{array}{c}\text { Sign } \boldsymbol{F} \\
\text { change }\end{array}$ \\
\hline SSS \& monthly income & 0.45 & 0.21 & 0.21 & 20.334 & $<.001$ \\
\hline $\begin{array}{l}\text { SSS, monthly income \& } \\
\text { SEWBS }\end{array}$ & 0.61 & 0.37 & 0.16 & 39.517 & $<.001$ \\
\hline
\end{tabular}


Table 23

Results of Hierarchical Regression Analysis-Socioeconomic Predictors of QOL with QLI Score as Dependent Variable

\begin{tabular}{|l|c|c|c|}
\hline \multicolumn{1}{|c|}{ Variable } & B & SE B & $\beta$ \\
\hline Step 1 & & & \\
\hline Monthly Income & $-4.37 \mathrm{E}-005$ & 0.00 & -.024 \\
\hline Subjective Social Status (SSS) & 1.64 & 0.26 & 0.525 \\
\hline Step 2 & & & \\
\hline Monthly Income & 0.00 & 0.00 & -0.088 \\
\hline Subjective Social Status (SSS) & 0.83 & 0.28 & 0.27 \\
\hline SEWBS & 0.18 & 0.03 & 0.47 \\
\hline
\end{tabular}

Table 24

Changes Resulting from Hierarchical Regression Analysis-Socioeconomic Predictors of OOL with OLI Score as Dependent Variable

\begin{tabular}{|l|r|r|r|r|r|}
\hline \multicolumn{1}{|c|}{ Models } & \multicolumn{1}{|c|}{$\boldsymbol{R}$} & $\boldsymbol{R}^{2}$ & \multicolumn{1}{c|}{$\begin{array}{c}\boldsymbol{R}^{2} \\
\text { change }\end{array}$} & $\begin{array}{c}\boldsymbol{F} \\
\text { change }\end{array}$ & $\begin{array}{c}\text { Sign } \boldsymbol{F} \\
\text { change }\end{array}$ \\
\hline Monthly income \& SSS & 0.51 & 0.26 & 0.26 & 28.33 & $<.001$ \\
\hline $\begin{array}{l}\text { Monthly income \& SSS \& } \\
\text { SEWBS }\end{array}$ & 0.63 & 0.39 & 0.13 & 33.77 & $<.001$ \\
\hline
\end{tabular}

These analyses indicate that the SEWBS adds significant information to the predictive ability of other socioeconomic indicators in predicting overall QOL as measured by the composites scores of the FACT-G and the QLI. 
A second regression analysis was performed to determine if the SEWBS added value to the existing subscales of the FACT-G when predicting QOL as measured by the total score on the QLI. First, a bivariate correlation matrix was developed to determine if correlations existed and if multicollinearity might be a consideration. Results are shown in Table 25 . All correlations were significant yet below the standard indicating multicollinearity $(0.85)$.

Table 25

Correlation Matrix - Subscales of FACT-G, SEWBS, and QLI

\begin{tabular}{|l|r|r|r|r|r|}
\hline & SWB & EWB & FWB & QLI & SEWB \\
\hline PWB & $0.27^{*}$ & $0.60^{*}$ & $0.67^{*}$ & $0.68^{*}$ & $0.48^{*}$ \\
\hline SWB & - & $0.30^{*}$ & $0.49^{*}$ & $0.52^{*}$ & $0.45^{*}$ \\
\hline EWB & - & - & $0.56^{*}$ & $0.64^{*}$ & $0.37^{*}$ \\
\hline FWB & - & - & - & $0.81^{*}$ & $0.59^{*}$ \\
\hline QLI & - & - & - & - & $0.60^{*}$ \\
\hline
\end{tabular}

*correlation significant at the 0.01 level (2-tailed)

PWB $=$ Physical Well-being $\quad$ EWB $=$ Emotional Well-being

SWB $=$ Social Well-being FWB $=$ Functional Well-being

QLI = total Quality of Life Index

SEWB = Socioeconomic Well-being

Next, the hierarchical regression was conducted. The first model consisted of the existing subscales of the FACT-G. The second model added the SEWBS as a potential predictor. Results of this analysis are shown in Table 26. 
Table 26

Results of Hierarchical Regression Analysis-Subscales of the FACT-G and the SEWBS with QLI Score as Dependent Variable

\begin{tabular}{|l|c|c|c|}
\hline \multicolumn{1}{|c|}{ Variable } & B & SE B & $\beta$ \\
\hline Step 1 & & & \\
\hline PWB & 0.13 & 0.04 & 0.16 \\
\hline SWB & 0.16 & 0.04 & 0.16 \\
\hline EWB & 0.21 & 0.05 & 0.21 \\
\hline FWB & 0.44 & 0.49 & 0.51 \\
\hline Step 2 & & & \\
\hline PWB & 0.12 & 0.04 & 0.15 \\
\hline SWB & 0.14 & 0.05 & 0.14 \\
\hline EWB & 0.20 & 0.05 & 0.20 \\
\hline FWB & 0.40 & 0.05 & 0.46 \\
\hline SEWBS & 0.05 & 0.02 & 0.12 \\
\hline
\end{tabular}

PWB $=$ Physical Well-being

SWB $=$ Social Well-being

QLI = total Quality of Life Index
$\mathrm{EWB}=$ Emotional Well-being

FWB $=$ Functional Well-being

SEWB $=$ Socioeconomic Well-being

Table 27

Changes in Hierarchical Regression Analysis-Subscales of the FACT-G and the

SEWBS with OLI Score as Dependent Variable

\begin{tabular}{|l|r|r|r|r|c|}
\hline \multicolumn{1}{|c|}{ Models } & \multicolumn{1}{|c|}{$\boldsymbol{R}$} & $\boldsymbol{R}^{2}$ & $\begin{array}{c}\boldsymbol{R}^{2} \\
\text { change }\end{array}$ & $\begin{array}{c}\boldsymbol{F} \\
\text { change }\end{array}$ & $\begin{array}{c}\text { Sign } \boldsymbol{F} \\
\text { change }\end{array}$ \\
\hline FWB, EWB, SWB, PWB & 0.85 & 0.72 & 0.72 & 131.39 & $<.001$ \\
\hline $\begin{array}{l}\text { FWB, EWB, SWB, PWB } \\
\text { \& SEWBS }\end{array}$ & 0.85 & 0.73 & 0.01 & 6.72 & $<.01$ \\
\hline
\end{tabular}

PWB $=$ Physical Well-being

SWB $=$ Social Well-being

QLI = total Quality of Life Index
EWB $=$ Emotional Well-being

FWB = Functional Well-being

SEWB $=$ Socioeconomic Well-being 
Using this method to assess incremental validity demonstrates that the newly validated measure of SEWB adds value to the existing subscales of the FACT-G in predicting overall quality of life as measured by the QLI.

\section{Conclusion}

This chapter on the results of the study described the sample and its congruence with the total population and normative and reliability samples used to evaluate the FACT-G in other studies. The results of the iterative process used to develop a reliable and valid theorybased instrument to measure socioeconomic well-being were presented. Support for incremental validity was also presented. 


\section{CHAPTER V}

\section{DISCUSSION, CONCLUSIONS, AND SOCIAL WORK IMPLICATIONS}

This research effort successfully applied classical measurement theory in the development and validation of a scale for the measurement of health-related socioeconomic well-being of persons with a cancer diagnosis. Work began by specifying a conceptual/theoretical basis for defining the construct and its measurement, the first step recommended by experts in scale development (Devellis, 2003; Netemeyer et al., 2003). Historically, domains of QOL measurement have been identified and developed using grounded theory and exploratory rather than confirmatory factor analysis, and this has resulted in a lack of clarity and consistently across domains and instruments (Hasse \& Braden, 2003). In this study, applying a theoretical foundation as the basis for the construct definition and item generation provided clarity and unity throughout the development and validation process. The end product demonstrated support for this theoretical foundation with only slight modifications in theory application.

Conceptualization of the domain of socioeconomic well-being in this study was grounded in the life model theory of Germain and Gitterman (1996), especially their concepts of niche and habitat, as well as Coleman's theory of socioeconomic status (1990) delineating three aspects of capital and subsequent work by Oakes and Rossi 
(2003), all of which were detailed in Chapter II. The development of the domain based upon relevant theory and justified by the reality of the impact of socioeconomic factors on healthcare treatment and outcomes offers a social work contribution to the field of quality of life measurement and assures that this important aspect of health-related wellbeing is not ignored.

\section{Strengths}

This study was congruent in following the recommended steps of scale development: (1) the construct and content domain were clearly defined based on a thorough search of the literature and an identified theoretical foundation; (2) an item pool reflective of the construct definition and underlying theory was generated; (3) an expert review process was used to further refine the item pool; (4) validation items and measures were selected for inclusion in the survey packet; (5) items were administered to a sample population; (6) the iterative process of establishing reliability and validity resulted in a final item pool and a clarification of the theoretical foundation of the construct as a domain of QOL.

An adequate number of respondents for statistical analysis was successfully recruited. Selecting a random sample from the Tumor Registry enabled the recruitment of a demographically diverse, adequately powered sample within a specified timeframe with limited financial and human resources.

Because participants were several years past their initial cancer diagnosis, they had experienced the impact of a diagnosis and the related disability and changes in employment status. Therefore, they had been impacted by not only their socioeconomic status prior to cancer, but also the impact of their cancer on their ongoing socioeconomic 
status. This convergence of socioeconomic impacts (pre and post cancer) may have contributed to the measure of socioeconomic well-being having higher correlation with quality of life than factors such as years of education and monthly income when considered as separate variables.

The final scale consisting of two subscales demonstrated strong reliability and validity performance on both the item and scale level. Negative items requiring reverse coding were the weakest of the items, but this was believed to be more a function of participant response patterns than the quality of the actual item and its construct validity.

\section{Limitations}

The fact that a scale validation study requires multiple instruments contributed to a survey that was 12 pages long. This plus a rather daunting preamble consent (as required by the Human Subjects Oversight Committees reviewing the protocol) was likely intimidating to persons of lower educational status or persons busy with work and family. Therefore, the sample was slightly skewed towards persons with educational levels above high school, persons with higher income levels and persons retired from professional careers.

Because survey completion and return was totally voluntary, self-selection bias confounds the results and affects the ability of the sample to be considered as totally representative of the total population. Administration and completion of the validation packet was not in control of the researcher leaving it unknown as to what, if any, assistance may have been required and who provided such assistance to those unable to complete the instruments independently. 
Although younger than the median age nationally for cancer diagnoses, the sample was significantly older than the total population of persons on the Tumor Registry which may be because more settled persons had more time and interest in completing the instruments. Also, residential stability determined who on the Tumor Registry actually received the survey, and older, more settle persons and those with more financial stability were more likely to receive the mailed packet.

The response rate of $24 \%$ was lower than desired but was predictable considering the population invited to participate. A slight token of appreciation was included in the mailing and a reminder/thank you postcard was sent as recommended by Dillman (2007), but other methods to increase response (i.e., a preliminary postcard, a second mailing of the survey) were not used due to the cost involved and the possibility that many of the potential participants could have relocated or died. Such additional efforts may have increased the response rate.

The majority of participants were no longer receiving active treatment for their cancer. Therefore, scores on the physical and functional well-being subscales were higher than would be expected of persons currently in treatment, and this may have escalated the overall QOL scores of the sample.

Ideally, more participants recently diagnosed and currently undergoing treatment would be included in a study of oncology related QOL. These persons could be reached through the clinic setting. Offering oral interviews as opposed to self-administered questionnaires would be one method of involving person of lower educational status. These methods were not attempted in this study due to time and resource limitations. 
This study was based upon a one-time administration of the instrument and validation measures. In order for a measure to be useful in clinical evaluation, responsiveness or the tool's ability to detect change is important (Guyatt et al., 1993). It was not within the scope of this study to determine the ability of the SEWBS to measure change over time, but a future longitudinal study would be beneficial to determine if the instrument has such ability.

\section{Summary of Findings}

The final SEWBS consisted of 17 items divided into two subscales: material and social capital. While this may appear to contradict the initial definition and conceptualization of a composite scale with three subscales (human, material, and social capital), it is, in fact, a logical evolution of the theory. Human capital is a more nebulous and latent construct than those of material (observable owned endowments under one's control) and social capital (resources that are a function of the social system). As defined earlier in Chapter II, human capital included the fixed endowments of an individual, instinctual motivation and acquired attributes such as education and skill which can be used to acquire socially valued goods. Such capital results in material and social capital which are more tangible constructs probably more easily understood by survey respondents. Therefore, human capital underlies or is imbedded in the other two constructs (material and social capital).

Springer, Abell, and Hudson (2002) suggest the scale developer consider collapsing multiple dimensions into simplified composite constructs when planned patterns do not emerge in the analysis. Similarly, Bryant and Yarnold (1995) state that the goodness of fit of various models to the data can be used to assess the plausibility of 
alternative hypothesized structural models. The Human Capital subscale items did not perform as expected based on the theoretical construct. Reasons for this may include:

- the difficulty of developing items which measure a more nebulous construct. This domain was intended to measure innate and acquired attributes influencing the ability to acquire material goods, purchase and access healthcare services. Such attributes may be seen as resulting in material and social components which can be more directly measured.

- human capital may be imbedded in the other two domains and may contribute to the outcomes of material capital and social influence.

- human capital may not be viewed as a present factor in determining QOL.

As QOL is temporal, constructs that are not viewed as present contributors may not appear relevant to the person's current functioning.

While this may be viewed as a failure to honor the underlying theory, review of the involved items, and the scale with which they loaded the best made sense. The concept of human capital as innate and acquired attributes of an individual such as cognitive ability, education, skills and abilities, motivation, and drive is more abstract than material or social capital domains. Human capital shapes material and social capital, as individual abilities and motivation result in social and material outcomes. Human capital may well be imbedded in those domains and interpreted by respondents as more concrete when it relates to material results (i.e., salary, ability to pay bills, and social status). Springer, Abell, and Hudson (2002) also suggest revisiting the theory and definitions when planned patterns do not emerge in evaluating content validity as was done in this case. 
Because QOL is a temporal concept reflective of the moment in which it is evaluated, participants are more likely to respond consistently to measures of tangible capital. A simple change of redirecting human capital into social capital and material capital domains contributing to socioeconomic position rather than having human capital directly contribute to socioeconomic position clarifies the conceptual framework in accordance with the findings of the validation study. The revised conceptual framework is depicted in Figure 2. 


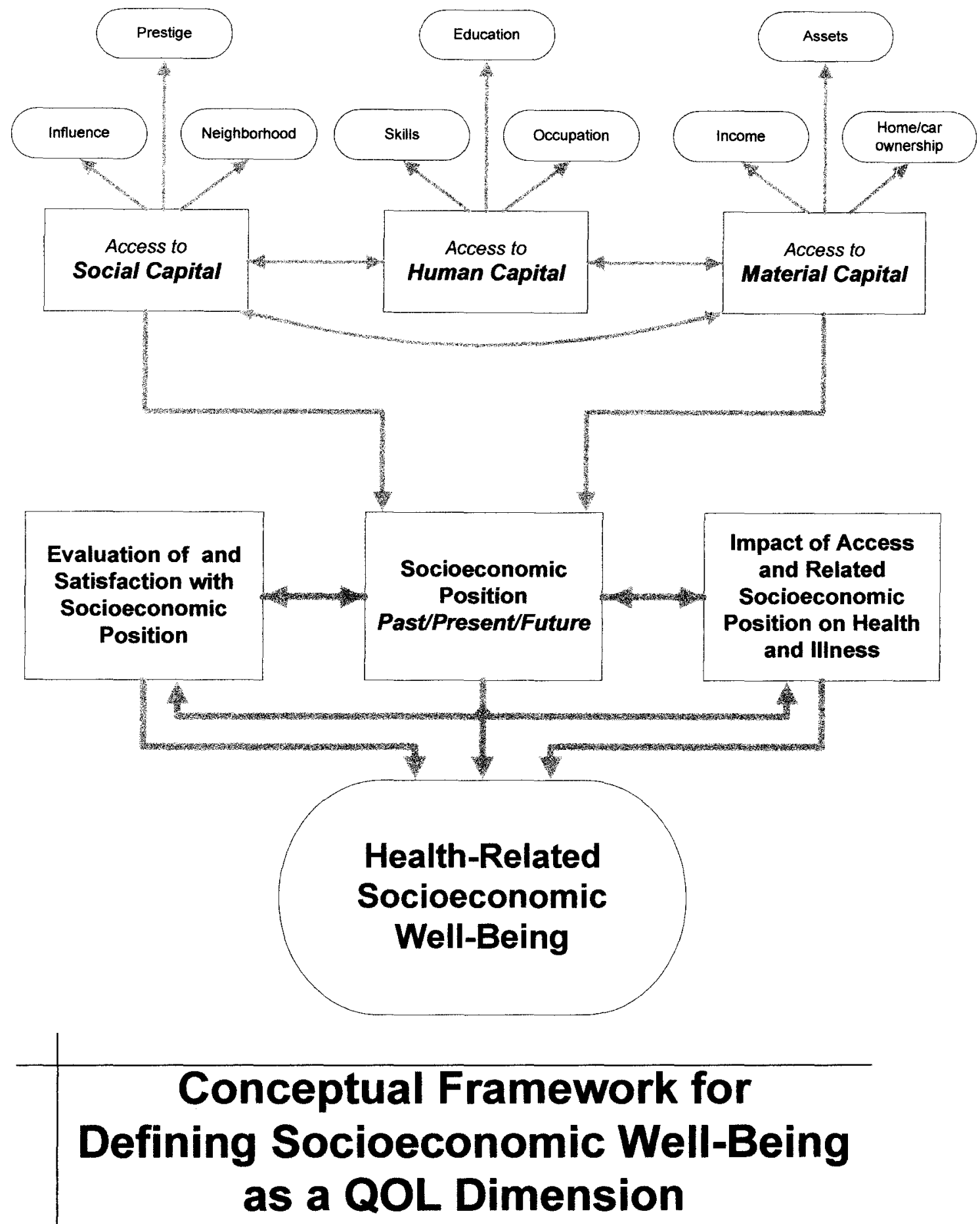

Figure 2. Revised conceptual framework for defining socioeconomic well-being as a QOL dimension. 
This imbedding of Human Capital into the other two subscales (Material Capital and Social Capital) is understandable if we analyze items within those subscales reflective of the Human Capital construct. In the Material Capital Subscale, the following items mirror human capital:

- People like me are able to get the healthcare they need.

- I am able to make enough money to pay for my healthcare

"People like me" may be understood by respondents as people of the same socioeconomic status and may be interpreted as being based more on tangible material resources rather than innate and acquired attributes. "I am able to make enough money" might also lead the respondent to think of the material, tangible aspects of money making rather than innate or acquired abilities behind the potential to make money.

In the Social Capital subscale, these items show an imbedding of the construct of human capital:

- I can easily get information about healthcare.

- I know how to get the healthcare services I need.

- I understand the healthcare system.

These items could speak to either the ability and attributes which enable one to navigate the healthcare system (a human capital meaning) or the resources available based on one's position in the social system (social capital meanings).

It may also be possible that Human Capital is a measurable latent construct and that the items created failed to reflect the construct. Therefore, future efforts to measure the construct using different items are warranted. 
While the number of items in the final scale is higher than the other core subscales of the FACT-G, a decision was made to include all items because each item seemed very unique and worthy of inclusion when considering the goals of the instrument and the theoretical basis and definition of the construct. Ideally, the scale will be further refined as used with various samples of diverse demographic and disease status populations. This study is intended to be an initial exploration of the scale's psychometric properties rather than conclusive in its findings. Because a study of the performance of a scale is always sample dependent (Springer, Abell, \& Hudson, 2002), the iterative process of scale development and validation is not and should not be isolated to one study with one sample.

The process of evaluating convergent, divergent and incremental validity as described in the previous chapter, revealed that socioeconomic well-being as measured by the SEWBS is correlated with demographic variables often associated with socioeconomic status such as monthly income and subjective social status, yet it is different and more predictive of QOL than these variables alone. This should not be surprising, in that the definition of the construct is so much more than demographic factors. Access to resources is only one part of the definition of socioeconomic wellbeing which was earlier defined as one's subjective evaluation of and satisfaction with his/her socioeconomic position in society based upon access to resources (material, human, and social) and the impact of that access on health and illness. It is a measurement of social class, a concept that is theoretically as well as empirically distinct from socioeconomic status (Wohlfarth, 1997). Establishing that the new scale adds predictive value to traditional measures of socioeconomic status (such as income and 
subjective social status) when quality of life is the dependent variable demonstrates its value in assessing the impact of socioeconomic factors on quality of life.

The new SEWBS was also shown to add value to the existing FACT-G domains when predicting overall quality of life in persons with cancer. This supports the rationale for adding the subscale to those existing subscales when measuring QOL.

\section{Implications for Measurement of Socioeconomic Status and Quality of Life in Health Research}

As detailed in Chapter I, the differences in health and risk behaviors among socioeconomic groups (Freeman, 2004), the reality of healthcare disparities for those of lower socioeconomic status (Institute of Medicine, 1999, 2003), the plight of the uninsured (Institute of Medicine, 2002), and the accumulation of research showing a strong relationship between socioeconomic status and disability and disease (Oakes \& Rosse, 2003) are all factors contributing to a call for new approaches to the measurement of socioeconomic factors in health-related research.

As Oakes and Rossi (2003) so aptly state: "More and more health researchers believe that a narrow focus on individuals outside of historical, social, and biophysical contexts limits the understanding of disease etiology, health, and intervention modes" (p. 769).

Similarly, Ashing-Giwa (2005) called for a transition from the traditional healthrelated QOL framework focused on a predominantly individual centered paradigm to a contextual model inclusive of healthcare system, cultural and socio-ecological domains. According to Ashing-Giwa:

Although the traditional health-related QOL model includes the social domain, it does not adequately incorporate the contextual 
milieu; these contextual dimensions may be more central to health-related QOL outcomes than previously acknowledged. Moreover, the expansion of the traditional health-related framework to include these contextual domains may increase the validity and utility of the health-related QOL framework to assess overall functioning among ethnically and socioeconomically diverse populations of survivors. (p. 298)

To this end, Ashing-Giwa (2005) suggests the addition of four contextual dimensions to the current paradigm of individual domains: demographic context (age and gender), healthcare context (including access to health care, quality of healthcare, and quality of relationship within the healthcare system), social-ecological context (inclusive of socioeconomic status, life burden, and social support), and cultural context (defined by Ashing-Giwa as a way of life, a way to view and behave in the world). The SEWBS developed in this study directly or indirectly addresses the last three dimensions healthcare context, social-ecological context, and cultural context in an effort to make at least one frequently used measure (the FACT-G) responsive to contextual domains.

The findings of this study and the successful development of a validated measure of socioeconomic well-being shown to add value to current domains measured by the FACT-G supports recommendations that socioeconomic factors should be a primary consideration whenever healthcare research is undertaken (Ashing-Giwa, 2005) and addresses the challenge of developing appropriate measures put forth by Oakes and Rossi (2003) and Krieger, Williams, and Moss (1997).

In this study, socioeconomic well-being has proven to be a construct inclusive of multiple factors and not just reflective of purely demographic indicators such as income and years of education. In a society where healthcare costs are astronomical, persons deemed middle or upper class in terms of income and/or education may still be threatened 
by the fear of financial hardship and loss of employment that illness can cause. On the other hand, persons with below poverty income who are covered by Medicaid may feel less financial threat when facing serious illness knowing that costs are covered by their benefits. Persons of any income or educational level may have difficulty navigating the complex healthcare system, and personal accountability for health may vary among educational and income levels. The SEWBS includes items directed at capturing such individual variations which contribute to the composite picture of one's socioeconomic well-being.

Krieger, Williams, and Moss (1997) called for consistent measures of social class (not solely measures of economic resources) and appealed for the inclusion of such measures in all public health data bases. Similarly, Oakes and Rossi (2003) called for new measures of socioeconomic status indicative of the social and economic forces that affect health. Because QOL is such a frequent measure in oncology studies, including a socioeconomic well-being dimension whenever QOL data is collected would be a major step towards the goal of always including comprehensive measures of social class and other important aspects of socioeconomic position.

The FACT-G generic instrument paradigm as conceptualized by Cella and Nowinski (2002) includes four components or dimensions of QOL: physical well-being (disease symptoms, treatment side effects), emotional well-being (coping, distress, and enjoyment), functional well-being (activities of daily living and role performance) and social well-being social activity/support, relationship quality, and family well-being) (Cella \& Nowinski, 2002). This paradigm is illustrated in Figure 3. 


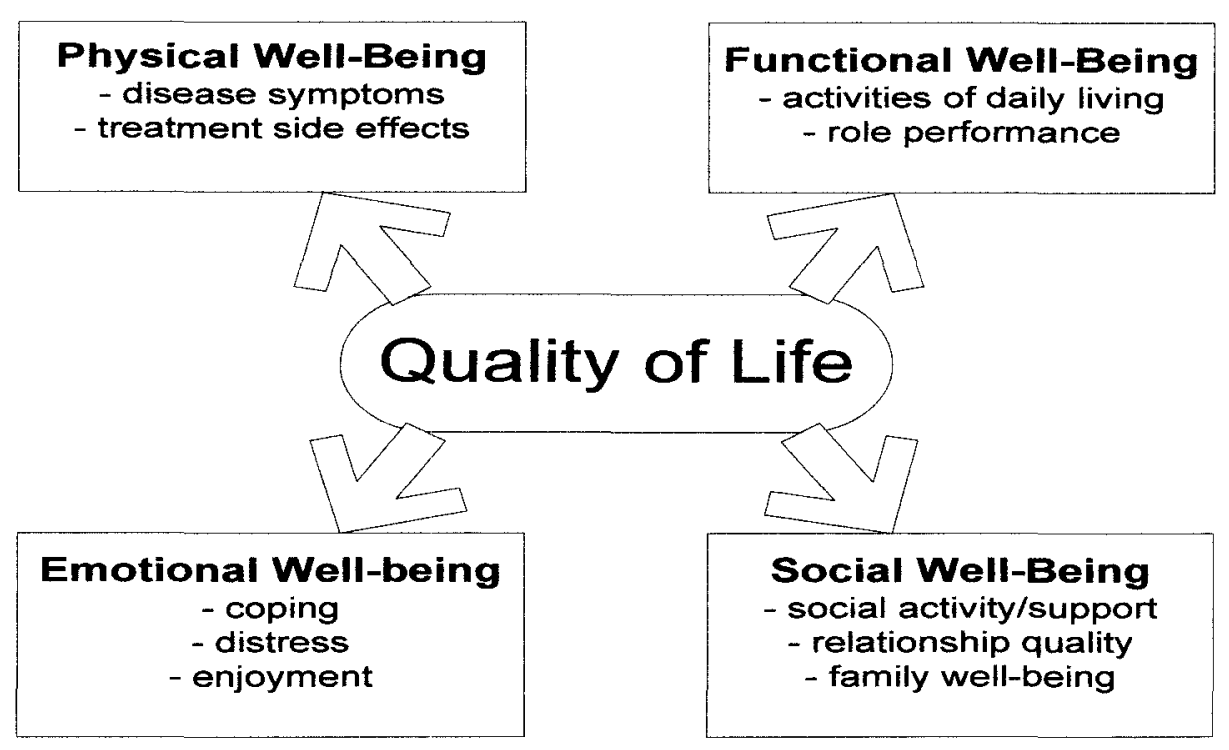

Figure 3. FACT-G Quality of Life dimensions as conceived by Cella and Nowinski (2002)

Note. From "Measuring quality of life in chronic illness: The functional assessment of chronic illness therapy measurement system," by D. Cella and C. Nowinski (2002), Archives of Physical Medicine and Rehabilitation, 83(12), pS13. Adapted with permission of the author, the American Congress of Rehabilitation Medicine and the American Academy of Physical Medicine and Rehabilitation.

This study has demonstrated that the addition of a socioeconomic well-being domain has value, and that the conceptual paradigm of quality of life should be expanded to include a fifth domain, socioeconomic well-being (see Figure 4). 


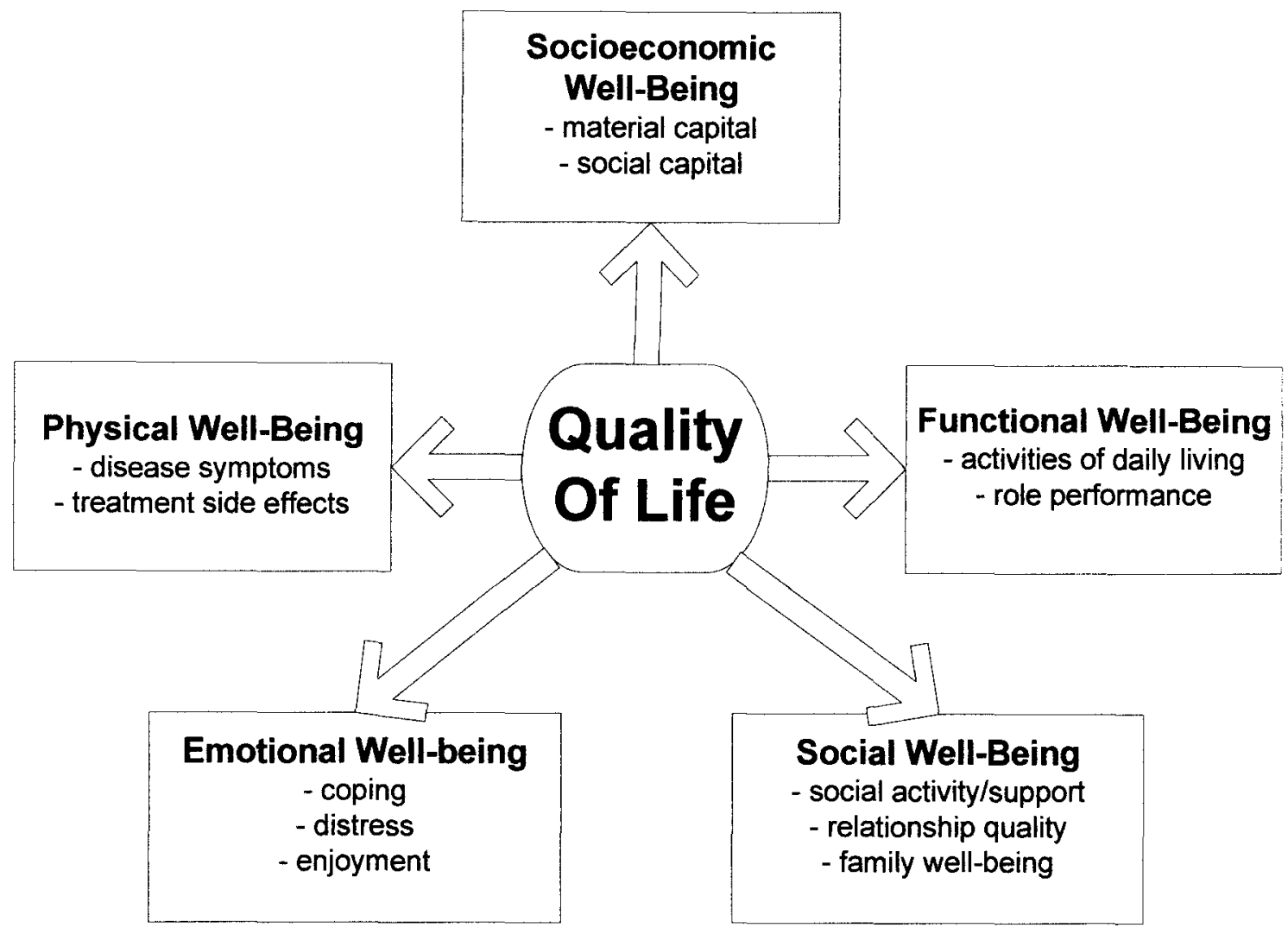

Figure 4. Quality of Life dimensions inclusive of socioeconomic well-being.

\section{Potential Applications for this Scale}

According to Webster, Cella, and Yost (2003), uses for the FACT-G and the related family of instruments encompass three applications: (1) as an evaluation of treatment including treatment administered during Phase I, II and III clinical trials; (2) as an intervention tool in the clinical management of symptoms (both physical and psychological); and (3) as an outcome measure in health practice studies. The newly developed SEWBS shares these potential applications as a useful measure for assessment, intervention, and outcome evaluation. This addition expands the current capabilities of the FACT-G to measure physical and psychological factors by also including the 
socioeconomic issues affecting health-related QOL therefore escalating the FACT-G beyond an individual focus to be inclusive of contextual concerns.

Unfortunately, QOL measurement has not been used to full potential. The vast majority of research studies in oncology include a QOL instrument as part of the outcome measurement plan. Yet, it is very probable that much of the data collected is entered into databases and analyzed without concern for the clinical implications and decision-making impact of the results. Goodwin et al. (2003) found that while QOL data was frequently collected, it seldom impacted treatment decision making. Rationale for including such measures in studies includes knowledge of the patient's values as an adjunct to treatment decision making and consideration of all available information in clinical decision making (Osoba, 1991). Suggested uses for QOL measures in clinical practice have included identifying and prioritizing problems, facilitating communication, and monitoring change (Higginson \& Carr, 2001). Calman (1984) challenged those using QOL measures not only to identify the "gap" between the individual's expectations and experience which he viewed as the essential determinant of QOL, but, once identified, to direct efforts towards narrowing or eliminating the gap and therefore improving the person's QOL.

As discussed in Chapter I, QOL measures have great potential not only for research purposes such as describing populations or measuring the impact of a specific intervention, but also as tools for clinical assessment, care planning and directing appropriate interventions (therapeutic utility). These two purposes have been referred to by some as "psychometric" versus "clinimetric" and some instruments (such as the 
Missoula-VITAS Quality of Life Index) have been proven to be stronger in one arena than the other (Schwartz, Merrimen, Reed, \& Byock, 2005).

While some have dichotomized QOL measures as either research instruments or clinical measures, measures included in a study for one purpose (i.e., describing the population before and after an intervention) could and should be used to full potential. Research data could easily be shared with the clinicians providing direct care as long as the informed consent included such permission. Those providing therapeutic care should know when their patients are undergoing QOL evaluation so that they can use such assessments in care planning and intervention. Asking persons to participate in QOL assessment can cause psychosocial repercussions and raise important issues for the participant; it is unethical to raise the issues without a willingness to address the concurrent concerns.

\section{Implications for Social Work Practice}

The field of QOL measurement has historically been led by medical professionals including physicians, nurses and psychologists and has been focused on individual rather than contextual considerations. Because social workers' unique focus is the constellation of "person in environment" and because social workers have expertise in integrating environmental and social influences in their assessment and related interventions, they can and should contribute to QOL measurement by creating new measures or developing adjunctive tools for existing measures. This dissertation research has been one such effort.

Ethical responsibilities to clients are first and foremost in the ethical standards of the National Association of Social Worker's Code of Ethics (NASW, 1996). Included in 
these responsibilities is the primary responsibility to promote the well-being of clients and a second standard which calls social workers to respect and promote the right of clients to self-determination and to assist clients in their efforts to identify and clarify their goals. This applies equally to social workers in research and clinical arenas. This calls oncology social workers to the following action related to QOL measurement:

1. The oncology social worker should be aware of any client's participation in research and the measures being collected for that research.

2. The oncology social worker should forge partnerships with researchers and other clinicians collecting QOL information on their clients and should encourage sharing of such data for clinical and therapeutic purposes after assuring the patient's informed consent for such access.

3. Social workers involved in research and the collection of QOL indicators have an ethical responsibility to respond to issues and needs identified by respondents when such data is collected.

4. Oncology social workers should consider the utilization of QOL measures as assessment tools to identify and prioritize problems, facilitate communication and shared decision making, and monitor changes and responses to treatment (Higginson \& Carr, 2001).

5. Social work theories can and should be used to guide the development and validation of QOL measures. In fact, social work theories such as the ecological theory of Germain and Gitterman (1996) and related concepts are key to the holistic, contextual approaches which are called for by the literature. 
6. Social workers should promote the use of QOL measures, including measures of socioeconomic well-being, by multidisciplinary teams in oncology settings. Such information is important to the understanding of the whole person response to a cancer diagnosis and related treatment. Such measures supply useful assessment and care planning data and can be used to measure the therapeutic impact of medical and psychosocial interventions.

\section{Future Research}

While this initial effort was successful in supporting the reliability and validity of the SEWBS, more study of the instrument is needed. An effort to recruit more persons with lower educational status and incomes via interviews would enable discriminative analysis between socioeconomic groups. A longitudinal study would enable evaluation of sensitivity of the instrument to change. Recruitment of a sample inclusive of more patients in active treatment with more diverse stages of the disease would also allow for further evaluation of the disease impact on socioeconomic well-being.

The focus of this study was scale development and validation, but the resulting database is rich in other opportunities for analysis including further multivariate analysis, assessment of predictive models for determining QOL, comparison of the performance of the two instruments used to evaluate QOL and their domains, and evaluation of the results of the Subjective Social Status Ladder Rating and its interface with the other measures and demographic variables.

Approximately one-third (33\%) of the respondents reported changes in employment status after the diagnosis of their cancer. The importance of work as an essential component of the quality of life in cancer survivors has been noted in the 
literature (Main, Nowels, Cavender, Etschmaier, \& Steiner, 2005). Because this sample is several years past their cancer diagnoses, the impact on employment is a potential variable affecting their QOL and is worthy of further study.

It is hoped that publication of this study will lead others to test further and utilize the SEWBS as a relevant domain in future studies using the FACT-G.

\section{Concluding Comments}

Social workers have been involved in healthcare since the turn of the $20^{\text {th }}$ century when primary concerns were making healthcare services available to the poor and improving social conditions related to disease (NASW, 2005). In describing the principles guiding social work practice in health care settings, NASW offers this description of the social worker's unique capabilities:

Social workers look at the person-in-environment, including all of the factors that influence the total health care experience. Social workers practice at the macro and micro level of health care and thus have the ability to influence policy change and development at local, state, and federal levels and within systems of care. Social work research in health care benefits not only individual and families, but also the very existence, effectiveness, and validation of the profession. (pp. 8-9)

This dissertation has been the effort of one social worker to affect change in how quality of life is measured by assuring that the person-in-environment and the socioeconomic considerations impacting the healthcare experience are a primary consideration. It is hoped that this effort will contribute to a better understanding of the contextual nature of quality of life, will result in better healthcare for those impacted by socioeconomic issues, will increase awareness of the impact of such factors both on the individual and for society as a whole, and will support the social change necessary to eliminate healthcare disparities in the richest industrial nation in the world. 


\section{REFERENCES}

Aaronson, N. K. (1990). Quality of life assessment in cancer clinical trials. In J. C.

Holland \& R. ZiHoun (Eds.), Psychosocial aspects of oncology (pp.97-113). New York: Springer-Verlag.

Abu-Bader, S. H. (2006). Using statistical methods in social work practice: A complete SPSS guide. Chicago: Lyceum Books.

Alter, J. (2005, Sept. 19). The other America. Newsweek, 146, 42-48.

Alwin, D., \& Wray, L. (2005). A life-span developmental perspective on social status and health. Journals of Gerontology, 60b, 7-14.

American Cancer Society. (1986). Special report on cancer in the economically disadvantaged. Atlanta, GA: American Cancer Society.

American Cancer Society. (1989). Cancer in the poor: A report to the nation. Atlanta, GA: American Cancer Society.

American Cancer Society. (2005). Cancer facts and figures. Atlanta, GA: American Cancer Society.

American Heritage Dictionary of the English Language. (2000). (4th ed.). Boston: Houghton Mifflin.

Ashing-Giwa, K., \& Kagawa-Singer, M. (2006). Infusing culture into oncology research on quality of life. Oncology Nursing Forum, 33(1), 31-36.

Ashing-Giwa, K. T. (2005). The contextual model of HRQoL: A paradigm for expanding the HRQoL framework. Quality of Life Research, 14, 297-307.

Balfour, J. L., \& Kaplan, G. A. (1998). Social class/socioeconomic factors. In J. C. Holland (Ed.), Psycho-oncology (pp. 78-90). New York: Oxford University Press.

Baquet, C., Horn, J., Gibbs, 'T., \& Greenwald, P. (1991). Socioeconomic factors and cancer incidence among blacks and whites. Journal of the National Cancer Institute, 83(8), 551-557. 
Beadle, G. F., Yates, P. M., Najman, J. M., Clavarino, A., Thomson, D., Williams, G. et al. (2004). Illusions in advanced cancer: The effect of belief systems and attitudes on quality of life. Psycho-Oncology, 13, 26-36.

Beauchamp, T. L., \& Childress, J. F. (2001). Principles of biomedical ethics. New York: Oxford University Press.

Berg, J., Ross, R., \& Latourette, H. (1977). Economic status and survival of cancer patients. Cancer, 39(2), 467-477.

Beshow, L., Sandler, R., \& Weinberger, M. (2006). Research recruitment through US central cancer registries: Balancing privacy and scientific issues. American Journal of Public Health, 96(11), 1920-1926.

Bottomley, A. (2002). The cancer patient and quality of life. The Oncologist, 7, 120125.

Brucker, P., Yost, K., Cashy, J., Webster, K., Cella, D. (2005). General population and cancer patient norms for the FACT-General (FACT-G). Evaluation and the Health Profession, 28(2), 192-211.

Bryant, F. B. (2000). Assessing the validity of measurement. In L.G. Grimm \& P.R. Yarnold (Eds.), Reading and understanding more multivariate statistics (pp 99146). Washington, DC: American Psychological Association.

Bryant, F.B., \& Yarnold, P.R. (1995). Principal-component analysis and exploratory and confirmatory factor analysis. In L.G. Grimm \& P.R. Yarnold (Eds.), Reading and understanding multivariate statistics (pp.99-136). Washington, DC: American Psychological Association.

Burdetti, P. P. (2004). 10 years beyond the Health Security Act failure: Subsequent developments and persistent problems. The Journal of the American Medical Association, 292(16), 2000-2006.

Burghardt, S. (1986). Marxist theory and social work. In F. J. Turner (Ed.), Social work treatment: Interlocking theoretical approaches (pp. 590-617). New York: The Free Press.

Calman, K. C. (1984). Quality of life in cancer patients-an hypothesis. Journal of Medical Ethics, 10, 124-127.

Carmines, E. G., \& Zeller, R. A. (1979). Reliability and validity assessment. Newbury Park, CA: Sage.

Carr, A. J., Gibson, B., \& Robinson, P. G. (2001). Is quality of life determined by expectations or experience? British Medical Journal, 322(7296), 1240-1243. 
Carr, A. J., \& Higginson, I. J. (2001). Are quality of life measures patient centred? British Medical Journal, 322(7298), 1357-1360.

Cella, D. (1994). Quality of life: Concepts and definitions. Journal of Pain and Symptom Management, 9, 186-192.

Cella, D. (1998). Quality of life. In J. Holland (Ed.), Psycho-oncology (pp. 1135-1147). New York: Oxford University Press.

Cella, D., Chang, C.-H., Lai, J.-S., \& Webster, K. (2002). Advances in quality of life measurements in oncology patients. Seminars in Oncology, 29(3), 60-68.

Cella, D., \& Nowinski, C. (2002). Measuring quality of life in chronic illness: The functional assessment of chronic illness therapy measurement system. Archives of Physical Medicine and Rehabilitation, 83(12), 10-17.

Cella, D., \& Tulsky, D. (1990). Measuring quality of life today: Methodological aspects. Oncology, 4(5), 29-69.

Cella, D., Tulsky, D., Gray, G., Sarafian, B., Linn, E., Bonomi, A., et al. (1993). The functional assessment of cancer therapy scale: Development and validation of the general measure. Journal of Clinical Oncology, 11(3), 570-579.

Centers for Medicare and Medicaid Services. (2006). Overview of Medicaid and Medicare services. Retrieved March 18, 2006, from http:/www.hhs.gov.

Chambers, D. E., \& Wedel, K. R. (2004). Social policy and social programs: A method for the practical public policy analyst. New York: McMillan.

Children's Defense Fund. (2005, Sept. 19). Portrait of the poor. Newsweek, 146, 46.

Christ, G. (1993). Psychosocial tasks throughout the cancer experience. In N. M. Stearns, M. M. Lauria, J. F. Herman, \& P. R. Fogelberg (Eds.), Oncology social work: A clinician's guide (pp. 79-99). Atlanta, GA: American Cancer Society.

Clavarino, A. M., Najman, J. M., \& Beadle, G. (2003). The impact of will to live and belief in curability on the subjective well-being of patients with advanced cancer. Mortality, 8(1), 3-17.

Clinton, H. R. (2003). Living history. New York: Scribner.

Coleman, J. S. (1990). Foundations of social theory. Cambridge, MA.: Harvard University Press. 
Cooper, L. A., \& Roter, D. L. (2004). Patient-provider communication: The effect of race and ethnicity on process and outcomes of healthcare. In B. D. Smedley, A. Y. Stith, \& A. R. Nelson (Eds.), Unequal treatment: Confronting racial and ethnic disparities in health care (pp.552-593). Washington, DC: National Academies Press.

Detmar, S.B., \& Aaronson, N.K. (1998). Quality of life assessment in daily clinical oncology practice: A feasibility study. European Journal of Cancer, 34(8), 11816.

DeVellis, R. F. (2003). Scale development: Theory and applications. Thousand Oaks, CA: Sage Publications.

Dillman, D.A. (2007). Mail and internet surveys: The tailored design method. New York: John Wiley and Sons.

Donnelly, S. (2000). Quality-of-life assessment in advanced cancer. Current Oncology Reports, 2, 338-342.

Faul, A. C. (1995). Scale development in social work. Unpublished doctoral dissertation, Rand Afrikaans University, Johannesburg, South Africa.

Faul, A. C., \& Van Zyl, M. A. (2004). Constructing and validating a specific multi-item assessment or evaluation tool. In A. R. Roberts \& R. Y. Kenneth (Eds.), Desk reference of evidence based practice in health care and human services (pp.564581). New York: Oxford University Press.

Fayers, P. M., Hand, D. J., Bjordal, K., \& Goenvold, M. (1997). Causal indicators in quality of life research. Quality of Life Research, 6, 393-406.

Ferrans, C. (1985). Psychometric assessment of a quality of life index for hemodialysis patients. Unpublished dissertation, University of Chicago, Chicago.

Ferrans, C., \& Ferrell, B. (1990). Development of a quality of life index for patients with cancer. Oncology Nursing Forum, 17(3, supplement), 15-21.

Ferrans, C., \& Powers, M. (1985). Quality of life index: Development and psychometric properties. Advances in Nursing Science, 8, 15-24.

Ferrell, B. R. (1998). Suffering. In R. M. Carroll-Johnson, L. M. Gorman, \& N. J. Bush (Eds.), Psychosocial nursing care along the cancer continuum (pp. 101-113). Pittsburgh, PA: Oncology Nursing Press.

Freeman, H. (1991). Race, poverty, and cancer. Journal of the National Cancer Institute, 83, 526-527. 
Freeman, H. P. (2004). Poverty, culture, and social injustice: Determinants of cancer disparities. CA: A Cancer Journal for Clinicians, 54(2), 72-77.

Germain, C. B., \& Gitterman, A. (1996). The life model of social work practice: Advances in theory and practice. New York: Columbia University Press.

Gill, T. M., \& Feinstein, A. R. (1994). A critical appraisal of the quality of quality-oflife measurements. Journal of the American Medical Association, 272(8), 619626.

Goodwin, P. J., Black, J. T., Bordeleau, L. J., \& Ganz, P. A. (2003). Health-related quality-of-life measurement in randomized clinical trials in breast cancer-taking stock. Journal of the National Cancer Institute, 95(4), 263-281.

Gorman, L. M. (1998). The psychosocial impact of cancer on the individual, family, and society. In R. M. Carroll-Johnson, L. M. Gorman, \& N. J. Bush (Eds.), Psychosocial nursing care along the cancer continuum (pp. 3-25). Pittsburgh, PA: Oncology Nursing Press, Inc.

Gornick, M. E. (1999). The association of race/socioeconomic status and use of Medicare services: A little known failure in access to care. Annals of the New York Academy of Sciences, 896, 497-500.

Grant, M., Padilla, G., Ferrell, B., \& Rhiner, M. (1990). Assessment of quality of life with a single instrument. Seminars in Oncology Nursing, 6(4), 260-270.

Guidry, J. J., Torrence, W., \& Herbelin, S. (2005). Closing the divide: Diverse populations and cancer survivorship. Paper presented at the Survivorship: Resilience Across the Lifespan, Washington, DC.

Guyatt, G. H., Feeny, D. H., \& Patrick, D. (1993). Measuring health-related quality of life. Annals of Internal Medicine, 118(8), 622-629.

Haase, J. E., \& Braden, C. J. (2003). Conceptualization and measurement of quality of life and related concepts: Guidelines for clarity. In C. R. King \& P. S. Hinds (Eds.), Quality of life from nursing and patient perspectives: Theory, research, practice (pp.65-92). Boston: Jones and Bartlett.

Higginson, I., \& Carr, A. (2001). Using quality of life measures in the clinical setting. British Medical Journal, 322, 1297-1300.

Holzner, B., Kemmler, G., Sperner-Unterweger, B., Kipp, M., Dunser, M., Margreiter, R., et al. (2001). Quality of life measurement in oncology - a matter of the assessment instrument? European Journal of Cancer, 37, 2349-2356. 
House, J., Lantz, P., \& Herd, P. (2005). Continuity and change in the social stratification of aging and health over the life course: Evidence from a nationally representative longitudinal study from 1986 to 2001/2002 (American's changing lives study). Journals of Gerontology, 60B, 15-26.

Hudson, W. W. (1991). The MPSI technical manual. Tempe, AZ: WALMYR.

Hudson, W. W. (1994, March). Developing short-form assessment scales. Paper presented at the annual meeting of the Council of Social Work Education, Atlanta, GA.

Hudson, W. W., \& Pike, C.K. (1995, March). Reliability and measurement error in the presence of homogeneity. Paper presented at the annual meeting of the Council on Social Work Education, San Diego, CA.

Iceland, J. (2003). Poverty in America. Los Angeles: University of California Press.

Institute of Medicine. (1999). The unequal burden of cancer: An assessment of NIH research and programs for ethnic minorities and the medically underserved. Washington, DC: National Academy Press.

Institute of Medicine. (2002). Care without coverage: Too little, too late. Washington, DC: National Academy Press.

Institute of Medicine. (2003). Unequal treatment: Confronting racial and ethnic disparities in health care. Washington, DC: National Academies Press.

Jacobson, S. (1988). Evaluating instruments for use in clinical nursing research. In M. Frank-Stromborg (Ed.), Instruments for clinical nursing research (pp 3-19). Norwalk, CT: Appleton-Lange.

Jemal, A., Murray, T., Ward, E., Samuels, A., Tiwari, R., Ghafoor, A., et al. (2005). Cancer statistics, 2005. CA: A Cancer Journal for Clinicians, 55(1), 10-30.

Jemal, A., Siegel, R., Ward, E., Murray, T., Xu, J., Smigal, C., \& Thun, M. (2006). Cancer statistics, 2006. CA: A Cancer Journal for Clinicians, 56(2), 106-130.

Jenkins, C. (1983). Social environment and cancer mortality in men. New England Journal of Medicine, 308(7), 395-398.

Karger, H. J., \& Stoesz, D. (1998). American social welfare policy. New York: Longman.

Keynes, J. M. (1933). The means to prosperity. New York: Harcourt, Brace. 
King, C. R. (2006). Advances in how clinical nurses can evaluate and improve quality of life for individuals with cancer. Oncology Nursing Forum, 33(1), 5-12.

Kirshner, B., \& Guyatt, G. (1985). A methodologic framework for assessing health indices. Journal of Chronic Disease, 38, 27-36.

Krieger, N., Williams, D., \& Moss, N. (1997). Measuring social class in public health research: Concepts, methodologies, and guidelines. Annual Review of Public Health, 18, 341-378.

Kutner, J., Nowels, D., Kassner, C., Houser, J., Bryant, L., \& Main, D. (2003). Confirmation of the "disability paradox" among hospice patients: Preservation of quality of life despite physical ailments and psychosocial concerns. Palliative and Supportive Care, 1, 231-237.

Lantz, P., Lynch, J., House, J., Lepkowski, J., Mero, R., Musick, M., \& Williams, D. (2001). Socioeconomic disparities in health change in a longitudinal study of US adults: The role of health-risk behaviors. Social Science and Medicine, 53, 29-40.

Lauria, M. M., Clark, E. J., Hermann, J. F., \& Stearns, N. M. (2001). Social work in oncology: Supporting survivors, families, and caregivers. Atlanta, GA: American Cancer Society..

Lent, L., Hahn, E., Eremenco, S., Webster, K., \& Cella, D. (1999). Using cross-cultural input to adapt the functional assessment of chronic illness therapy (FACIT) scales. Acta Oncologica, 38(6), 695-702.

Leplege, A., \& Hunt, S. (1997). The problem of quality of life in medicine. Journal of the American Medical Association, 278(1), 47-50.

Lewis, O. (1966). The culture of poverty. Scientific America, 215(4), 19-25.

Lewis, O. (1969). The culture of poverty. In D. Moynihan (Ed.), On understanding poverty: Perspectives from the social sciences (pp. 187-200). New York: Basic Books.

Liao, Y., McGee, D., Kaufman, J., Cao, G., \& Cooper, R. (1999). Socioeconomic status and morbidity in the last years of life. American Journal of Public Health, 89(4), 569-572.

Licht, M. (1995). Multiple regression and correlation. In L. Grimm \& P. Yarnold (Eds.), Reading and understanding multivariate statistics (pp. 19- 64). Washington, DC: American Psychological Association.

Lillie-Blanton, M., \& Laveist, T. (1996). Race/ethnicity, the social environment, and health. Social Science and Medicine, 43(1), 83-91. 
Linder, J. (2004). Oncology. In J. Berzoff \& P. Silverman (Eds.), Living with dying: A handbook for end-of-life healthcare practitioners (pp. 696-722). New York: Columbia University Press.

Lipworth, L., Abelin, T., \& Conelly, R. (1970). Socio-economic factors in the prognosis of cancer patients. Journal of Chronic Disease, 23(2), 105-116.

Lynch, J., \& Kaplan, G. (2000). Socioeconomic position. In L. F. Berkman \& I. Kawachi (Eds.), Social epidemiology (pp.13-35). New York: Oxford University Press.

Mackenbach, J. P., \& Kunst, A. E. (1997). Measuring the magnitude of socio-economic inequalities in health: An overview of available measures illustrated with two examples from Europe. Social Science and Medicine, 44, 757-771.

Main, D. S., Nowels, C. T., Cavender, T. A., Etschmaier, M., \& Steiner, J. F. (2005). A qualitative study of work and work return in cancer survivors. Psycho-Oncology, 14, 992-1004.

Mandelblatt, J. S., Yabroff, K. R., \& Kerner, J. F. (1999). Equitable access to cancer services: A review of barriers to quality care. Cancer, 86(11), 2378-2390.

Marx, K., \& Engels, F. (1845/1956). The holy family. Moscow: Foreign Language.

Mechanic, D. (1974). Social structure and personal adaptation: Some neglected dimensions. In G.V. Coelho, D.A. Hamburg, \& J. E. Adams (Eds.), Coping and adaptation (pp. 32-44). New York: Basic Books.

McMillan, S. C. (1996). Quality-of-life assessment in palliative care [Electronic version]. Cancer Control Journal of the Moffitt Cancer Center, 3(3).

McWhorter, W., Schatzkin, A., Horn, J., \& Brown, C. (1989). Contribution of socioeconomic status to black/white differences in cancer incidence. Cancer, 63(5), 982-987.

Mongan, J. J., \& Lee, T. H. (2005). Do we really want broad access to health care? The New England Journal of Medicine, 352(12), 1260-1263.

Morris, J., Perez, D., \& McNoe, B. (1998). The use of quality of life data in clinical practice. Quality of Life Research, 7, 85-91.

Muldoon, M. F., Barger, S. D., Flory, J. D., \& Manuck, S. B. (1998). What are quality of life measurements measuring? British Medical Journal, 316(7139), 542-545. 
National Association of Social Workers. (2005). NASW standards for social work practice in health care settings. Washington, DC: NASW.

National Association of Social Workers. (1996). Code of ethics. Washington, DC: National Association of Social Workers.

National Comprehensive Cancer Network. (1999). Practice guidelines for the management of psychosocial distress. Oncology, 13(5A), 113-147.

Netemeyer, R. G., Bearden, W. O., \& Sharma, S. (2003). Scaling procedures: Issues and applications. Thousand Oaks, CA: Sage.

Nunnally, J. C., \& Bernstein, I. H. (Eds.). (1994). Psychometric theory (3rd ed.). New York: McGraw-Hill.

Nurius, P. S., \& Hudson, W. W. (1993). Human services practice, evaluation, and computers: A practical guide for today and beyond. Pacific Grove, CA: Brooks/Cole.

Oakes, J. M., \& Rossi, P. H. (2003). The measurement of SES in health research: Current practice and steps toward a new approach. Social Science and Medicine, $56,769-784$.

Osoba, D. (1991). Measuring the effect of cancer on quality of life. In D. Osoba (Ed.), Effect of cancer on quality of life (pp. 25-40). Boston: CRC Press.

Overcash, J., Extermann, M., Parr, J., Perry, J., \& Balducci, L. (2001). Validity and reliability of the FACT-G Scale for use in the older person with cancer. American Journal of Clinical Oncology, 24(6), 591-596.

Pearson, L. (2003). Understanding the culture of poverty. The Nurse Practitioner, $28(4), 6$.

Pinquart, M., \& Sorensen, S. (2000). Influences of socioeconomic status, social network, and competence on subjective well-being in later life: A meta-analysis. Psychology and Aging, 15, 187-224.

Rainwater, L. (1969). The problem of lower-class culture. In D. P. Moynihan (Ed.), On understanding poverty: Perspectives from the social sciences (pp.229-259). New York: Basic Books.

Ries L., Harkins, D., Krapcho, M., Mariotto, A., Miller, B. A., Feuer, E. J., Clegg, L., Eisner, M. P., Horner, M. J,, Howlader, N., Hayat, M., Hankey, B. F., Edwards, B. K. (Eds). (2006). SEER Cancer Statistics Review, 1975-2003. National Cancer Institute: Bethesda, MD. 
Rimpela, A., \& Pukkala, E. (1987). Cancers of affluence: Positive social class gradient and rising incidence trend in some cancer forms. Social Science and Medicine, 24(7), 601-606.

Ritzer, G. (2000). Modern sociological theory. Boston: McGraw-Hill.

Rodary, C., Pezet-Langevin, V., Garcia-Acosta, S., Lesimple, T., Lortholary, A., Kaminsky, M. C., et al. (2004). Patient preference for either the EORTC QLQC30 or the FACIT quality of life (QOL) measures: A study performed in patients suffering from carcinoma of an unknown primary site (CUP). European Journal of Cancer, 40, 521-528.

Roetzheim, R. G., Gonzalez, E. C., Ferrante, J. M., Pal, N., Van Durme, D. J., \& Krischer, J. P. (2000). Effects of health insurance and race on breast carcinoma treatments and outcomes. Cancer, 89(11), 2202-2213.

Roetzheim, R. G., Pal, N., Gonzalez, E., Ferrante, J. M., Van Durme, D. J., \& Krischer, J. P. (2000). Effects of health insurance and race on colorectal cancer treatments and outcomes. American Journal of Public Health, 90(11), 1746-1754.

Roetzheim, R. G., Pal, N., Tennant, C., Voti, L., Aranian, J. Z., Schwabe, A., et al. (1999). Effects of health insurance and race on early detection of cancer. Journal of the National Cancer Institute, 91(16), 1409-1415.

Schultz, A., \& Winstead-Fry, P. (2001). Predictors of quality of life in rural patients with cancer. Cancer Nursing, 24(1), 12-19.

Schwartz, C. E., Merriman, M. P., Reed, G., \& Byock, I. (2005). Evaluation of the Missoula-VITAS Quality of Life Index-revised: Research tool or clinical tool? Journal of Pallative Medicine, 8(1), 121-135.

Shipler, D. K. (2004). The working poor: Invisible in America. New York: Alfred A. Knopf.

Silveira, M. J., Kabeto, M. U., \& Langa, K. M. (2005). Net worth predicts symptom burden at the end of life. Journal of Palliative Medicine, 8(4), 827-835.

Singh-Manoux, R., Adler, N. E., \& Marmot, M. G. (2003). Subjective social status: Its determinants and its association with measures of ill-health in the Whitehall study. Social Science and Medicine, 56(6), 1321-1333.

Singleton, R. A., \& Straits, B. C. (1999). Approaches to social research. New York: Oxford University Press.

Spector, P. E. (1992). Summated rating scale construction: An introduction. Newbury Park, CA: Sage. 
Spilker, B. (1996). Quality of life and pharmacoeconomics in clinical trials (2nd ed.). Philadelphia: Lippincott-Raven.

Springer, D. W., Abell, N., \& Hudson, W. W. (2002). Creating and validating rapid assessment instruments for practice and research: Part 1. Research on Social Work Practice, 12(3), 408-439.

SPSS. (2005). Statistical program for the social sciences (Version 14) [Computer software]. Chicago: SPSS.

Subcommittee on the Economically Disadvantaged. (1985). Special report on cancer in the economically disadvantaged. New York: American Cancer Society.

Tanaka, T., \& Gotay, C. (1998). Physicians' and medical students' perspectives on patients' quality of life. Academic Medicine, 73, 1003-1005.

Terkelson, K. G. (1980). Towards a theory of the family life cycle. In E. A. Carter \& M. McGoldrick (Eds.), The family life cycle: A framework for family therapy (pp. 21-52). New York: Gardner.

Thorpe, K. E. (2004). Election 2004: Protecting the uninsured. The New England Journal of Medicine, 351(15), 1479-1481.

Underwood, S. M., \& Hoskins, D. (1994). Increasing nursing involvement in cancer prevention and control among the economically disadvantaged: The nursing challenge. Seminars in Oncology Nursing, 10(2), 89-95.

U.S. Census Bureau. (2007). Fact sheet: Louisville, Kentucky. American Fact Finder. Retrieved 01/15/2007 from http://factfinder.census.gov.

Vallerand, A., \& Payne, J. (2003). Theories and conceptual models to guide quality of life related research. In C. King \& P. Hinds (Eds.), Quality of life from nursing and patient perspectives (pp. 45-64). Boston: Jones and Bartlett.

Varricchio, C. G. (2006). Measurement issues in quality-of-life assessments. Oncology Nursing Forum, 33(1), 13-21.

Waldron, D., O'Boyle, C., Kearney, M., Moriarty, M., \& Carney, D. (1999). Quality-oflife measurement in advanced cancer: Assessing the individual. Journal of Clinical Oncology, 17(11), 3603-3611.

Ward, E., Jemal, A., Cokkinides, V., Singh, G. K., Cardinez, C., Ghafoor, A., et al. (2004). Cancer disparities by race/ethnicity and socioeconomic status. $C A: A$ Cancer Journal for Clinicians, 54(2), 78-93. 
Warner, W. L., Meeker, M., \& Eells, K. (1960). Social class in America: The evaluation of status. New York: Harper and Row.

Warren, B., \& Sydenstricker, E. (1916). Health of garment workers: The relation of economic status to health. Public Health Report, 31, 1298-1305.

Weber, M. (1958). Class, status, party. In H. H. Gerth \& C. W. Mills (Eds.), Max Weber: Essays in sociology (pp. 180-195). New York: Routledge and Kegan Paul.

Webster, K., Cella, D., \& Yost, K. (2003). The functional assessment of chronic illness therapy (FACIT) measurement system: Properties, applications, and interpretation. Health and Quality of Life Outcomes, 1(79), 1-7.

Webster, K., Odom, L., Peterman, A., Lent, L., \& Cella, D. (1999). The functional assessment of chronic illness therapy (FACIT) measurement system: Validation of version 4 of the core questionnaire. Quality of Life Research, 8(7), 604.

Wells, N. L., \& Turney, M. E. (2001). Common issues facing adults with cancer. In M. M. Lauria, E. J. Clark, J. F. Hermann, \& N. M. Stearns (Eds.), Social work in oncology (pp. 27-43). Atlanta, GA: American Cancer Society.

World Health Organization Quality of Life Group. (1993). Study protocol for the World Health Organization project to develop a quality of life assessment instrument. Quality of Life Research, 2, 153-159.

Wilkes, G., Freeman, H., \& Prout, M. (1994). Cancer and poverty: Breaking the cycle. Seminars in Oncology Nursing, 10(2), 79-88.

Winstead-Fry, P., \& Schultz, A. (1997). Psychometric analysis of the functional assessment of cancer therapy-general (FACT-G) scale in a rural sample. Cancer, 79(12), 2446-2452.

Wohlfarth, T. (1997). Socioeconomic inequality and psychopathology: Are socioeconomic status and social class interchangeable? Social Science and Medicine, 45(3), 399-410. 


\section{APPENDIX A}

\section{VALIDATION PACKET}

\section{The Impact of Socioeconomic Well-Being on Health-Related Quality of Life}

$7 / 01 / 2006$

Dear Potential Participant:

You are being invited to take part in a research study by answering the attached questionnaire and surveys about socioeconomic well-being and health-related quality of life. There are no known risks for your participation in this research study. The information collected may not benefit you directly. The information learned in this study may be helpful to others. The information you provide will be used to determine if socioeconomic well-being is an important factor in the quality of life of people who have been diagnosed with cancer. It will also be used to develop a tool to measure socioeconomic well-being or how people feel about their financial situation and position in life and how that impacts their health. Your completed survey will be stored at the University of Louisville, Kent School of Social Work. The survey will take approximately 30 minutes to complete.

You are receiving this mailing because you are listed on the Tumor Registry, a list of people who have been diagnosed with cancer. It is hoped that this study will help in understanding the needs and feelings related to quality of life for people who have or have had cancer.

Individuals from the Department of Social Work, the Institutional Review Board (IRB), the Human Subjects Protection Program Office (HSPPO), and other regulatory agencies may inspect the returned questionnaires and surveys. In all other respects, however, the data will be held in confidence to the extent permitted by law. Should the data be published, your identity will not be disclosed. Your name will not be attached to your completed questionnaire and surveys. Once you return them, there will be no way to connect the information you provide directly to you.

Included in this mailing is an addressed, stamped envelop for you to use in returning your completed surveys and questionnaire. You do not need to put your return address or any other identifying information on the envelop or on your surveys and questionnaire.

Taking part in this study is voluntary. By completing this survey you agree to take part in this research study. You do not have to answer any questions that make you uncomfortable. You may choose not to take part at all. If you decide to be in this study 
you may stop taking part at any time. If you decide not to be in this study or if you stop taking part at any time, you will not lose any benefits for which you may qualify.

If you have any questions, concerns, or complaints about the research study, please contact Dr. Annatje Faul at 502 852-1981or Barbara Head at 502 727-4590.

If you have any questions about your rights as a research subject, you may call the Human Subjects Protection Program Office at (502) 852-5188. You can discuss any questions about your rights as a research subject, in private, with a member of the Institutional Review Board (IRB). You may also call this number if you have other questions about the research, and you cannot reach the study doctor, or want to talk to someone else. The IRB is an independent committee made up of people from the University community, staff of the institutions, as well as people from the community not connected with these institutions. The IRB has reviewed this research study.

If you have concerns or complaints about the research or research staff and you do not wish to give your name, you may call 1-877-852-1167. This is a 24 hour hot line answered by people who do not work at the University of Louisville.

Sincerely,

Annatje Faul, $\mathrm{PhD}$

Investigator
Barbara Head, RN, CHPN, ACSW

Co-Investigator 


\section{Demographic Questionnaire}

Please put an $X$ in the box that reflects your answer. Please only mark $O N E$ box per statement.

How old are you? years

Gender Male $\lfloor$ (1) Female $\lceil(2)$

Race: Caucasian (White)

African-American

Hispanic

Asian

Other

What is your occupation?

What is your family's monthly income (include pay checks, Social Security, pensions, and any government assistance): dollars

How many years of education have you completed? (start with first grade and include years of college or special training) years

\section{Marital Status:}

Single, never married

Single, divorced

Single, living $\mathrm{w} /$ partner

Married

Remarried

Widowed

Widowed, remarried

Other

$\square(8)$

What type(s) of insurance do you have?

Medicare

Medicaid or Passport

Private

HMO/PPO

None 


\section{to having cancer?}

Employed full-time

Employed full-time

Employed part-time

Employed part-time

Homemaker

Homemaker

Retired

$\square$ (4)

Retired

Student

Student

Unemployed

Unemployed

Disabled

Disabled

Other

Other

Do you have any special skills or training? Yes $\square \quad$ No $\square$ If so, please describe:

Do you consider the neighborhood you live in now to be:

Wealthy or rich?

Middle income?

Poor?

Do you consider the family you grew up in to be:

Wealthy or rich?

Middle class?

Poor?

Do you have any children?

Yes

No

If YES, how many?

What is your current living situation? Check ALL that apply.

$\square \quad$ Live alone

ए] Live with spouse/partner

$\square$ Live with children/grandchildren under the age of 18

$\square \quad$ Live with adult children 
Live with parents

Live with other family members

Live with friends

$\square$ Other

What is the total number of people living in your household, including yourself?

Are you the main money earner in your household? Yes $\square \quad$ No

If not, who in your household earns the most?

My husband or wife $\square \quad$ My parent $\square \quad$ My child $\square$

Other:

No one in my household works

Do you own a car? Yes $\square$ No

Do you own a house? Yes $\square \quad$ No $\square$

What kind of cancer do you (or did you) have?

How long have you known you have cancer?

Is your cancer:

Early stage

Locally advanced

Spread to lymph nodes

Spread to another part of the body

Don't know

[1] (5)

Are you getting treatment for your cancer now? Yes $\square \quad$ No $\square$

If you are getting treatment, check the types of treatment you are getting:

$\square \quad$ chemotherapy

$\square$ radiation

$\square$ hormone treatment

$\square$ other 
Below is a list of statements that other people with your illness have said are important. By circling one (1) number per line, please indicate how true each statement has been for you during the past 7 days.

\section{PHYSICAL WELL-BEING}

I have a lack of energy.

I have nausea.

Because of my physical condition, I have trouble meeting the needs of my family.

I have pain

I am bothered by side effects of treatment.

I feel ill

I am forced to spend time in bed

\section{SOCIAL/FAMILY WELL-BEING}

I feel close to my friends

I get emotional support from my family

I get support from my friends

My family has accepted my illness.

I am satisfied with family communication about my illness

I feel close to my partner (or the person who is my main support)

Regardless of your current level of sexual activity, please answer the following question. If you prefer not to answer it. pleuse check this box and go to the next section.

$\begin{array}{cccc}\text { Not A little } & \text { Some- } & \text { Quite } & \text { Very } \\ \text { at all bit what a bit much }\end{array}$

$\begin{array}{lllll}0 & 1 & 2 & 3 & 4 \\ 0 & 1 & 2 & 3 & 4\end{array}$

I am satisfied with my sex life.

Not A little Some- Quite Very
at all bit

$\begin{array}{lllll}0 & 1 & 2 & 3 & 4 \\ 0 & 1 & 2 & 3 & 4 \\ 0 & 1 & 2 & 3 & 4 \\ 0 & 1 & 2 & 3 & 4 \\ 0 & 1 & 2 & 3 & 4 \\ 0 & 1 & 2 & 3 & 4\end{array}$




\section{FACT-G (Version 4)}

By circling one (1) number per line, please indicate how true each statement has been for you during the past 7 days.

\section{EMOTIONAL WELL-BEING}

I feel sad

I am satisfied with how I am coping with my illness

I am losing hope in the fight against my illness

I feel nervous

I worry about dying

I worry that my condition will get worse

Not A little Some- Quite Very
at all bit what a bit much

$\begin{array}{lllll}0 & 1 & 2 & 3 & 4\end{array}$

$\begin{array}{lllll}0 & 1 & 2 & 3 & 4\end{array}$

$\begin{array}{lllll}0 & 1 & 2 & 3 & 4\end{array}$

$\begin{array}{lllll}0 & 1 & 2 & 3 & 4\end{array}$

$\begin{array}{lllll}0 & 1 & 2 & 3 & 4\end{array}$

$\begin{array}{lllll}0 & 1 & 2 & 3 & 4\end{array}$

\section{FUNCTIONAL WELL-BEING}

Not A little Some- Quite Very
at all bit what a bit much

I am able to work (include work at home)

My work (include work at home) is fulfilling

I am able to enjoy life

I have accepted my illness

I am sleeping well.

I am enjoying the things I usually do for fun.

I am content with the quality of my life right now

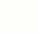

at all bit

0

(3)

0

0

0

0

0

0

$\begin{array}{lccc}1 & 2 & 3 & 4 \\ 1 & 2 & 3 & 4 \\ 1 & 2 & 3 & 4 \\ 1 & 2 & 3 & 4 \\ 1 & 2 & 3 & 4 \\ 1 & 2 & 3 & 4 \\ 1 & 2 & 3 & 4\end{array}$


By circling one (1) number per line, please indicate how true each statement has been for you during the past 7 days.

\section{SOCIOECONOMIC WELL-BEING}

I know how to take care of my health.

$$
\text { at }
$$

I believe that being sick will hurt me financially.

People like me are able to get the healthcare they need.

I am able to make enough money to pay for my healtheare.

I have to pay more for my medical care than I can afford.

Ilive in a healthy neighborhood.

I do my best to take care of my body.

I am able to pay my medical bills.

I can easily get information about healthcare.

I have always taken good care of myself.

I can afford medical check-ups even when I am not sick.

My doctors treat me with respect.

I have enough money to take care of my healthcare needs.

I can get the hoalth insurance I need.

My family thinks good healthcare is important.

I know how to get the healthcare services I need.

I know people who will help me out when I am sick.

People I know best have healthy habits

1 understand the healthcare system.

The medicine I need is too expensive for me.

I am treated the same as other patients when I go for medical care.

I want to get the best healthcare possible

Healthcare services are easy to get in my neighborhood.

\begin{tabular}{|c|c|c|c|c|}
\hline $\begin{array}{l}\text { Not } \\
\text { at all }\end{array}$ & $\begin{array}{c}\text { A little } \\
\text { bir }\end{array}$ & $\begin{array}{l}\text { Some- } \\
\text { what }\end{array}$ & $\begin{array}{l}\text { Quite } \\
\text { A bit }\end{array}$ & $\begin{array}{l}\text { Very } \\
\text { much }\end{array}$ \\
\hline 0 & 1 & 2 & 3 & 4 \\
\hline 0 & 1 & 2 & 3 & 4 \\
\hline 0 & 1 & 2 & 3 & 4 \\
\hline 0 & 1 & 2 & 3 & 4 \\
\hline 0 & 1 & 2 & 3 & 4 \\
\hline 0 & 1 & 2 & 3 & 4 \\
\hline 0 & 1 & 2 & 3 & 4 \\
\hline 0 & 1 & 2 & 3 & 4 \\
\hline 0 & 1 & 2 & 3 & 4 \\
\hline 0 & 1 & 2 & 3 & 4 \\
\hline 0 & 1 & 2 & 3 & 4 \\
\hline 0 & 1 & 2 & 3 & 4 \\
\hline 0 & 1 & 2 & 3 & 4 \\
\hline 0 & 1 & 2 & 3 & 4 \\
\hline 0 & 1 & 2 & 3 & 4 \\
\hline 0 & 1 & 2 & 3 & 4 \\
\hline 0 & 1 & 2 & 3 & 4 \\
\hline 0 & 1 & 2 & 3 & 4 \\
\hline 0 & 1 & 2 & 3 & 4 \\
\hline 0 & 1 & 2 & 3 & 4 \\
\hline 0 & 1 & 2 & 3 & 4 \\
\hline 0 & 1 & 2 & 3 & 4 \\
\hline 0 & 1 & 2 & 3 & 4 \\
\hline
\end{tabular}


Subjective Social Status ${ }^{1}$

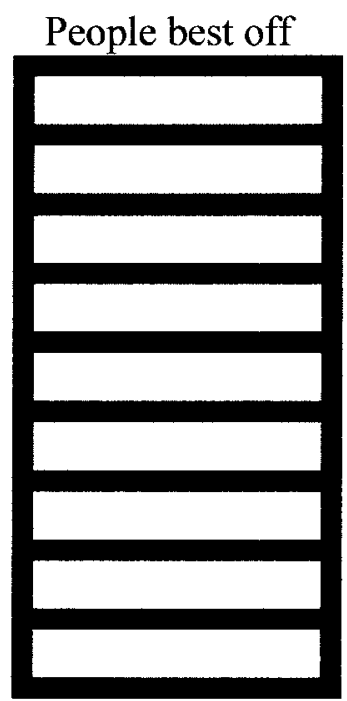

People worst off

Think of this ladder as representing where people stand in society. At the top of the ladder are the people who are best off-those who have the most money, most education and the best jobs. At the bottom ware the people who are worst off-who have the least money, least education and the worst jobs or no job. The higher up you are on this ladder, the closer you are to people at the very top and the lower you are, the closer you are to the bottom. Where would you put yourself on the ladder? Please place a large $X$ on the rung where you think you stand.

1 A. Singh-Manoux, N. E. Adler, \& M. G. Marmot. (2003). Subjective social status: Its determinants and its association with measures of ill-health in the Whitehall II Study, Social Science \& Medicine, 1333. 


\section{Ferrans and Powers \\ QUALITY OF LIFE INDEX \\ CANCER VERSION - III}

PART 1. For each of the following, please choose the answer that best describes how satisfied you are with that area of your life. Please mark your answer by circling the number. There are no right or wrong answers.

HOW SATISFIED ARE YOU WITH:

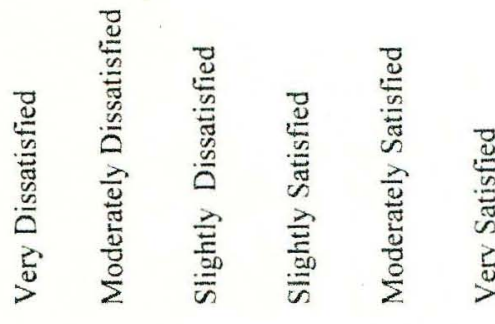

\begin{tabular}{|c|c|c|c|c|c|c|}
\hline 1. Your health? & 1 & 2 & 3 & 4 & 5 & 6 \\
\hline 2. Your health care? & 1 & 2 & 3 & 4 & 5 & 6 \\
\hline 3. The amount of pain that you have? & 1 & 2 & 3 & 4 & 5 & 6 \\
\hline 4. The amount of energy you have for everyday activities? & 1 & 2 & 3 & 4 & 5 & 6 \\
\hline 5. Your ability to take care of yourself without help? & 1 & 2 & 3 & 4 & 5 & 6 \\
\hline 6. The amount of control you have over your life? & 1 & 2 & 3 & 4 & 5 & 6 \\
\hline 7. Your chances of living as long as you would like? & 1 & 2 & 3 & 4 & 5 & 6 \\
\hline 8. Your family's health? & 1 & 2 & 3 & 4 & 5 & 6 \\
\hline 9. Your children? & 1 & 2 & 3 & 4 & 5 & 6 \\
\hline 10. Your family's happiness? & 1 & 2 & 3 & 4 & 5 & 6 \\
\hline 11. Your sex life? & 1 & 2 & 3 & 4 & 5 & 6 \\
\hline 12. Your spouse, lover, or partner? & 1 & 2 & 3 & 4 & 5 & 6 \\
\hline 13. Your friends? & 1 & 2 & 3 & 4 & 5 & 6 \\
\hline 14. The emotional support you get from your family? & 1 & 2 & 3 & 4 & 5 & 6 \\
\hline $\begin{array}{l}\text { 15. The emotional support you get from people other } \\
\text { than your family? }\end{array}$ & 1 & 2 & 3 & 4 & 5 & 6 \\
\hline
\end{tabular}

(Please Go To Next Page)

(c) Copyright 1984 \& 1998 Carol Estwing Ferrans and Marjorie J. Powers

Page 1 
HOW SATISFIED ARE YOU WITH:

\begin{tabular}{|c|c|c|c|c|c|c|}
\hline 16. Your ability to take care of family responsibilities? & 1 & 2 & 3 & 4 & 5 & 6 \\
\hline 17. How useful you are to others? & 1 & 2 & 3 & 4 & 5 & 6 \\
\hline 18. The amount of worries in your life? & 1 & 2 & 3 & 4 & 5 & 6 \\
\hline 19. Your neighborhood? & 1 & 2 & 3 & 4 & 5 & 6 \\
\hline 20. Your home, apartment, or place where you live? & 1 & 2 & 3 & 4 & 5 & 6 \\
\hline 21. Your job (if employed)? & 1 & 2 & 3 & 4 & 5 & 6 \\
\hline 22. Not having a job (if unemployed, retired, or disabled)? & 1 & 2 & 3 & 4 & 5 & 6 \\
\hline 23. Your education? & 1 & 2 & 3 & 4 & 5 & 6 \\
\hline 24. How well you can take care of your financial needs? & 1 & 2 & 3 & 4 & 5 & 6 \\
\hline 25. The things you do for fun? & 1 & 2 & 3 & 4 & 5 & 6 \\
\hline 26. Your chances for a happy future? & 1 & 2 & 3 & 4 & 5 & 6 \\
\hline 27. Your peace of mind? & 1 & 2 & 3 & 4 & 5 & 6 \\
\hline 28. Your faith in God? & 1 & 2 & 3 & 4 & 5 & 6 \\
\hline 29. Your achievement of personal goals? & 1 & 2 & 3 & 4 & 5 & 6 \\
\hline 30. Your happiness in general? & 1 & 2 & 3 & 4 & 5 & 6 \\
\hline 31. Your life in general? & 1 & 2 & 3 & 4 & 5 & 6 \\
\hline 32. Your personal appearance? & 1 & 2 & 3 & 4 & 5 & 6 \\
\hline 33. Yourself in general? & 1 & 2 & 3 & 4 & 5 & 6 \\
\hline
\end{tabular}

(Please Go To Next Page)

(c) Copyright 1984\& 1998 Carol Estwing Ferrans and Marjorie J. Powers 
PART 2. For each of the following, please choose the answer that best describes how important that area of your life is to you. Please mark your answer by circling the number. There are no right or wrong answers.

HOW IMPORTANT TO YOU IS:

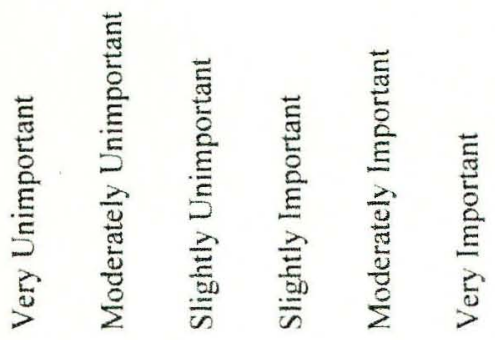

\begin{tabular}{|c|c|c|c|c|c|c|}
\hline 1. Your health? & 1 & 2 & 3 & 4 & 5 & 6 \\
\hline 2. Your health care? & 1 & 2 & 3 & 4 & 5 & 6 \\
\hline 3. Having no pain? & 1 & 2 & 3 & 4 & 5 & 6 \\
\hline 4. Having enough energy for everyday activities? & 1 & 2 & 3 & 4 & 5 & 6 \\
\hline 5. Taking care of yourself without help? & 1 & 2 & 3 & 4 & 5 & 6 \\
\hline 6. Having control over your life? & 1 & 2 & 3 & 4 & 5 & 6 \\
\hline 7. Living as long as you would like? & 1 & 2 & 3 & 4 & 5 & 6 \\
\hline 8. Your family's health? & 1 & 2 & 3 & 4 & 5 & 6 \\
\hline 9. Your children? & 1 & 2 & 3 & 4 & 5 & 6 \\
\hline 10. Your family's happiness? & 1 & 2 & 3 & 4 & 5 & 6 \\
\hline 11. Your sex life? & 1 & 2 & 3 & 4 & 5 & 6 \\
\hline 12. Your spouse, lover, or partner? & 1 & 2 & 3 & 4 & 5 & 6 \\
\hline 13. Your friends? & 1 & 2 & 3 & 4 & 5 & 6 \\
\hline 14. The emotional support you get from your family? & 1 & 2 & 3 & 4 & 5 & 6 \\
\hline $\begin{array}{l}\text { 15. The emotional support you get from people other } \\
\text { than your family? }\end{array}$ & 1 & 2 & 3 & 4 & 5 & 6 \\
\hline
\end{tabular}

(Please Go To Next Page)

(c) Copyright 1984 \& 1998 Carol Estwing Ferrans and Marjorie J. Powers 
HOW IMPORTANT TO YOU IS:

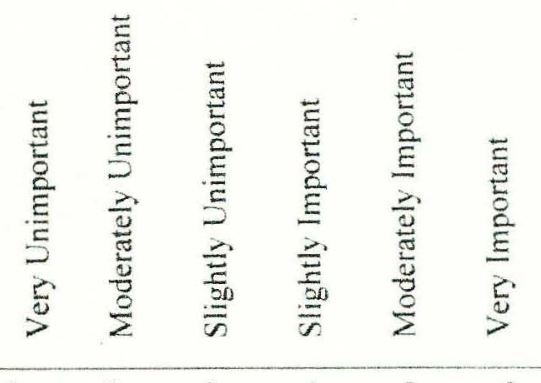

\begin{tabular}{l|llllll}
\hline 16. Taking care of family responsibilities? & 1 & 2 & 3 & 4 & 5 & 6 \\
\hline 17. Being useful to others? & 1 & 2 & 3 & 4 & 5 & 6 \\
\hline 18. Having no worries? & 1 & 2 & 3 & 4 & 5 & 6 \\
\hline 19. Your neighborhood? & 1 & 2 & 3 & 4 & 5 & 6 \\
\hline 20. Your home, apartment, or place where you live? & 1 & 2 & 3 & 4 & 5 & 6 \\
\hline 21. Your job (if employed)? & 1 & 2 & 3 & 4 & 5 & 6 \\
\hline 22. Having a job (if unemployed, retired, or disabled)? & 1 & 2 & 3 & 4 & 5 & 6 \\
\hline 23. Your education? & 1 & 2 & 3 & 4 & 5 & 6 \\
\hline 24. Being able to take care of your financial needs? & 1 & 2 & 3 & 4 & 5 & 6 \\
\hline 25. Doing things for fun? & 1 & 2 & 3 & 4 & 5 & 6 \\
\hline 26. Having a happy future? & 1 & 2 & 3 & 4 & 5 & 6 \\
\hline 27. Peace of mind? & 1 & 2 & 3 & 4 & 5 & 6 \\
\hline 28. Your faith in God? & 1 & 2 & 3 & 4 & 5 & 6 \\
\hline 29. Achieving your personal goals? & 1 & 2 & 3 & 4 & 5 & 6 \\
\hline 30. Your happiness in general? & 1 & 2 & 3 & 4 & 5 & 6 \\
\hline 31. Being satisfied with life? & 1 & 2 & 3 & 4 & 5 & 6 \\
\hline 32. Your personal appearance? & 1 & 2 & 3 & 4 & 5 & 6 \\
\hline 33. Are you to yourself? & 1 & 2 & 3 & 4 & 5 & 6 \\
\hline
\end{tabular}

Copyright 1984 \& 1998 Carol Estwing Ferrans and Marjorie J. Powers

Page 4 


\section{APPENDIX B}

\section{EXPERT REVIEW PACKET}

\section{Expert Review \\ Socioeconomic Well-Being Scale}

Attached you will find a proposed item pool to be used in measuring the construct of socioeconomic well-being as a dimension of quality of life for persons with a diagnosis of cancer. The construct of socioeconomic well-being used in developing this construct and related item pool is as follows: socioeconomic well-being is one's subjective evaluation of and satisfaction with his/her socioeconomic position in society based upon one's current, past and projected future access to resources including material, human and social capitol.

Also attached you will find a table delineating the relevant theory and definitions used in the development of this construct and a figure depicting the conceptual framework used as foundational to this inquiry.

Lastly, you will find a form to be used in guiding your evaluation of the proposed item pool. Please complete the form related to each proposed item and include your overall comments and suggestions.

Thank you so much for your assistance in validation of the proposed measure! 
Theories and Definitions Contributing to Conceptual

Framework for Construct of Socioeconomic Well-being

\begin{tabular}{|l|l|l|}
\hline $\begin{array}{l}\text { Theory/Definition } \\
\text { Theorist or Source }\end{array}$ & Relevant Concepts & Related Items for Item Pool \\
\hline Ecological Theory & $\begin{array}{l}\text { Focus on both person and environment } \\
\text { and the interface between the two as } \\
\text { explanatory } \\
\text { Concepts of habitat and niche, coercive } \\
\text { and exploitative power }\end{array}$ & $\begin{array}{l}\text { Items related to neighborhood, } \\
\text { environment, ability to assess } \\
\text { and receive healthcare }\end{array}$ \\
\hline $\begin{array}{l}\text { Functionalist Tradition } \\
\text { Warner, 1960 }\end{array}$ & $\begin{array}{l}\text { Multi-faceted character of social class } \\
\text { (not solely economic) } \\
\text { Stratification as serving a variety of } \\
\text { functions for society } \\
\text { Social class viewed as permeating all } \\
\text { aspects of thought and action } \\
\text { Consideration of contextual } \\
\text { socioeconomic affects }\end{array}$ & $\begin{array}{l}\text { Items assessing impact of } \\
\text { socioeconomic status on health } \\
\text { assessment and care, respect } \\
\text { and prestige }\end{array}$ \\
\hline $\begin{array}{l}\text { Coleman, } 1990 \\
\text { Oakes \& Rossi, 2003 }\end{array}$ & $\begin{array}{l}\text { Theory that three domains compose } \\
\text { social class: physical capitol, human } \\
\text { capitol, and social capitol }\end{array}$ & $\begin{array}{l}\text { Items regarding not only } \\
\text { economic concerns but also } \\
\text { education and skills, prestige, } \\
\text { influence and neighborhood }\end{array}$ \\
\hline $\begin{array}{l}\text { Class as a Social Relationship } \\
\text { Krieger, Williams \& Moss, } \\
\text { 1997 }\end{array}$ & $\begin{array}{l}\text { Classes exist in relationship to each } \\
\text { other, define each other }\end{array}$ & $\begin{array}{l}\text { Items related to reactions of } \\
\text { others (respect, self-efficacy } \\
\text { neighborhood), ability to get } \\
\text { needs met, occupational } \\
\text { prestige }\end{array}$ \\
\hline $\begin{array}{l}\text { Songh-Manoux, Adler \& } \\
\text { Marmot, 2003 }\end{array}$ & $\begin{array}{l}\text { One's beliefs about social status include } \\
\text { current, past and future circumstances }\end{array}$ & $\begin{array}{l}\text { Items addressing past, present } \\
\text { and future social status }\end{array}$ \\
\hline $\begin{array}{l}\text { Socioecological dimension including } \\
\text { socioeconomic status and life burden } \\
\text { included in assessment of QOL }\end{array}$ & $\begin{array}{l}\text { Items addressing relationship } \\
\text { with healthcare systems, ability } \\
\text { to get medical care, } \\
\text { neighborhood, ability to get } \\
\text { needs met }\end{array}$ \\
\hline
\end{tabular}



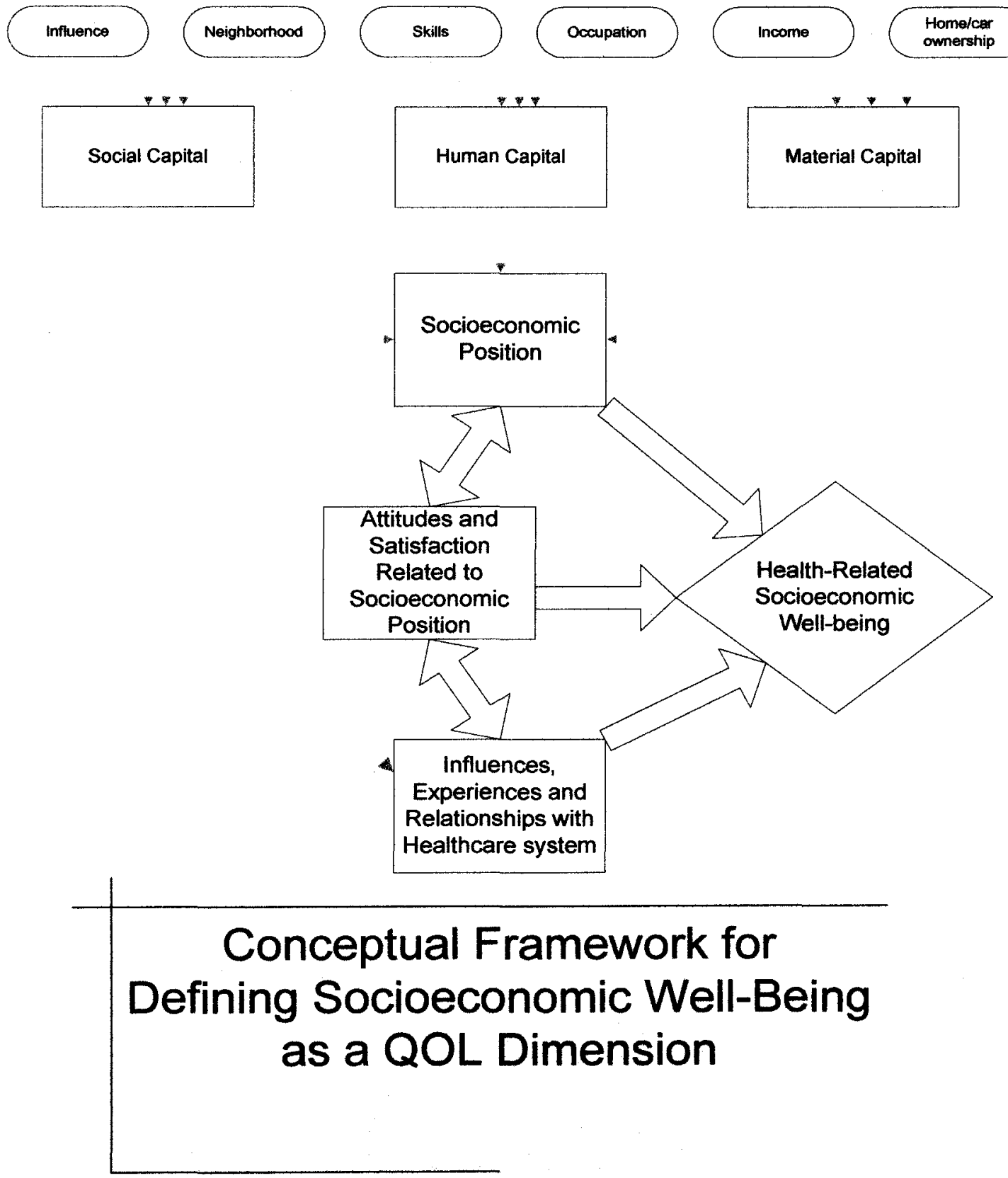


\section{SOCIOECONOMIC WELL-BEING}

Below is a list of statements that other people with your illness have said are important. By circling one (1) number per line, please indicate how true each statement has been for you during the past 7 days.

Not A little Some- Quite Very at all bit what a bit much

1. I am satisfied with my education.

$\begin{array}{lllll}0 & 1 & 2 & 3 & 4\end{array}$

2. I have valuable skills.

$\begin{array}{lllll}0 & 1 & 2 & 3 & 4\end{array}$

3. I am happy with the place where I live.

$\begin{array}{lllll}0 & 1 & 2 & 3 & 4\end{array}$

4. I grew up in a good neighborhood.

0

5. I am able to pay my bills on times.

0

$\begin{array}{lll}2 & 3 & 4\end{array}$

6. I cannot afford the food I need to stay healthy.

$\begin{array}{lll}0 & 1 & 2\end{array}$

34

7. I don't have good credit.

$\begin{array}{lllll}0 & 1 & 2 & 3 & 4\end{array}$

8. I have to pay more for my medical care than I can afford.

$\begin{array}{lllll}0 & 1 & 2 & 3 & 4\end{array}$

9. Growing up, my family was able to buy what we needed.

$\begin{array}{lllll}0 & 1 & 2 & 3 & 4\end{array}$

10. My neighborhood is a healthy place to live.

$\begin{array}{lllll}0 & 1 & 2 & 3 & 4\end{array}$

11. I get medical check-ups even when I am not sick.

$\begin{array}{lllll}0 & 1 & 2 & 3 & 4\end{array}$

12. I need financial help to pay my bills.

13. I hope to better my living situation.

$\begin{array}{lllll}0 & 1 & 2 & 3 & 4\end{array}$

14. My doctors treat me with respect.

15. I cannot afford the medicine I need. $(M, C)$

$\begin{array}{lllll}0 & 1 & 2 & 3 & 4\end{array}$

16. I am sure I will be able to handle the costs of my illness.

$\begin{array}{lllll}0 & 1 & 2 & 3 & 4\end{array}$


Not A little Some- Quite Very at all bit what a bit much

17. My family is able to get everything we really need.

18. I am proud of the work I do (including work at home).

$\begin{array}{lllll}0 & 1 & 2 & 3 & 4\end{array}$

19. I am treated the same as other patients when I go for medical care.

$\begin{array}{lllll}0 & 1 & 2 & 3 & 4\end{array}$

20. Growing up, my family thought education was important.

$\begin{array}{lllll}0 & 1 & 2 & 3 & 4\end{array}$

21. I can find a way to get what I really need.

$\begin{array}{lllll}0 & 1 & 2 & 3 & 4\end{array}$

22. I am not happy with the kind of work I do.

$\begin{array}{lllll}0 & 1 & 2 & 3 & 4\end{array}$

23. I have what I need to get by in my home.

24. I worry about having enough money in the future.

$\begin{array}{lllll}0 & 1 & 2 & 3 & 4\end{array}$

25. I plan to get more education.

$\begin{array}{lllll}0 & 1 & 2 & 3 & 4\end{array}$

26. Most people look down on me.

$\begin{array}{lllll}0 & 1 & 2 & 3 & 4\end{array}$

27. Growing up, I went to the doctor for check-ups.

$\begin{array}{lllll}0 & 1 & 2 & 3 & 4\end{array}$

28. My family is respected in our community. $\quad \begin{array}{lllllll}0 & 1 & 2 & 3 & 4\end{array}$

29. Growing up, I got healthcare when I needed it. $\begin{array}{lllllll}0 & 1 & 2 & 3 & 4\end{array}$

$\begin{array}{llllllll}\text { 30. My health insurance is good enough. } & 0 & 1 & 2 & 3 & 4\end{array}$

$\begin{array}{llllllll}\text { 31. I have money saved for emergencies. } & 0 & 1 & 2 & 3 & 4\end{array}$

32. I worry about how having cancer will affect my income.

$\begin{array}{lllll}0 & 1 & 2 & 3 & 4\end{array}$

33. My family has the ability to earn a good living.

$\begin{array}{lllll}0 & 1 & 2 & 3 & 4\end{array}$




\section{Expert Review}

Item Pool - Socioeconomic Well-Being Scale

Name of Reviewer:

Item 1

\begin{tabular}{|l|l|l|l|}
\hline & Low & Moderate & High \\
\hline Relevance to the construct & & & \\
\hline Clarity of item & & & \\
\hline Conciseness of item & & & \\
& & & \\
& & \\
\end{tabular}

Item 2

\begin{tabular}{|l|l|l|l|}
\hline & Low & Moderate & High \\
\hline Relevance to the construct & & & \\
\hline Clarity of item & & & \\
\hline Conciseness of item & & & \\
\hline Comments/suggestions: & & \\
& & \\
& & \\
\end{tabular}

Item 3

\begin{tabular}{|l|l|l|l|}
\hline & Low & Moderate & High \\
\hline Relevance to the construct & & & \\
\hline Clarity of item & & & \\
\hline Conciseness of item & & & \\
\hline Comments/suggestions: & & \\
& & \\
& & \\
\end{tabular}


Item 4

\begin{tabular}{|l|l|l|l|}
\hline & Low & Moderate & High \\
\hline Relevance to the construct & & & \\
\hline Clarity of item & & & \\
\hline Conciseness of item & & & \\
\hline Comments/suggestions: & & \\
& & \\
& & \\
\end{tabular}

Item 5

\begin{tabular}{|l|l|l|l|}
\hline & Low & Moderate & High \\
\hline Relevance to the construct & & & \\
\hline Clarity of item & & & \\
\hline Conciseness of item & & & \\
\hline Comments/suggestions: & & \\
& & \\
& & \\
\end{tabular}

Item 6

\begin{tabular}{|l|l|l|l|}
\hline & Low & Moderate & High \\
\hline Relevance to the construct & & & \\
\hline Clarity of item & & & \\
\hline Conciseness of item & & & \\
\hline Comments/suggestions: & & \\
& & \\
& & \\
\end{tabular}


Item 7

\begin{tabular}{|l|l|l|l|}
\hline & Low & Moderate & High \\
\hline Relevance to the construct & & & \\
\hline Clarity of item & & & \\
\hline Conciseness of item & & & \\
\hline Comments/suggestions: & & \\
& & \\
& & \\
\end{tabular}

Item 8

\begin{tabular}{|l|l|l|l|}
\hline & Low & Moderate & High \\
\hline Relevance to the construct & & & \\
\hline Clarity of item & & & \\
\hline Conciseness of item & & & \\
& & \\
& & \\
& & \\
\end{tabular}

Item 9

\begin{tabular}{|l|l|l|l|}
\hline & Low & Moderate & High \\
\hline Relevance to the construct & & & \\
\hline Clarity of item & & & \\
\hline Conciseness of item & & & \\
\hline Comments/suggestions: & & \\
& & \\
& & \\
\end{tabular}


Item 10

\begin{tabular}{|l|l|l|l|}
\hline & Low & Moderate & High \\
\hline Relevance to the construct & & & \\
\hline Clarity of item & & & \\
\hline Conciseness of item & & & \\
\hline Comments/suggestions: & & \\
& & \\
& & \\
\end{tabular}

\section{Item 11}

\begin{tabular}{|l|l|l|l|}
\hline & Low & Moderate & High \\
\hline Relevance to the construct & & & \\
\hline Clarity of item & & & \\
\hline Conciseness of item & & & \\
\hline Comments/suggestions: & & \\
& & \\
\end{tabular}

Item 12

\begin{tabular}{|l|l|l|l|}
\hline & Low & Moderate & High \\
\hline Relevance to the construct & & & \\
\hline Clarity of item & & & \\
\hline Conciseness of item & & & \\
\hline Comments/suggestions: & & \\
& & \\
& & \\
\end{tabular}


Item 13

\begin{tabular}{|l|l|l|l|}
\hline & Low & Moderate & High \\
\hline Relevance to the construct & & & \\
\hline Clarity of item & & & \\
\hline Conciseness of item & & & \\
& & \\
& & \\
& & \\
\end{tabular}

\section{Item 14}

\begin{tabular}{|l|l|l|l|}
\hline & Low & Moderate & High \\
\hline Relevance to the construct & & & \\
\hline Clarity of item & & & \\
\hline Commeneness of item & & & \\
& & & \\
& & \\
\end{tabular}

Item 3

\begin{tabular}{|l|l|l|l|}
\hline & Low & Moderate & High \\
\hline Relevance to the construct & & & \\
\hline Clarity of item & & & \\
\hline Conciseness of item & & & \\
& & & \\
& & \\
\end{tabular}


Item 15

\begin{tabular}{|l|l|l|l|}
\hline & Low & Moderate & High \\
\hline Relevance to the construct & & & \\
\hline Clarity of item & & & \\
\hline Conciseness of item & & & \\
\hline Comments/suggestions: & & \\
& & \\
& & \\
\end{tabular}

Item 16

\begin{tabular}{|l|l|l|l|}
\hline & Low & Moderate & High \\
\hline Relevance to the construct & & & \\
\hline Clarity of item & & & \\
\hline Commenesseness of item & & & \\
& & & \\
& & \\
\end{tabular}

Item 17

\begin{tabular}{|l|l|l|l|}
\hline & Low & Moderate & High \\
\hline Relevance to the construct & & & \\
\hline Clarity of item & & & \\
\hline Conciseness of item & & & \\
\hline Comments/suggestions: & & \\
& & \\
& & \\
\end{tabular}


Item 18

\begin{tabular}{|l|l|l|l|}
\hline & Low & Moderate & High \\
\hline Relevance to the construct & & & \\
\hline Clarity of item & & & \\
\hline Conciseness of item & & & \\
\hline Comments/suggestions: & & \\
& & \\
& & \\
\end{tabular}

\section{Item 19}

\begin{tabular}{|l|l|l|l|}
\hline & Low & Moderate & High \\
\hline Relevance to the construct & & & \\
\hline Clarity of item & & & \\
\hline Conciseness of item & & & \\
\hline Comments/suggestions: & & \\
& & \\
\end{tabular}

Item 20

\begin{tabular}{|l|l|l|l|}
\hline & Low & Moderate & High \\
\hline Relevance to the construct & & & \\
\hline Clarity of item & & & \\
\hline Conciseness of item & & & \\
\hline Comments/suggestions: & & \\
& & \\
& & \\
\end{tabular}




\section{Item 21}

\begin{tabular}{|l|l|l|l|}
\hline & Low & Moderate & High \\
\hline Relevance to the construct & & & \\
\hline Clarity of item & & & \\
\hline Conciseness of item & & & \\
\hline Comments/suggestions: & & \\
& & \\
\end{tabular}

Item 22

\begin{tabular}{|l|l|l|l|}
\hline & Low & Moderate & High \\
\hline Relevance to the construct & & & \\
\hline Clarity of item & & & \\
\hline Conciseness of item & & & \\
\hline Comments/suggestions: & & \\
& & \\
& & \\
\end{tabular}

\section{Item 23}

\begin{tabular}{|l|l|l|l|}
\hline & Low & Moderate & High \\
\hline Relevance to the construct & & & \\
\hline Clarity of item & & & \\
\hline Conciseness of item & & & \\
\hline Comments/suggestions: & & \\
& & \\
& & \\
\end{tabular}


Item 24

\begin{tabular}{|l|l|l|l|}
\hline & Low & Moderate & High \\
\hline Relevance to the construct & & & \\
\hline Clarity of item & & & \\
\hline Conciseness of item & & & \\
\hline Commens/suggestions: & & \\
\hline
\end{tabular}

Comments/suggestions:

Item 25

\begin{tabular}{|l|l|l|l|}
\hline & Low & Moderate & High \\
\hline Relevance to the construct & & & \\
\hline Clarity of item & & & \\
\hline Conciseness of item & & & \\
\hline Comments/suggestions: & & \\
& & \\
& & \\
\end{tabular}

Item $\mathbf{2 6}$

\begin{tabular}{|l|l|l|l|}
\hline & Low & Moderate & High \\
\hline Relevance to the construct & & & \\
\hline Clarity of item & & & \\
\hline Conciseness of item & & & \\
\hline Comments/suggestions: & & \\
& & \\
& & \\
\end{tabular}




\section{Item 27}

\begin{tabular}{|l|l|l|l|}
\hline & Low & Moderate & High \\
\hline Relevance to the construct & & & \\
\hline Clarity of item & & & \\
\hline Conciseness of item & & & \\
\hline Comments/suggestions: & & \\
& & \\
& & \\
\end{tabular}

Item 28

\begin{tabular}{|l|l|l|l|}
\hline & Low & Moderate & High \\
\hline Relevance to the construct & & & \\
\hline Clarity of item & & & \\
\hline Conciseness of item & & & \\
\hline Comments/suggestions: & & \\
& & \\
& & \\
\end{tabular}

Item 29

\begin{tabular}{|l|l|l|l|}
\hline & Low & Moderate & High \\
\hline Relevance to the construct & & & \\
\hline Clarity of item & & & \\
\hline Conciseness of item & & & \\
\hline Comments/suggestions: & & \\
& & \\
& & \\
\end{tabular}


Item 30

\begin{tabular}{|l|l|l|l|}
\hline & Low & Moderate & High \\
\hline Relevance to the construct & & & \\
\hline Clarity of item & & & \\
\hline Conciseness of item & & & \\
\hline Comments/suggestions: & & \\
& & \\
& & \\
\end{tabular}

Item 31

\begin{tabular}{|l|l|l|l|}
\hline & Low & Moderate & High \\
\hline Relevance to the construct & & & \\
\hline Clarity of item & & & \\
\hline Conciseness of item & & & \\
\hline Comments/suggestions: & & \\
& & \\
& & \\
\end{tabular}

Item 32

\begin{tabular}{|l|l|l|l|}
\hline & Low & Moderate & High \\
\hline Relevance to the construct & & & \\
\hline Clarity of item & & & \\
\hline Conciseness of item & & & \\
\hline Comments/suggestions: & & \\
& & \\
& & \\
\end{tabular}


Item 33

\begin{tabular}{|l|l|l|l|}
\hline & Low & Moderate & High \\
\hline Relevance to the construct & & & \\
\hline Clarity of item & & & \\
\hline Conciseness of item & & & \\
\hline Comments/suggestions: & & \\
& & \\
& & \\
\end{tabular}

Please list specific items you believe are not appropriate to this construct or that you would omit for any reason:

Overall comments/suggestions related to proposed measure:

Aspects of construct not included in items: 
Suggested additional items:

Return to: Barbara Head

Interdisciplinary Program for Palliative Care and Chronic Illness

University of Louisville

Health Sciences Campus

MDR Building, Suite 110

511 South Floyd Street

Louisville, KY 40202 


\section{APPENDIX C}

\section{FINAL DISPOSITION OF ITEMS AFTER PSYCHOMETRIC ANALYSIS}

\begin{tabular}{|c|l|l|c|}
\hline $\begin{array}{c}\text { Original } \\
\text { Subscale }\end{array}$ & \multicolumn{1}{|c|}{ Item } & $\begin{array}{c}\text { Final Disposition } \\
\text { Subscale }\end{array}$ \\
\hline HC & $\begin{array}{l}\text { I know how to take care of my } \\
\text { health. }\end{array}$ & $\begin{array}{l}\text { Performed weakly and loaded } \\
\text { more highly onto another } \\
\text { subscale. Decision made to } \\
\text { delete. }\end{array}$ & Deleted \\
\hline HC & $\begin{array}{l}\text { I am able to make enough } \\
\text { money to pay for my } \\
\text { healthcare }\end{array}$ & $\begin{array}{l}\text { Loaded more strongly onto } \\
\text { Material Capital Subscale. } \\
\text { Retained but moved to that } \\
\text { subscale. }\end{array}$ & MC \\
\hline HC & $\begin{array}{l}\text { I do my best to take care of my } \\
\text { body. }\end{array}$ & $\begin{array}{l}\text { Initial item total correlation and } \\
\text { factor loading were very low. } \\
\text { Item deleted }\end{array}$ & Deleted \\
\hline HC & $\begin{array}{l}\text { I have always taken good care } \\
\text { of myself. }\end{array}$ & $\begin{array}{l}\text { Initial item total correlation and } \\
\text { factor loading were very low. } \\
\text { Item deleted }\end{array}$ & Deleted \\
\hline HC & $\begin{array}{l}\text { I know how to get the } \\
\text { healthcare services I need. }\end{array}$ & $\begin{array}{l}\text { Loaded more strongly onto } \\
\text { Social Capital subscale. Moved } \\
\text { to that subscale. }\end{array}$ & SC \\
\hline HC & $\begin{array}{l}\text { I understand the healthcare } \\
\text { system. }\end{array}$ & $\begin{array}{l}\text { Loaded more strongly onto } \\
\text { Social Capital Subscale. } \\
\text { Moved to that subscale. }\end{array}$ & SC \\
mossible.
\end{tabular}




\begin{tabular}{|c|c|c|c|}
\hline & & important item. & \\
\hline $\mathrm{MC}$ & $\begin{array}{l}\text { I am able to pay my medical } \\
\text { bills. }\end{array}$ & $\begin{array}{l}\text { Performed well in assigned } \\
\text { subscale. Retained. }\end{array}$ & $\mathrm{MC}$ \\
\hline $\mathrm{MC}$ & $\begin{array}{l}\text { I believe that being sick will } \\
\text { hurt me financially. }\end{array}$ & $\begin{array}{l}\text { Negative item which performed } \\
\text { slightly weaker probably as a } \\
\text { result of response patterns. } \\
\text { Retained as it was felt to be an } \\
\text { important item address feelings } \\
\text { related to financial security. }\end{array}$ & $\mathrm{MC}$ \\
\hline $\mathrm{MC}$ & $\begin{array}{l}\text { I have enough money to take } \\
\text { care of my healthcare needs. }\end{array}$ & $\begin{array}{l}\text { Performed well in assigned } \\
\text { subscale. Retained. }\end{array}$ & $\mathrm{MC}$ \\
\hline $\mathrm{MC}$ & $\begin{array}{l}\text { I can afford medical check-ups } \\
\text { even when I am not sick. }\end{array}$ & $\begin{array}{l}\text { Performed well in assigned } \\
\text { subscale. Retained. }\end{array}$ & $\mathrm{MC}$ \\
\hline $\mathrm{MC}$ & $\begin{array}{l}\text { I can get the health insurance I } \\
\text { need. }\end{array}$ & $\begin{array}{l}\text { Performed well in assigned } \\
\text { subscale. Retained. }\end{array}$ & $\mathrm{MC}$ \\
\hline MC & $\begin{array}{l}\text { The medicine I need is too } \\
\text { expensive for me. }\end{array}$ & $\begin{array}{l}\text { Negative item which performed } \\
\text { slightly weaker probably as a } \\
\text { result of response patterns. } \\
\text { Retained as it was felt to be an } \\
\text { important item. }\end{array}$ & $\mathrm{MC}$ \\
\hline $\mathrm{SC}$ & $\begin{array}{l}\text { People like me are able to get } \\
\text { the healthcare they need. }\end{array}$ & $\begin{array}{l}\text { Item loaded more strongly onto } \\
\text { Material Capital subscale and } \\
\text { was retained but moved to that } \\
\text { subscale. Participants may } \\
\text { have felt "people like me" } \\
\text { referred to economic status } \\
\text { rather than educational or } \\
\text { motivational factors. }\end{array}$ & $\mathrm{MC}$ \\
\hline $\mathrm{SC}$ & $\begin{array}{l}\text { I live in a healthy } \\
\text { neighborhood. }\end{array}$ & $\begin{array}{l}\text { Initial ITC and factor loading } \\
\text { were very low. Item deleted. }\end{array}$ & Deleted \\
\hline $\mathrm{SC}$ & $\begin{array}{l}\text { Healthcare services are easy to } \\
\text { get in my neighborhood. }\end{array}$ & $\begin{array}{l}\text { Performed well in assigned } \\
\text { subscale. Retained. }\end{array}$ & $\mathrm{SC}$ \\
\hline SC. & $\begin{array}{l}\text { My doctors treat me with } \\
\text { respect. }\end{array}$ & $\begin{array}{l}\text { Performance was weak. Item } \\
\text { very similar to item below. } \\
\text { Item deleted as it felt that the } \\
\text { similar item was better and }\end{array}$ & Deleted \\
\hline
\end{tabular}




\begin{tabular}{|c|l|l|c|}
\hline & & $\begin{array}{l}\text { inclusive of all healthcare } \\
\text { treatment and not just the } \\
\text { doctor's response. }\end{array}$ & \\
\hline SC & $\begin{array}{l}\text { I am treated the same as other } \\
\text { patients when I go for medical } \\
\text { care. }\end{array}$ & $\begin{array}{l}\text { Performance was rather weak in } \\
\text { terms of item total correlation } \\
(0.44) \text { and factor loading (0.48). } \\
\text { However, item was retained as } \\
\text { it was felt that samples with } \\
\text { larger percentages of persons } \\
\text { with lower socioeconomic } \\
\text { status might perform differently } \\
\text { related to the item. Retained in } \\
\text { assigned subscale. }\end{array}$ & SC \\
\hline SC & $\begin{array}{l}\text { People I know best have } \\
\text { healthy habits. }\end{array}$ & $\begin{array}{l}\text { Performed adequately in } \\
\text { assigned subscale. Retained. }\end{array}$ & SC \\
\hline SC & $\begin{array}{l}\text { My family thinks good } \\
\text { healthcare is important. }\end{array}$ & $\begin{array}{l}\text { Performed adequately in } \\
\text { assigned subscale. Retained. }\end{array}$ & SC \\
\hline SC & $\begin{array}{l}\text { I know people who will help } \\
\text { me out when I'm sick. }\end{array}$ & $\begin{array}{l}\text { Performed well in assigned } \\
\text { subscale. Retained. }\end{array}$ & SC \\
\hline SC & $\begin{array}{l}\text { I can easily get information } \\
\text { about healthcare. }\end{array}$ & $\begin{array}{l}\text { Performed well in assigned } \\
\text { subscale. Retained. }\end{array}$ & SC \\
\hline
\end{tabular}

$\mathrm{HC}=$ Human Capital $\quad \mathrm{MC}=$ Material Capital $\quad \mathrm{SC}=$ Social Capital 


\section{CURRICULUM VITAE}

NAME: $\quad$ Barbara Anderson Head

ADDRESS: 1122 Garden Creek Circle

Louisville, KY 40223

EDUCATION

\& TRAINING: $\quad$ Union College, Barbourville, KY

Bachelors of Science, Majors: Sociology, Social Work

May 1972, Summa Cum Laude

University of Louisville, Kent School of Social Work

Master of Science in Social Work

May 1974

Pennyrile Associate Degree Nursing Program

University of Kentucky, Hopkinsville Community College

May 6, 1984

University of Louisville, Kent School of Social Work

Doctor of Philosophy in Social Work

May 12, 2007

AWARDS:

Outstanding Student Nurse Award, Awarded by the Kentucky Nurses'

Association

1984

Heart of Hospice Award, Administrative Professional of the Year

Awarded by National Hospice and Palliative Care Organization

2000

Hospice and Palliative Nurses Association Annual Award for Innovations in

Nursing

March 2002

Phi Kappa Phi, Louisville Chapter

Initiated May 7, 2007 


\section{GRANTS/SPECIAL}

\section{PROJECTS:}

Co-Investigator on Centers for Disease Control funded initiative to develop a model program based upon chronic disease principles for beast cancer patients at the James Graham Brown Cancer Center. Grant period 9/01/2005-11/30/2006.

Project coordinator and for National Institute of Health funded study to evaluate a telehealth intervention for head and neck cancer patients at the James Graham Brown Cancer Center. Grant period 10/01/2005-9/30/2007. Led team in preparing grant application.

Project coordinator for study funded by the Foundation for a Healthy Kentucky to incorporate palliative care management policies and principles into the practices of a Medicaid managed care provider. Grant period 10/01/2005-9/30/2006. Led team in preparing grant application.

Consultant for Kentucky Community-Based Geriatric Interdisciplinary Training and Self-Management Project funded by Health Resources and Services Administration. This project will involve social workers and physical therapists in utilizing bestpractice geriatric assessment, case, and self management skills in medically underserved communities. Grant period 05/01/2005-4/30/2007.

Participant on Project on Death in America, social work education grant funded by the Soros Foundation to develop decision cases to be used in teaching death and grief to social workers. Prepared two case studies and related teaching notes, recruited cases, reviewed cases. Terry Wolfer, $\mathrm{PhD}$, principal investigator, University of South Carolina.

Content specialist for the Nursing Assistant End-of-Life Care Computerized Education Project recently funded by the National Institutes of Health at the Swedish Medical Center, Seattle, Washington. Developed modules on spirituality and bereavement. Work completed 1/1/2005.

Caregiver Training Grant - developed grant proposal to provide in-home caregiver education for hospice patient caregivers. Services funded under The Older Americans Act. (2002)

American Massage Therapy Association Foundation Outreach Grant - developed grant proposal to provide massage therapy to patients with advanced dementia or other conditions limiting their communication. Served as Project Director. (2002)

\section{PROFESSIONAL SOCIETIES:}

National Association of Social Workers

ACSW, Academy of Certified Social Workers since 1981 
Hospice and Palliative Nurses Association

Member and Certified Hospice and Palliative Nurse (CHPN) since September 1994

Oncology Nursing Society

Member since 2004, currently serving as State Health Policy Liaison for Kentucky

\section{PROFESSIONAL ASSOCIATIONS}

AND ACTIVITIES:

Expert Review Panel Member. National Hospice and Palliative Care

Organization's project to development a patient evaluation instrument for hospice and palliative care. November 2006 (ongoing).

Journal of Hospice and Palliative Nursing. Member of Editorial Board since January 2005.

Journal of Hospice and Palliative Care: Guest Editor, Third Issue of 2001.

National Board for Certification of Hospice Nurses: elected October, 1996.

President 1998-2000.

Chairperson, Kentucky Association of Hospice and Palliative Care Quality

Committee. Led statewide benchmarking project 1997-2000.

National Hospice Organization Standards and Accreditation Committee: member 1993-1999. Chairperson January 1997-January 1999.

Author/Editor Hospice column for Home Healthcare Nurse. January 2000-2003. Member of Editorial Board for this publication.

Professional and Technical Advisory Committee for Homecare, Joint Commission on Accreditation of Healthcare Organizations: NHO representative 1998-1999.

Expert witness for U.S. Attorney's office: Prepared defense report on Medicare Hospice fraud and abuse case. March-November, 1999.

Book/Article Reviewer, Home Healthcare Nurse since June 1997. Carolyn Humphrey, Editor.

Examiner, QuBE Program (Quality and Business Excellence), Louisville Area Chamber of Commerce, 1996.

\section{ABSTRACTS AND}

PUBLICATIONS:

Pfeifer, M., Ritchie, C., Scharfenberger, J., Keeney, C., Hermann, C., Berwick, M., \& Head, B. (2006, Nov.-Dec.). The Caring Connections Project: Providing 
palliative care to Medicaid patients with advanced cancer, Lippincott's Case Management, 11(6), 318-326.

Head, B., \& Faul, Anna. (in review). Research risks and benefits as perceived by persons with a terminal prognosis.

Furman, C., Head, B., Lazor, B., Casper, B., \& Ritchie, C. (2006, August).

Evaluation of an education intervention to encourage advance directive discussions between medicine residents and patients, Journal of Palliative Medicine, 9(4), 964967.

Head, B. (2005, Nov.-Dec.). The transforming power of prison hospice: Changing the culture of incarceration one life at a time, Journal of Hospice and Palliative Nursing, 7(6), 354-359.

Head, B., Smoot, T., \& Ritchie, C. S. (2005, June). Prognostication in hospice care: Can the palliative performance scale help?, Journal of Palliative Medicine, $8(3), 492-502$.

Head, B., \& Faul, Anna. (2005, July-Aug.). Terminal restlessness as perceived by hospice professionals, American Journal of Hospice and Palliative Care, 22(4), 277-282,

Head, B., Ritchie, C. S., Scharfenberger, J., Keeney, C., Hermann, C., \& Pfeifer, M. (2004, February). Kentucky's palliative care report card, Journal of the Kentucky Medical Association, 102(2), 57-65.

Head, B. (Ed). (2004). Study guide for the hospice and palliative nursing assistant. Dubuque, IA: Kendall Hunt.

Head, B., \& Ritchie, C.S. (2004, Jan.). Researching end-of-life care: Challenges, strategies, and opportunities, Home Healthcare Nurse, 22(1), 37-44.

Head, B. (2003). Spiritual care at the end of life. Core Curriculum for the Hospice and Palliative Nursing Assistant. Dubuque, IA: Kendall Hunt.

Head, B. (2003, Mar.). End-stage dementia: Hospice offers expert interdisciplinary care for end-stage dementia, Home Healthcare Nurse, 21(3), 150-151.

Head, B. (2003, Jan.). Palliative care for persons with dementia, Home Healthcare Nurse, 21(1), 53-60.

Head, B. (2002, Jan.). Dementia: Whose problem is it, anyway? (Editorial), Home Healthcare Nurse, 2l(1), 7. 
Head, B. (2002, May). The blessings and burdens of interdisciplinary teamwork, Home Healthcare Nurse, 20(5), 337-338.

Head, B. (2003, Mar.). Who sets the standard for hospice care?, Home Healthcare Nurse, 19(3), 175.

Gohlman, S., \& Head, B. (2001, April/June). Hospice benchmarking: One state's initiative, Journal of Hospice and Palliative Nursing, 3(2).

Head, B. (2001, May). Hospice outcomes: meeting requirements and developing a national consensus, Home Healthcare Nurse, 19(5), 290-296.

Head, B. (2001, Sept.). The prognostication problem, Home Healthcare Nurse, 19(9), 535-536,

Head, B. (2000, May). Corporate compliance and the hospice nurse, Home Healthcare Nurse, 18(5), 290-291.

Head, B. (2000, Mar.). Hospice and palliative research: Is it worth the effort?, Home Healthcare Nurse, 18(9), 618-619.

Head, B. (2000, Mar.). Hospice and palliative nursing: The NBCHPN certification examination, Home Healthcare Nurse, 18(3), 155-156.

Head, B. (2000, Jan.). Hospice nursing - taking charge of our future, Home Healthcare Nurse, 18(1), 13-14.

Head, B. (2000, Winter). Short length of stay: Lessons learned, The Hospice Professional.

Head, B. (1997). An overview of hospice home care. In J. Spratt, B. S. Rhonda, \& R. Hoye (Eds.). Home Health Care Principles and Practices (pp. 147-166). Delray Beach, FL: St Lucie Press.

\section{INVITED PRESENTATIONS:}

Head, B. (2007, Feb.). Providing palliative case management services to a Medicaid population. Presentation at the annual meeting of the Academy of Hospice and Palliative Medicine and the Hospice and Palliative Nurses Association, Salt Lake City, UT.

Pfeifer, M., Head, B., Bumpous, J., Studts, J., Gregg, J., Scharfenberger, J., \& Willett, A. (2006, Nov.). Telehealth symptom management in head and neck cancer. Abstract and poster presentation at James Graham Brown Cancer Center annual retreat. 
Head, B., Deck, S., Stone, R., Antle, B., Pfeifer, M., Keeney, C., Scharfenberger, J., $\&$ Studts, J. (2006, Nov.). Use of the distress thermometer as an assessment tool for persons with breast cancer. Abstract and poster presentation at the James Graham Brown Cancer Center annual retreat, Louisville, KY.

Head, B., Deck, S., Stone, R., Antle, B., Pfeifer, M., Keeney, C., Scharfenberger, J., \& Studts, J. (2006, Oct.). Use of the distress thermometer as an assessment tool for persons with breast cancer. Abstract and poster presentation at Research Louisville!, Louisville, KY.

Head, B., Deck, S., Stone, R., Antle, B., Pfeifer, M., Keeney, C., Scharfenberger, J., \& Studts, J. (2006, Sept.). Use of the distress thermometer as an assessment tool for persons with breast cancer. Abstract and poster presentation at the Louisville Breast Cancer Update, Louisville, KY.

Head, B. (2006, Feb.). Making a difference: Public policy advocacy for hospice and palliative care professionals. Annual meeting of the Academy of Hospice and Palliative Medicine and the Hospice and Palliative Nurses Association, Nashville, TN.

Head, B. (2005, Oct.). Decision case teaching method: Preparing students for professional Practice. Presented at Delphi Center Celebration of Teaching and Learning, University of Louisville, Louisville, KY.

Head, B. (2005, Jan.). Portraits of the Dying Poor. Annual meeting of the Academy of Hospice and Palliative Medicine and the Hospice and Palliative Nurses Association, New Orleans, LA.

Head, B. (2004, Jan.). Prognostication: Art or Science. Annual meeting of the Academy of Hospice and Palliative Medicine and the Hospice and Palliative Nurses Association. Phoenix, AZ.

Head, B. (2001, June). The new NHPCO standards for hospice practice. National Hospice and Palliative Care's Leadership and Management Conference and New York State Hospice Association, New York.

Head, B. (2001, Apr.). Effectively meeting patient/family needs despite short length of stay. Pennsylvania Hospice Network Annual Meeting, Harrisburg, Pennsylvania.

Head, B. (2000, Nov.). The new NHPCO standards for hospice practice. National Hospice and Palliative Care's Leadership and Management Conference and New York State Hospice Association, Albany, New York. 